Nachdruck verboten.

Übersetzungsrecht vorbehalten.

\title{
Zur Kenntnis des Genitalapparats der Neuropteren.
}

\author{
Von \\ Hermann Stitz in Berlin.
}

Mit Tafel 25-29 und 26 Abbildungen im Text.

Die älteste Darstellung von Genitalorganen bei Neuropteren findet sich in den Abhandlungen über Insecten von DegeER (1). Er beschreibt sie von "Hemerobius (lutarius) niger" in folgender Weise:

„In dem letzten Ring des Hinterleibes ${ }^{1}$ ) liegen der After und die Geschlechtsteile. Der erstere zeigt sich frei am Ende des Schwanzes oben auf, wie eine etwas erhabene Warze. ${ }^{1}$ ) Die anderen Teile zu sehen, muß man den Hinterleib ziemlich stark drücken. Dann gibt sich ein hornartiger, muschelförmiger, inwendig flachhohler Teil unten vom Ring ab. Unmittelbar neben dem After zeigen sich zwei braune, häutige, etwas erhabene Teile, unter diesen aber ein dickes, fleischichtes Stück mit einem kleinen, hornartigen, unterwärts gekrümmten Häkchen in der Mitte, ohne Zweifel das Werkzeug, womit sich das Nännchen an den Hinterleib des Weibchens bei der Begattung anklammert. Drückt man noch etwas stärker, so kommt zwischen dem Hakenstück und der hornartigen Muschel ein dicker, weißer Fleischteil zum Vorschein, der sich desto mehr aufbläht, je mehr man bis auf einen gewissen Punkt zu drücken fortfährt, und in der Mitte ein kleines Wärzchen hat. An diesem Teil sitzt zu beiden Seiten ein kleines, hornartiges Stück, das ihm gleichsam zum Träger dient. Dieser weiße, weiche Fleischteil kann nichts anders als der Geschlechtsteil des Männchens sein. Im natürlichen Zustand sind diese Teile zwischen der Muschel unten und dem hornartigen, vom Oberteil des Ringes bedeckten Stücke verschlossen.

Der After des Weibchens liegt auch am Ende des Schwanzes eben da, wo er bei dem Männchen liegt, und ist auch wie eine Warze gestaltet. Der letzte Ring hat unten zwei hornartige, muschelförmige Stücke ${ }^{1}$ ),

1) Durch Abbildungen erläutert.

Zool. Jahrb. XXVII. Abt. f. Anat. 
welche sich öffnen und auseinander treten, wenn man den Hinterleib zwischen den Fingern drückt. Dann zeigt sich unten im Grunde eine Höhlung oder Vertiefung, in welcher sich das Geschlechtsglied oder die weibliche Öffnung befinden muß, die man aber nicht wohl zu Gesicht bringen kann. In gedachter Höhlung bemerkt man auch einige weiche Teile.... Hier im Leibe liegen nun die Eier in zwei Bündeln oder Eierstöcken, welche zwei unterwärts gekrümmte Klumpen bilden. In den hiervon gegebenen Abbildungen sind die beiden Eierstöcke von einander abgesondert. Das ist aber ihre natürliche Lage nicht. In derselben liegt einer dicht am andern, so daß ihre krumme Seite nach dem Unterteil des Bauches $\mathrm{zu}$ steht. Oberwärts sind sie untereinander geflochten, lassen sich aber leicht trennen.... Die Eier liegen schnurweise in einer großen Nenge dünner Gefäße, die man leicht auseinanderziehen kann. Sie flattern ganz frei nach dem Oberende zu und hängen daselbst nicht zusammen; am andern Ende aber sind sie vereinigt und gleichsam in ein räumlicheres, längs der krummen oder unteren Seite jedes Eierstocks herunterlaufendes Gefäß eingemündet. Diese Getäße mit den darin enthaltenen Eiern liegen in krummen und parallelen Linien. Die Krümmung geht vorwärts oder nach dem Anfang des Hinterleibes zu, und die Eier haben hier eine solche Lage, daß die kleine Spitze oder das Schwänzchen, womit sie versehen sind, in die Höhe steht."

Vom Abdominalende der „Ka melhal sflieg en “ berichtet DEGEER: „Der Hinterleib. . . besteht aus 9 Ringen, den kleinen, kegeltörmigen Teil, womit der Schwanz endigt, nicht mitgerechnet. . . Das Weibchen hat hinten ein sehr langes Rohr ${ }^{1}$ ), mit dem Hinterleib beinahe von gleicher Länge, welches unter dem 9. Ring oder dicht am Ende des Körpers anhängt. . . . Dieses Rohr ist aber, wie ein bis ans Ende . . . immer dünner werdender Faden, an beiden Seiten flach gedrückt und sowohl oben als unten scharf, so daß es gleichsam eine schmale Degenklinge oder Sichel vorstellt. Die Materie ist halb hornartig und so biegsam wie Horn. . . . Es hat eine wurmförmige Krümmung, und das Ende steht in die Höhe. An der äußersten Spitze ist es beweglich, welche das Insekt auch nach Belieben hoch und niedrig, von einer Seite zur andern drehen kann, ohne den übrigen langen Teil mit bewegen zu dürfen.

Das Rohr selbst besteht aus zwei Stücken oder aus zwei sehr dünnen, dicht aufeinander liegenden Lamellen. Man bemerkt einigen Widerstand, wenn man sie trennen will, weil sie mit einem Häutchen zusammenhängen, das man zerreißen muß, wenn man sie mit einer Nadelspitze auseinander treibt. An der Innenseite scheinen sie etwas flachhohl zu sein, so daß sie geschlossen eine Röhre bilden. Jedes Stück endigt mit einem kleinen, eiförmigen Teilchen, das vermittelst eines äußerst feinen Stielchens hier angegliedert ist. An beiden Seiten sind die Lamellen mit Haaren bewachsen. Das Werkzeug dient zum Eierlegen, weil die Eier durch die hohle Röhre hindurch können, um an bequeme Oerter hingelegt zu werden, die ich aber nicht kenne."

1) Durch Abbildungen erläutert. 
Weniger genau hat sich DEGEER das männliche Abdominalende angesehen, wie aus seinen Worten hervorgeht: "Das Männchen ist dem Weibchen außer dem Rohr vollkommen gleich."

HegetschweILER (2) versucht 1820 eine systematische Übersicht über die Genitalorgane der verschiedenen Insectengruppen zu geben, die er durch Zeichnung veranschaulicht. Von Ascalaphus italicus (Männchen) heißt es darin: „Tunica testiculi remota vascula sese praebent. Vas deferens abbreviatum simul cum vesiculis seminalibus ductui excretorio sese inserit. Vesiculae seminales quatuor, quarum duae minores vasculum cylindricum excipiunt." Bei den weiblichen Organen unterscheidet er "Ovaria flagelliformia" und "Ovaria racemosa“. Erstere, zu denen er auch die von Ascalaphus rechnet, charakterisiert er: "Tubuli conici aequali gaudent longitudine et insertione. Cloaca rotunda, membranacea, ovarii tantum fundum circumdat."

Eine Darstellung des innern Genitalapparats von Sialis mit Abbildungen dazu finden wir in der bekannten Abhandlung von Suckow (3) aus dem Jahre 1828.

In Burmeister's Handbuch (4) aus dem Jahre 1838 finden sich Beschreibungen des Genitalapparats von Neuropteren. „Die männlichen Genitalien (von Sialis) bestehen aus zwei nierenförmigen ... Hoden, deren gekrümmtes Vas deferens sich im vierten Teil seiner Länge stark erweitert und an der Zusammenmündungsstelle mit dem Nachbar noch zwei mäBige kolbige Schläuche aufnimmt. Aus dem Verein dieser vier Organe entspringt der kurze Ductus ejaculatorius. Die Ruthe ist... am Grunde stark verdickt. - An den weiblichen Genitalien fallen die sehr großen, bohnenförmigen Eierstöcke, deren zahlreiche Eierröhren mehrere reife Eier enthalten, besonders leicht in die Augen; ihre kurzen Tuben vereinen sich in eine wenig längere Scheide, an welcher der sehr große, blasige Samenbehälter hängt. - Beim Männchen (von Rhaphidia) stellen die Genitalien eine starke Anschwellung der Hinterleibsspitze dar, welche unten der Länge nach geteilt und klaffend ist, in der Lücke aber eine zweite, innere Scheide enthält, welche den Penis umschließt. Die äußeren Scheidenhälften sind an ihrem Grunde und Ende angeschwollen und hier mit ein paar großen hornigen Haken bewaffnet. Über diesem an der Bauchseite des 8. Ringes angebrachten Apparat ragt die kurze Afterröhre als 9. Ring hervor. - Beim Weibchen findet sich am Ende des Hinterleibes eine lange feine Röhre, die aus dem an der Bauchseite gespaltenen 8. Körperring hervortritt und am Ende mit zwei kleinen elliptischen Blättchen von mehr horniger Beschaffenheit bewaffnet ist. Die eigentliche Röhre besteht aus zwei in senkrechter Stellung neben einander liegenden Halbröhren, deren eigentliche Substanz weich zu sein scheint, obwohl jede in der Mitte eine festere und daher dunklere Längslinie hat. Oben und unten an den Berührungsrändern stoßen sie genau zusammen, und auf der äußeren Fläche sind sie fein in die Quere gestrichelt. Über der Legscheide ragt dann noch der kurze, 9. Ring hervor, welcher den After umschlieBt."

Rambur (5) gibt 1842 in den Einzelbeschreibungen mancher Arten Bemerkungen über deren Genitalanhänge, aber keine zusammenhängende 
Darstellung, und auch S'CHNEIDER (6) berücksichtigt 1843 in seiner Monographie von Rhaphidia nur kurz die äußern Verhältnisse: „Abdomen cylindricum, paulo depressum, postice attenuatum, e segmentis novem constitutum, a quorum penultimo vel ultimo partes sexuales includuntur. Partes sexuales marium in penultimo vel etiam ultimo abdominis segmento turgescentiam formant, quae media fissa est, vel etiam patet, atque penem in tabulo interno collocatum continet. In externa parte turgescentia illa unguiculis duabus instructa, vel omnino simplex, neque vero patens apparet. - Partes sexuales feminarum vaginam formant longitudine abdomini aequalem a fissura segmenti penultimi subtus orientem, e semitubulis duobus compositam, quorum altera pars supra alteram posita est. Hi vaginae semitubuli paralleli, utrinque membrana coriacea coniuncti, in basi et in apice conniventes ibique appendiculis duobus ovatus subcorneis instructi sunt. - Anus conspicuus est in ultimo abdominis segmento supra turgescentiam marium et supra vagina feminarum." - Hierzu gehört eine kleine Zeichnung des weiblichen und eine ebensolche etwas dürftige des männlichen Abdominalendes.

Aus FreY-Ledckart's Lehrbuch (7) (1847) seien folgende zerstreute Bemerkungen zusammengestellt: (Männliche Organe.) Die Hoden sind bei Hemerobius nur die erweiterten Enden der Samenleiter, die zugleich sich etwas spindelförmig drehen und eine gelbliche Färbung annehmen. Sialis besitzt jederseits einen nierenförmigen Hoden, an welchem man ganz deutlich zwei übereinander gelegene Häute unterscheiden kann, deren innere in mehrere Nebentaschen zusammengefaltet und frei in der äußern Membran enthalten ist. Die Vasa deferentia (der Neuropteren) sind in der Regel lange, feine und geschlängelte Gefäße, die bisweilen (Sialis) zu einer Samenblase sich erweitern. Die accessorischen Absonderungswerkzeuge erscheinen bei Sialis als kolbige Schläuche. Gewöhnlich findet sich nur ein Paar solcher Drüsen, die in den obern Teil des weiten, kurzen Ductus excretorius münden. Ascalaphus besitzt 2 Paar birnförmige Bläschen, deren kleinere mit einem gefäßartigen Anhang versehen sind. - (Weibliche Organe.) Bei den Neuropteren sitzen zahlreiche, meist nur kurze Eiröhren in mehr oder minder regelmäßigen Reihen auf dem obern, schlauchförmigen Teile der Eileiter. Konstant findet sich eine Samenkapsel und bei Hemerobius ein unpaarer, zu einer lang gestielten Blase ausgebildeter Anhang. - Alles andere bezieht sich auf die mit den Neuropteren zusammengefaßten Trichopteren, Panorpaten, Odonaten, Perliden u. a. Die Abbildungen, auf welche Bezug genommen ist, sind in den Icon. phys., tab. 19 (fig. 2) und tab. 24 (fig. 25) zu finden.

Nach v. Siebold $(8)^{1}$ ) (1848) sollen die Neuropteren nur wenige Nodifikationen an den männlichen Geschlechtsorganen bieten. Die Hoden bestehen aus 2 Büscheln länglicher oder runder Schläuche, welche bei Myrmeleon und Hemerobius 2 ovale von besondern Hüllen umgebene Organe darstellen. Die beiden kurzen Samenleiter nehmen an ihrem untern Ende stets die Mündungen zweier eiförmigen oder länglichen,

1) Zum größten Teil nach Dufour, Recherches sur les Orthoptères. 
akzessorischen Drüsenschläuche auf. Ein äußeres und ein inneres Klappenpaar umgibt den röhren- oder rinnenförmigen Penis. - Die weiblichen Organe bestehen aus vielkammerigen Eierstocksröhren, von welchen je 10 bei den Hemerobiden und Myrmeleoniden an der äuBern Seite der beiden weiten Tuben entspringen. Die Samentasche stellt bei Myrmeleon einen langgestielten Behälter dar, in dessen Grund bei Hemerobius eine einfache, bei Rhaphidia eine doppelte Glandula appendicularis einmündet. Bei Sialis besitzt die Scheide außer 2 seitlichen, als Samentaschen fungierenden, blindsackförmigen Ausstülpungen einen ansehnlichen, blasenförmigen, mit einer schwärzlichen Flüssigkeit gefüllten Anhang. 2 einfache, mehr oder weniger gewundene Drüsenschläuche hängen bei Myrmeleon und Hemerobius mit der Scheide zusammen.

Am meisten wurde die Kenntnis über unsern Gegenstand im Jahre 1848 durch Löw und Dufoun gefördert, welche in ihren Arbeiten über Lebensweise und Bau der Neuropteren auch den Genitalapparat derselben beschrieben und abbildeten. Von Löw (10) haben wir eine eingehende Darstellung der Anatomie von Sialis, Rhaphidia und Chrysopa, aus welcher das auf den Geschlechtsapparat Bezügliche hier wiedergegeben ist.

(Sialis 3.) - „Die Testikeln sind anfangs bei noch geringerer Anschwellung fast rundlich, doch schon mit einer Andeutung der nierenförmigen Gestalt, welche sie bei größerer Anschwellung annehmen. Jeder Hode ist von einer äußeren, stärkeren Haut bekleidet, welche an der Unterseite desselben um den Ursprung des Samenleiters herum derber ist und eine gelbliche Farbe hat. Von dieser Stelle aus laufen fünf reifenförmige Streifen, welche dieselbe derbere Textur und dieselbe gelbliche Farbe haben, um den Körper des Hoden herum, welcher dadurch in sechs Abschnitte geteilt wird. Wenn die Hoden durch fortschreitende Entwicklung der Spermatozoen mehr aufgetrieben werden, nehmen sie zunächst eine nierenförmige Gestalt an. Wenn die Anschwellung derselben ihren höchsten Grad erreicht, treten die sechs Abschnitte der Hoden zwischen den derberen, ringförmigen Streifen der äußeren Haut taschenförmig hervor, und das ganze Organ bekommt eine fast fächerförmige Gestalt. Die Samenleiter sind von bedeutender Länge und fast gleichmäßiger Weite; nur ganz in der Nähe des Hodens haben sie eine kleine, blasenförmige Anschwellung. In natürlicher Lage bilden sie etwa auf der Mitte ihrer Länge eine Schlinge. Nicht gar fern von ihrem hinteren Ende biegen sich die Samenleiter nach vorn um, treten etwa auf der Mitte eines ansehnlichen, einer Samenkapsel ähnlichen Behälters hart aneinander, um sich sogleich wieder voneinander zu entfernen und gesondert in ihn einzumünden; die Einmündung in denselben findet an der Innenseite der blasenförmig vortretenden Vorderecke statt. Jede dieser beiden blasenförmigen Vorderecken zeigt einen bräunlichen Ring und eine unregelmäßig viereckige, dunkler braune Stelle; beide scheinen von durchschimmernden festeren, fast hornartigen Wandungen hervorgebracht $\mathrm{zu}$ werden. Vorn in der Mitte finden sich zwei ziemlich ansehnliche, blasige Anhänge von mehr kegelförmiger als cylindrischer Gestalt. Ein größerer blasenförmiger Anhang liegt hinten auf der Samenkapsel; noch passender ließe er sich wohl als eine blasenförmige Aufschwellung betrachten. Ganz 
am Hinterende endlich finden sich noch zwei äußerst kleine und ziemlich schwer aufzufindende Anhangsbläschen.

(Sialis ․) - Die weiblichen Genitalien zeigen sehr zahlreiche Tuben; die Eikeime sind von weißlicher Farbe, eiförmig; ihre Länge übertrifft die Breite um mehr als das doppelte. An ihrem oberen Ende haben sie einen ganz ähnlichen warzenförmigen Anhang wie bei Rhaphidia ophiopsis; nur ist derselbe verhältnismäßig etwas länger. Die Samenkapsel und Colleterien habe ich nicht abgebildet, finde auch über dieselben keine Notiz; sie scheinen sich demnach der Beobachtung entzogen zu haben und sind wohl minder leicht aufzufinden gewesen. ${ }^{1}$ )

(Rhaphidia ठ.) — Die Testikeln fand ich von fast fächerförmiger Gestalt; sie bestehen aus einer großen Anzahl langgestreckter Taschen, welche durch eine gemeinschaftliche Haut miteinander verbunden sind und erinnern in ihrem Bau am meisten an die Beschaffenheit dieser Teile bei Sialis. Die Vasa deferentia sind sehr lang, dünn, von ziemlich zartem Bau und in ihrer Länge von ziemlich gleichem Durchmesser; sie münden jedes in ein unregelmäßig cylindrisches Gefäß; diese beiden Gefäße dürften als Analoga der Samenblasen anzusehen sein; sie liegen beide dicht aneinander, und es gelang mir nie, sie ohne Zerreißung zu trennen, so daß ich an eine Verwachsung derselben glauben muB. Am oberen Ende sind sie abgestutzt; etwas unterhalb ihrer Mitte und zwar auf der einander zugekehrten Seite nehmen sie die Samenleiter auf. Am unteren Ende sind sie ziemlich stark verdickt, und jedes geht dann in einen viel dünneren aber noch immer weiten, zweimal zusammengeknickten Ausführungsgang über: diese beiden Ausführungsgänge liegen bei der natürlichen Anordnung der Genitalien unmittelbar nebeneinander und vereinigen sich zuletzt aller Wahrscheinlichkeit nach $\mathrm{zu}$ einem gemeinschaftlichen Ausführungsgang, welcher aber jedenfalls sehr kurz sein muß, da ich ihn auch nicht ein einziges Mal deutlich beobachten konnte. Colleterien werden wohl jedenfalls vorhanden sein; ich fand mehrmals an der Stelle, wo sie vermutet werden müssen, zwei kurze, weißliche Gefäße mit engem inneren Lumen und dicker äußerer Hülle; sie im Zusammenhang mit den Genitalien zu beobachten, ist mir nicht gelungen; doch kann ich kaum einen Zweifel über ihre Deutung hegen.

(Rhaphidia +.) - Die weiblichen Genitalien unterscheiden sich durch die Gestalt der Ovarien sehr erbeblich von denen aller übrigen mir in dieser Beziehung bekannten Gattungen der Neuropteren. Während letztere nämlich kammförmige Ovarien haben, sind sie bei Rhaphidia vollkommen büschelförmig und aus einer viel größeren Anzahl einzelner Tuben gebildet. Die Eier entwickeln sich in jeder einzelnen Röhre, wie es scheint in ziemlich langen Zeitzwischenräumen; wenigstens fand ich das unterste Ei in seiner Entwicklung sehr weit fortgeschritten, während das vorhergehende in seiner Entwicklung noch äußerst weit zurückstand. Die Eier sind weiß, sehr langgestreckt, da ihre Länge die Dicke etwa 7 mal übertreffen mag. Am oberen Ende sind sie von einem kleinen, warzenförmigen Fortsatz gekrönt, welcher nur äußerst wenig durchscheinend ist. Die Eileiter sind

1) Vgl. v. Siebold, p. 381. 
sehr kurz und vereinigen sich zu einem gemeinschaftlichen Eiergang; an einer muskulösen Anschwellung desselben, welche im hintersten Ende des Abdomens liegt, ist das blasenförmige, rundliche Receptaculum seminis befestigt. Es ist verhältnismäßig ziemlich groß, nicht gestielt und ziemlich farblos. Von der muskulösen Verdickung aus läuft der Eiergang in der Legröhre noch bis zu deren hinterem Ende; von der Verdickung aus verschmächtigt er sich ziemlich schnell und ist dann in diesem ganzen letzten Teil seines Verlaufes eine so feine Röhre, daß man selbst bei der gestreckten Gestalt der Eier kaum begreift, wie das Insekt dieselben durch ihn hindurchzuzwängen vermag. Die Legescheide ist von nicht ganz einfachem Bau, von mehr häutiger als horniger Beschaffenheit, aus zwei aneinander liegenden, beiderseits weitläufig gewimperten Rinnen und zwei kurzen, fast eiförmigen Anhängseln derselben gebildet. Die Rinnen sind in der Quere gerippt und ihrer ganzen Länge nach innerlich mit deutlichen Nuskelfasern versehen, welche die Bewegung nach unten und oben sowie nach links und rechts vermitteln.

(Chrysopa ठ.) - Die inneren männlichen Genitalien sind nicht bei allen Arten gleich gebildet; namentlich zeigt sich in der Gestalt der Hoden ein recht wesentlicher Unterschied. Bei Chrysopa perla finden sich schön dottergelb gefärbte Testikeln, welche ihre Färbung der sie äußerlich bedeckenden Haut verdanken, von pfropfenzieherförmiger Gestalt und bilden drei und eine halbe Windung, von denen die zweite die dickste und weiteste ist. Die sie äußerlich bedeckende gelbe Haut ist von ziemlicher Derbheit. Die Spermatozoe hat die Gestalt eines sehr langen, an keinem Ende verdickten, feinen Fadens und eine gelbliche Farbe. Die Samenleiter sind wie gewöhnlich in der Ordnung der eigentlichen Neuropteren sehr lang, ganz gerade, oben sanft erweitert und vom Hoden selbst etwas abgeschnürt. Sie haben eine weißliche Farbe; ihr innerer Kanal aber hat, vielleicht von darin enthaltener, gekreister Spermatozoe, ein etwas gelbliches Ansehen. Sie vereinigen sich in den gemeinschaftlichen Ductus ejaculatorius, der ziemlich kurz ist. Das obere Ende desselben ist kraus zusammengerollt und verbirgt sich hinter der beutelförmigen oder vielmehr blasenförmigen Erweiterung, welche die Mitte desselben trägt. Diese obere Hälfte ist viel dünner und etwas länger als die untere auf die blasenförmige Erweiterung desselben folgende Hälfte... A Am unteren Ende des Ductus ejaculatorius befestigen sich die sehr kurzen Anhangsgefäße, welche die Gestalt verschieden geformter Bläschen haben und vielleicht richtiger als die verschiedenen Zweige eines kurzästigen, paarigen Anhangs angesehen werden dürfen. Das erste Paar dieser Bläschen hat ein knopfförmiges Ende und zwei seitliche, nach außen gerichtete bauchige Anschwellungen; es ist nach vorn gerichtet. Das zweite Bläschenpaar hat eine divergente Richtung nach vorn und außen; in seiner Gestalt hat es etwas Analoges mit dem ersten Paar; sein Ende ist nämlich ebenfalls, obgleich nicht so stark und nicht so kopfförmig, angeschwollen, und auf seiner Außenseite hat es ebenfalls zwei bauchige Anschwellungen. Weiter nach hinten und außen liegen jederseits noch ein Paar sehr kleine, rundliche Bläschen. - Der Anheftungspunkt dieses Anhanges liegt ganz nahe am hintersten Ende des Ductus ejaculatorius. Ob jedes der Bläs- 
chen gesondert in ihn einmündet oder nicht, ist schwer zu entscheiden. Ich glaube mit ziemlicher Sicherheit die Vereinigung sämmtlicher Bläschen jeder Seite vor ihrer Einmündung in den Ductus ejaculatorius gesehen zu haben, was mich um so mehr bestimmt, das ganze Organ als einen einzigen, paarigen Anhang zu betrachten.

(Chrysopa ‥) - Die weiblichen Genitalien bestehen zuerst aus den Ovarien. Jedes derselben ist aus 12, zuerst sehr schlanken Eiröhren gebildet, deren jede sich nach oben hin fadenförmig verlängert. Diese einzelnen Fäden, in welche die Tuben ausgehen, verbinden sich allmählich miteinander in ganz ähnlicher Weise wie dies bei dem Weibchen von Panorpa communis der Fall ist, und scheinen zuletzt auch bei Chrysopa nur einen einzigen, dünnen, aber doch ziemlich derben Faden zu bilden. Es ist nicht schwer, diesen Faden bis zur Gegend des oberen Magenmundes zu verfolgen. Seinen weiteren Verlauf mit voller Sicherheit zu ermitteln, ist mir zwar nicht gelungen; doch schien es mir stets, als ob er sich dem Schlund innig anlege. - Die Eikeime von Chrysopa sind zuerst weiß und nehmen erst allmählich bei weiterer Entwicklung eine bunte Färbung an, welche im allgemeinen durch Gelb in Grün übergeht. Die Farbe, welche sie zuletzt erreichen, ist nach Ton und Intensität sehr verschieden; dies richtet sich vollkommen nach der allgemeinen Körperfärbung der Art und ist bei Chrysopa perla selbst bei verschieden gefärbten Individuen recht merklich verschieden. Ein sehr schönes Ansehen haben die mehr gelbgrünen oder blaugrünen Eier anderer Arten. Die Gestalt der Eier ist bei allen von mir untersuchten Arten dieselbe; sie sind an beiden Seiten abgerundet und im Verhältnis zu ihrer Länge ziemlich dick. - Die Eierleiter sind von mäBiger Länge und Weite; da, wo sie sich zum gemeinschaftlichen Eiergang vereinigen, liegt auch bei Chrysopa das letzte Abdominalganglion. Der Eiergang ist weit und von mäßiger Länge. An ihn befestigt sich an seinem Ende der Samenbehälter. Dieser ist einfach, von Gestalt einer kurz gestielten, großen fast eitörmigen Blase; bei unlängst ausgeschlüpften, noch nicht befruchteten Weibchen fand ich ihn am Rande kraus zusammengefaltet. Er ist von einer weißlichen Farbe und von nicht sehr derbem, häutigem Bau. - Die Anwesenheit von Colleterien zu bezweifeln, habe ich keinen bestimmten Grund; doch ist es mir nicht gelungen, sie aufzufinden. Es läßt sich also wohl vermuten, daß sie sehr klein, wohl auch von sehr zartem Bau sein werden."

DUFouR's Abhandlung (9) beschäftigt sich mit der Anatomie von Osmylus. Das auf die Genitalorgane Bezügliche gebe ich hier, ins Deutsche übertragen, wieder und füge DUfouR's Zeichnungen hinzu, da ich selbst nicht in der Lage war, die innern Organe dieser Form zu untersuchen. ${ }^{1}$ )

Nachdem Dufour eines Anhanges gedacht hat, welcher an der Basis der Vorderhüften nur bei den Weibchen vorkommt und eine Rolle

1) Dasselbe gilt für die weiter unten noch zu berücksichtigenden Arbeiten HaGeN's (11) und BRAUER's $(12,13)$. Figurennummern und Erklärungen sind die der Originalabhandlung. 
bei der Copulation spielen soll, beschreibt er die Genitalanhänge und dann die innern Organe:

Nur die Weibchen tragen am vordern Grunde der Vorderhüften, welche viel länger als die andern sind, einen rotgelben, schwach hornigen Anhang, einen ziemlich langen Sporn, der fast gerade oder schwach bogenförmig gekrümmt ist. Vermutlich dient der Sporn bei der Copulation zum Festhaken der Vorderkrallen des Männchens.

Außer diesem charakteristischen Sporn hat das Weibchen unter dem Abdominalende eine schwarze, rechteckige Platte von häutiger Beschaffenheit, die beim Männchen nicht vorhanden ist. Diese vorn leicht ausgeschweifte Platte, welche hinten mit 2 eingliedrigen, klappenförmigen Palpen (palpes valvaires) versehen ist, ist in der Mittellinie gespalten und enthält im Grunde dieser Spalte den After und die Genitalöffnung (vulve). Letztere liegt im Ruhezustande gänzlich innen, was beim Copulationsakt eine noch unbekannte Funktion erforderlich macht. Die Platte liegt auf einem häutigen Grunde, der ihr Beweglichkeit und vielleicht eine gewisse Verschiebbarkeit gestattet.

Wenn man auf das Hinterleibsende eines lebenden Männchens, vorsichtig stärker werdend, einen Druck nach außen ausübt, so erblickt man folgendes: Das letzte Segment trägt dorsal 2 Lappen, die zueinander geneigt sind. 2 dreieckige, etwas zottige Felder von rötlicher Farbe zeigen sich unter dem vorhergehenden Segment, und zwischen ihren Ursprüngen sieht man den Anus, den eine Verlängerung (prolapsus) des Enddarms umgibt. Ganz hinten endlich liegt ventral ein häutiges Stück, welches 4 kurze, eiförmige Anhänge trägt, die eingliedrig und wenig beborstet sind. Hinter und ein wenig unterhalb dieser Gruppe von Anhängen liegt die Öffnung für den Penis.

Von den 6 Abdominalganglien ist das vorletzte, kleinere im letzten enthalten. Dieses, das größte von allen, sendet nach hinten wie bei andern Insecten 4 große Genitalnerven.

1. Männlicher Genitalapparat. - Hoden. - Diese beiden Organe sind in einem oval-herzförmigen Scrotum eingeschlossen und lebhaft gelb. Sie sind gerundet oder zusammengedrückt, je nach dem Grade der Füllung mit Sperma. Jeder ist aus einem Bündel von ungefähr 20 Follikeln (capsules spermifiques) von langzylindrisch-konischer Form zusammengesetzt, welche durchscheinend oder weißlich sind, je nach der Füllung mit Sperma.

Vasa deferentia (Conduits déférents). - Das noch im Innern des Scrotums aus dem Bündel der Hodenfollikel hervorgehende Vas deferens übertrifft letztere an Länge und ist farblos. Es durchbohrt das Scrotum an den Ecken von dessen Ausschweifung und stellt dann ein haarfeines, schokoladenbraunes Röhrchen dar. Es verläuft mehr oder weniger über die jederseitige Vesicula seminalis hingebogen, an deren unterer Fläche es sich anheftet. Letztere Stelle ist schwer festzustellen. Wo das Vas deferens an den Ecken des Scrotums entspringt, umgibt es sich mit einem fettig-schwammigen Gewebe, welches es stellenweise verdeckt und erst da aufhört, wo es sich den Vesiculae seminales nähert.

Vesiculae seminales (Vésicules séminales). - Sie sind durch Zer- 


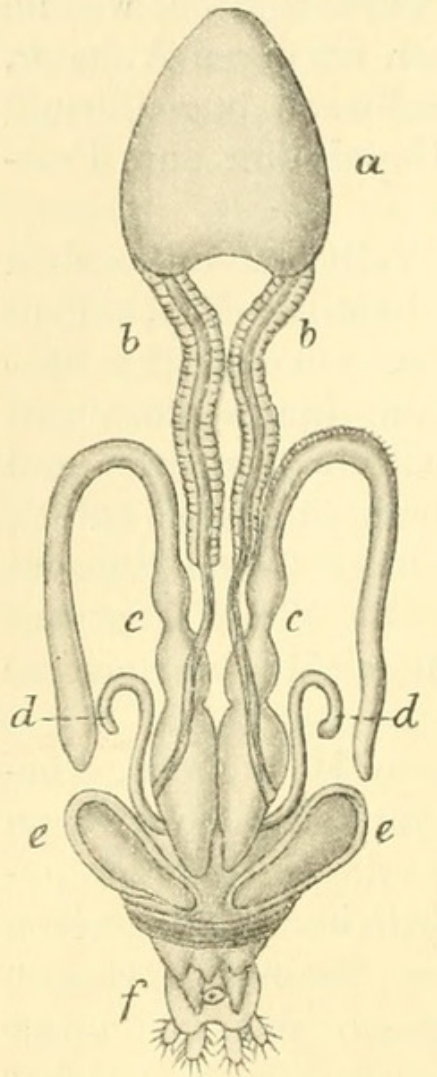

fig. 21.

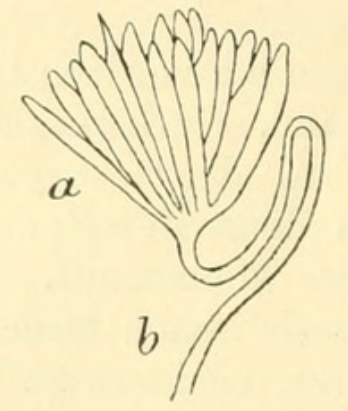

fig. 22 .

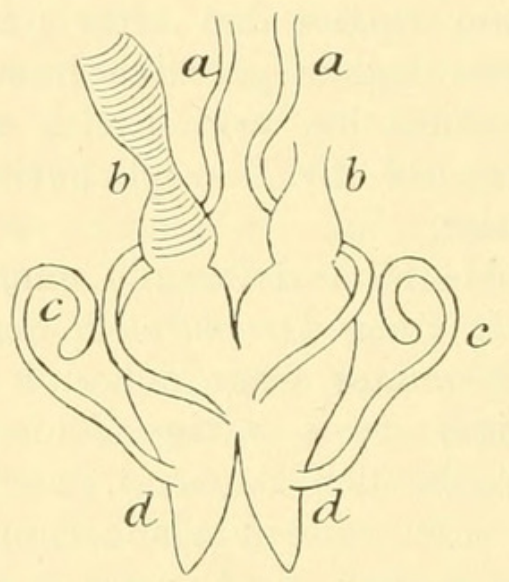

fig. 23.

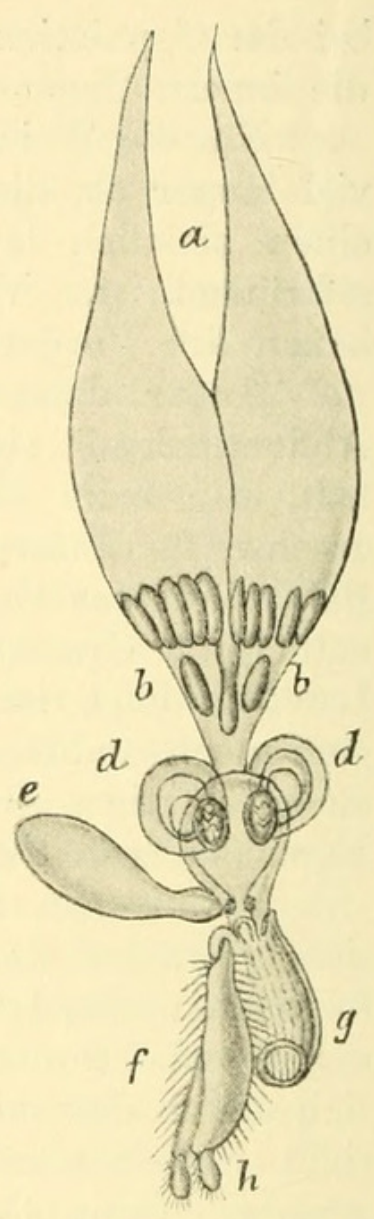

fig. 26 .

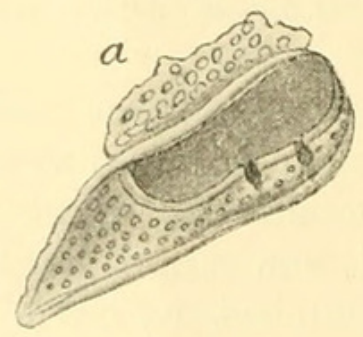

fig. 24.

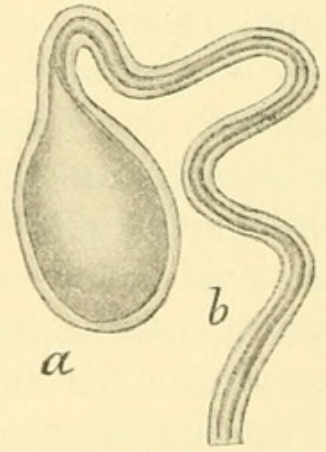

fig. 27.

fig. 21. Appareil génital mâle. $a$ scrotum, renfermant les testicules. $b, b$ conduits déférents avec leur enveloppe épiploique. $c, c$ vésicules séminales principales. $d, d$ vésicules séminales accessoires. $e, e$ glandes insolites exclusivement propres au mâle. $f$ extrémité de l'abdomen étalée par une compression expulsive, pour mettre en évidence ses diverses pièces constitutives.

fig. 22. Un des testicules hors du scrotum. a faisceau des capsules spermifiques. $b$ conduit déférent intra-scrotal.

fig. 23. Partie de l'appareil génital mâle, pour mettre en évidence les connexions et insertions. $a, a$ conduits déférents. $b, b$ parties des vésicules séminales principales, l'une avec ses bandelettes annulaires. $c, c$ vésicules séminales accessoires. $d, d$ les euls-de-sac des vésicules principales.

fig. 24. Organe ou glande insolite du mâle detaché. a un lambeau de la tunique extérieure déjétée, pour mettre à découvert la bourse noire.

fig. 26. Appareil génital femelle. $a$ ovaires. $b, b$ cols ou calices. $c$ oviducte. $d, d$ glandes sébifiques. $e$ poche copulatrice. $f$ plague vulvaire. $g$ partie déchirée. $h$ palpes vulvaires.

fig. 27. Une glande sébifique isolée. $a$ vésicule sécrétrice. $b$ conduit efférent. 
gliederung sehr schwer zur Anschauung zu bringen. Man unterscheidet an ihnen einen Hauptteil, zu dem die Vasa deferentia gehen, und einen Anhang.

Die Hauptteile sind, in Anbetracht der Kleinheit der andern Organe, 2 ziemlich dicke Schläuche, die in ihrem hintern Drittel aneinander liegen. Sie zeigen einige Auftreibungen oder Wülste und endigen vorn in Gestalt einer fadenförmigen, weißen oder durchscheinenden Röhre henkelartig so, daß ihr freies Ende an der Außenseite des Apparats liegt. Stärkere Vergrößerung läßt hier 2 ringartige Bändchen erkennen, die kontraktil zu sein scheinen. An der Stelle, wo sie zusammengehen oder aneinander haften, sind sie merklich aufgeblasen, und die durchsichtige Hülle läßt eine gelbe Farbe des Innern erkennen. Sie enden hinten in Form eines Blindsackes, der schwer zur Darstellung zu bringen ist.

Die akzessorischen Drüsen erscheinen im Vergleich zu den vorhergehenden rudimentär. Jede von ihnen ist ein feiner, fadenförmiger Schlauch, der kolbenförmig umgebogen ist und seitlich zu dem Ursprunge des Blindsackes des Hauptteiles der Vesicula seminalis geht.

Ductus ejaculatorius (Canal éjaculateur). - (Wurde von Dufour nicht aufgefunden.)

Penis (Verge). - Hinter und unterhalb einer Gruppe von 4 kurzen Anhängen, wie sie anfangs für das männliche Genitalende beschrieben worden sind, findet sich eine Öffnung, aus welcher die Copulationsorgane heraustreten müßten. Aber weder bei leisestem noch bei kräftigstem Druck gelang es, das Vorhandensein jener mehr oder weniger hornigen und festen Teile festzustellen, die allgemein bei den Insecten den Copulationsapparat darstellen, so daß Osmylus keinen solchen zu haben scheint. Ein mäBiger heraustreibender Druck bewirkt das Hervortreten von mehr oder weniger durchscheinenden Wülsten, welche augenscheinlich die Blindsäcke der Vesiculae seminalis sind, und die beim Nachlassen des Druckes wieder in den Körper zurücktreten. Bei stärkstem Drucke wird ein länglicher, biegsamer, weißlicher, anscheinend fleischiger Körper herausgedrückt, welcher der Penis zu sein scheint. Eine gefärbte oder lederartige Platte, die als Scheide desselben aufgefaßt werden könnte, ist mit der Lupe nicht zu sehen. Wenn eine solche vorhanden ist, ist sie vielleicht auch fleischig.

2. Eigenartiges Organ, nur beim Männchen vorhanden. - Am Ende der Bauchhöhle, unmittelbar unter dem Genitalapparat, aber ohne Verbindung mit ihm, liegt links und rechts vom Enddarm ein Organ mit vollkommen unbekannter Funktion. Dieses paarige Organ ist ein länglicher, platter Körper, welcher auf der Innenwand der letzten Abdominalsegmente liegt; das eine Ende ist stumpf, während das andere sich verschmälert und in der Umgebung des Afters befestigt ist. Genauere Betrachtung zeigt daran 1. eine innere, schwarze, durchscheinende Tasche von lederartiger Beschaffenheit, die zuweilen jederseits wie eine Schuhsohle leicht ausgeschweift ist; 2. eine äußere, weiche, fleischige Hülle, welche weißlich und kontraktil ist. Diese Hülle scheint mit der eingeschlossenen Tasche mehr oder weniger zusammenzuhängen; denn wenn man sie zerreißt, um diese zu erhalten, so löst sie sich leicht davon ab. In diesem 
Falle erscheint die dunkle Färbung der Tasche, welche vorher durch die Haut abgeschwächt war, tiefschwarz, und ihre Oberfläche ist vollkommen gleichmäßig und glatt. Der Reichtum an Tracheen ist ein Maßstab für die physiologische Bedeutung dieser Organe . . .

3. Weiblicher Genitalapparat. - Ovarien. - Jedes derselben ist ein kegelförmig verlaufendes Bündel, das sich nach vorn in Gestalt von 10 vielkammerigen Eiröhren (gaînes ovigères) verjüngt, dessen konvergierende Spitzen mit einem Aufhängebändchen von äußerster Feinheit enden. Es heftet sich, wie bei vielen andern Insecten, im Thorax fest. Der Hals des Ovariums ist gleichzeitig der Calyx und erweitert sich in dem Grade, in dem die Eier darin nach außen gehen.

Oviduct. - Dieser Kanal, welcher aus der Vereinigung der beiden Ovarialhälse hervorgeht, bildet kurz hinter seinem Ursprunge eine dickwandige Auftreibung, die nicht immer leicht festzustellen ist.

Kittdrüsen (Glandes sébifiques). - Von solchen ist ein Paar vorhanden. Sie befinden sich über der Auftreibung des Oviducts und liegen inmitten einer fettartigen, tracheenhaltigen Masse, von der sie sich äußerst schwierig isolieren lassen. Sie bestehen aus einem secretorischen Organ und einem ausführenden Gang.

Das secretorische Organ ist eine sehr kleine, fast kuglige oder eiförmige Blase von schwach rötlicher Farbe. Bei stärkerer Vergrößerung zeigt sich, daß sie aus einer innern Kapsel und einer fleischigen, ziemlich durchscheinenden Hülle besteht, die vielleicht kontraktil ist.

Der ausführende Gang ist ein bräunlicher Faden, dessen Stärke kaum den zehnten Teil der eines Haares erreicht. Er ist elastisch und läßt sich einrollen. Unter dem Mikroskop bemerkt man daran eine äußere Haut, derjenigen des secretorischen Organs sehr ähnlich, deren Fortsetzung sie ist. Der Gang mündet in den obern und hintern Teil des Oviducts....

Bursa copulatrix. - Sie liegt links und an der Seite des hintern Teiles des Oviducts. Sie stellt einen häutigen oder länglich blasenartigen Behälter dar, der mehr oder weniger aufgeblasen ist, je nach der Menge der von ihm eingeschlossenen Flüssigkeit. Er öffnet sich mit einem Hals in die Vagina, die nur eine Fortsetzung des Oviducts ist.

Ebenso eingehend und die Resultate Dufour's an Osmylus berücksichtigend sind die Untersuchungen HaGen's (11) über diese Gattung (1852). Soweit sie den Genitalapparat hetreffen, sind sie im Folgenden wiedergegeben:

„Dufour's Bemerkung, daß die Individuen mit Haken an den Vorderhüften Weibchen sind (RAMBUR hielt sie für Männchen), ist richtig; dagegen wird seine Vermutung, daß diese Haken bei der Begattung Stützpunkte dem Männchen gewähren, durch meine Beobachtung widerlegt.

Das Scrotum ist durch seine intensiv gelbe Farbe schon durch die Hautdecke sichtbar. Es liegt auf dem Darm, sein oberes Ende ungefähr wo der Magen aufhört. Zahlreiche Tracheen befestigen es, und ein starker Ast, von der Seitentrachee direkt kommend, geht zwischen dem Zipfel der Samenblase durch und dicht neben dem Vas deferens in das Scrotum hinein, um die Testikel zu versorgen. Dufoun's Abbildung des Scrotums stimmt nicht genau mit der von mir beobachteten Form; doch sieht man 
leicht, daß nur die Zeichnung etwas verfehlt ist. Auf der äußern Oberfläche des Scrotums finden wir dasselbe von den zwar getrennten, doch nahe beisammen liegenden Hoden angefüllt. Der weiße, gelbe Hode ist birnförmig und besteht aus etwa 20 kurzen, geraden, dicht nebeneinander liegenden Schläuchen, welche sich in einem Punkte, aus welchem das Vas deferens entspringt, vereinen. Die freien Enden der Schläuche bilden (getrennt, doch nahe beieinander liegend) die gegen den Kopf des Tieres gerichtete Spitze des Hodens.

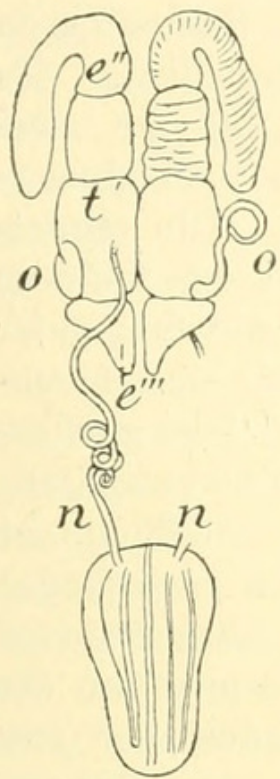

fig. 31 .

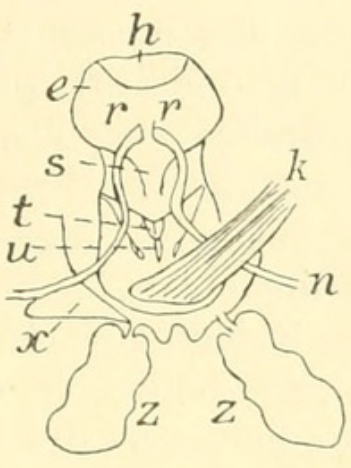

fig. 32 .

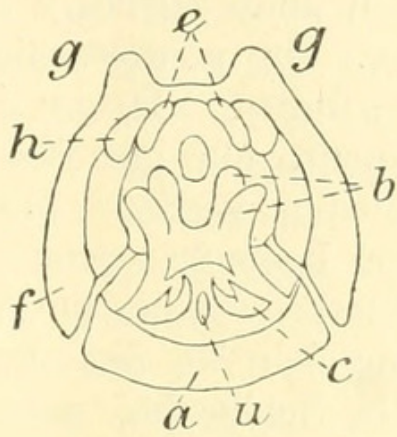

fig. 33 .

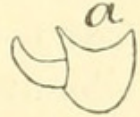

fig. 34 .

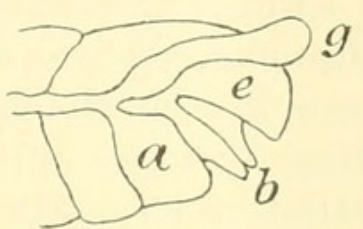

fig. 35́.

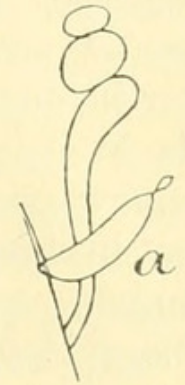

fig. 36 .

fig. 31. $\left.{ }^{1}\right)$ Männliche Geschlechtsteile, das Scrotum heruntergeklappt. $m$ Scrotum. $n$ Vas deferens mit seinen Krümmungen; geht hinter die Samenblase, die, um seinen Verlanf zu zeigen, durchsichtig gezeichnet ist. $l$ Samenblase. l' Mittlerer Teil. l" Oberer Anhang. l" Unterer Anhang. o Accessorische Drüse, auf einer Seite aufgerollt gezeichnet.

fig. 32. Männliche Geschlechtsteile, von der Leibeshöhle aus gezeichnet; der vordere Teil der Samenblase ( $l$ aus Fig. 31 inseriert bei $p$ ) und das Scrotum sind entfernt. $\quad l$ Hinterer Teil der Samenblase. $s$ Ductus ejaculatorius. $r$ Mündung: der Vasa deferentia neben einem kleinen, hornigen Halbmond. $n$ Vasa deferentia. $k$ Dickdarm. $t$ Gespaltene Hornspitze des Penis. $u$ Öffnung, durch welche der Penis austritt, jederseits eine hornige Platte. $z$ Schuhsohlendrüse. $x$ Der Beutel, der sie umgibt,.. abgezogen.

fig. 33. Äußere Bildung der Hinterleibspitze des Männchens. $a$ 8. Bauchschild. $u$ Öffnung, durch welche der Penis austritt. $c$ Fleischiger Cylinder mit seitlicher Hornspitze. $b$ Die stumpfen Hornkegel des 9. Bauchschildes. $\bar{d}$ After. e Die beiden Platten als Rudimente des letzten Rückenschildes. f Das vorhergehende, letzte, ungeteilte Rückenschild und $g$ dessen stumpfe Hornkegel. $h$ Die seitlichen weißen Buckel.

fig. 34. Die fleischigen Cylinder (Fig. $33 c$ ) vergrößert: $a$ ihre Hornspitze.

fig. 35. Seitliche Ansicht der Hinterleibsspitze des Männchens. Bezeichnungen wie in Fig. 33.

fig. 36. Ausstülpung der Scheide des Weibchens nach der Begattung: $a$ die aufgerichtete Scheidenklappe.

1) HAGEN (11). 
Das Vas deferens bildet noch im Scrotum eine einfache, neben dem Hoden liegende, weiße Schlinge, durchbohrt dann das hintere untere Ende des Scrotums und tritt jetzt als kräftiges, freies Gefäß in die Bauchhöhle. Anfangs gerade, bildet es dann 4 pfropfenzieherartige Krümmungen, die erste von innen nach außen, die 3 andern umgekehrt, von außen nach innen gerichtet; dann schlägt es sich von außen um den Darm und geht unter dem dreieckigen Zipfel der Samenblase in die Höhe, macht eine doppelte Krümmung und inseriert in den später zu beschreibenden untern Anhang der Samenblasen. Die erste Hälfte des Vas deferens ist von einem feinen Fettnetz, dessen auch Dufour gedenkt, eng umgeben.

Es gelang, die merkwürdig und kompliziert gebauten Samenblasen genau zu ergründen. Dufour beschreibt nur ihren obern Teil. Es müssen zuvörderst, um die Beschreibung zu verdeutlichen, an ihr zwei Teile unterschieden werden: die oben liegenden, eigentlichen Samenblasen und der unten liegende, gemeinschaftliche Ausführungsteil. Die eigentlichen Samenblasen fallen durch ihre bedeutende Größe bei der Öffnung des Tieres sogleich in die Augen und bilden 2 dicht nebeneinander liegende, pralle Schläuche, welche deutlich aus drei Partien zusammengesetzt sind und hinter dem untern Ende des Magens liegen. Die mittlere Partie bildet einen geraden, dicken Cylinder, etwa noch einmal so lang als breit, genau neben der entgegengesetzten Seite befestigt, 'weißlich, im Innern eine citronengelbe Färbung, welche durch seine weißen Wandungen durchschimmert. Die zweite Partie bildet eine nur wenig dünnere, viel längere, wurstförmige Schlinge, welche mit kurzer Abschnürung an das obere Ende der Cylinder befestigt ist. Sie liegt lose neben dem der entgegengesetzten Seite, ist weiß von Farbe, ihre sackartig geschlossene Spitzenhälfte nach außen umgebogen. Die dritte Partie bildet einen kleinen dreieckigen Sack (cul de sac, Dufour) mit stumpfen Spitzen und etwas eingebogener Außenseite. Er inseriert am untern Ende der Cylinder, ist weiß und gleichfalls lose neben dem entsprechenden der andern Seite liegend. Diese 3 Partien bilden die eigentlichen Samenblasen, die bei ihrer Öffnung quergefaltet zusammensinken. Ihr Inneres bildet eine durch alle drei Partien fortlaufende, hohle Röhre, in welcher ein durchsichtiger, gallertartiger Cylinder steckt. Seine äußern Konturen sind wenig bestimmt, so daß er nur aus Gallerte (die zahlreiche Haarbüschel von Spermatozoen ähnlich denen der Lepidopteren nahe beisammen liegend und bewegungslos enthält) gebildet scheint.

Eine kleine, accessorische Drüse findet sich an dem untern Ende der mittlern Partie, etwas nach außen, fest angekapselt, ein kurzer und enger Schlauch mit blindem Ende und etwas erweitertem Ursprunge, eng ineinandergerollt. Es sind dies die vésicules accessoires DUFouR's.

Der untere oder Ausführungsteil ist nur in einfacher Zahl vorhanden und unter der mittlern Partie der Samenblasen gelegen. Er ist weiß, birnförmig, breit, oben abgestutzt und mit der mittlern Partie der Samenblasen verbunden, nach unten sich rasch verengend und in einen kurzen Ausführungsgang mündend. Oberhalb desselben auf der vordern Seite gehen in denselben, nahe beisammen und durch eine kleine, halbmondförmige Hornleiste gestützt, die Enden der Vasa deferentia. Es kriecht 
also das Ende des Vas deferens zwischen den Samenblasen und ihrem Ausführungstheil etwas von unten in die Höhe, ehe es seine Insertionsstelle erreicht.

Den Ausführungsgang der Samenblase umgibt ein Hautcylinder, der zu einer etwas weiter gegen das Schwanzende des Tieres hin gelegenen Längsspalte geht. In diesem Cylinder sitzt der häutige Penis, dessen unten gespaltene Spitze 2 dreieckige Hornplatten decken. Der Penis kann durch die Längsspalte hervorgeschoben werden, um durch die Spitzenspalte den Samen in die weiblichen Geschlechtstheile zu übertragen. Da bei der Begattung die Geschlechtstheile der Thiere nahe bei einander lagen, so habe ich übrigens die Emissio des Penis nicht gesehen. Auch nach der Begattung war er augenblicklich in den Leib zurückgetreten. Daß er jedoch während des Akts recht weit herausgeschoben wird, beweist die bedeutende Scheidenausstülpung des Weibchens, welche unbezweifelt beim Herausziehen des Penis durch die divergierenden Spitzen der Hornplatten, welche die Eichel bedecken, bewirkt wird.

Die Beschreibung der äußern Geschlechtsteile bei Dufour ist richtig, ihre Abbildungen dagegen sehr unrichtig und verfehlt. Das 8. Bauchschild bildet eine vorn gerade abgeschnittene Klappe, welche auf dem 9. Schilde, das jederseits in 2 nahe hintereinanderstehende, kurze und stumpfe Hornspitzen oder Hornkegel ausläuft, aufliegt. In der Verbindungshaut zwischen dem 8. und 9. Schilde findet sich die Öffnung der Geschlechtsteile. Zwischen jenen Hornkegeln des 9. Gliedes und etwas über demselben, jederseits durch 2 lange, dreieckige Hornplatten geschützt (beide bilden das letzte Rückenschild oder vielmehr die gespaltenen Rudimente desselben), liegt der After. Oberhalb dieser Platten folgt das letzte, ungeteilte Rückenschild, an der Spitze mit 2 stumpfen Hornkegeln versehen. Heben wir das 8. Bauchschild auf, um die Geschlechtsöffnung zu untersuchen, so zeigt sich hier ein eigentümliches, neues Organ. Tief in der Verbindungshaut findet sich die kleine Längsspalte zum Austritte des Penis. Jederseits von ihr liegt ein kleiner, fleischiger Cylinder, dessen Spitze eine scharfe Hornplatte deckt. An seiner innern Seite beweglich angefügt, steht eine weiße, fleischige Spitze, einem nach außen gekrümmten Finger zu vergleichen. Der ganze Apparat kann durch kleine Muskeln nach außen bewegt werden und dient sehr wahrscheinlich zur Öffnung der beiden Hornplatten, welche den Eingang in die Scheide des Weibchens bedecken.

Noch muß ich eines Organs erwähnen, welches ganz übersehen zu sein scheint. Es sitzt nämlich auf der Außenseite jener dreieckigen Hornplatten, welche den After seitlich schützen, ein kleiner, halbkugliger Buckel, der durch seine Farbe und stärkere Behaarung sehr deutlich von seiner Umgebung absticht. Ich möchte ihn für ein Überbleibsel der in der Larve vorhandenen Hakenröhren erklären. Was er bei der Imago für eine Rolle spielt, weiß ich nicht; doch bildet er den letzten Punkt, bis zu welchem ich den Ausführungsgang zweier gleich zu erwähnenden Drüsen verfolgen konnte. DUFour beschreibt dieselbei als „organe insolite exclusivement propre à l'Osmyle mâle"; doch ist seine Beschreibung und besonders seine Abbildung nicht ganz richtig. 
Ganz in der Spitze des Hinterleibes liegt jederseits ein platter, länglicher Körper. Äußerlich umgibt ihn lose ein weißer, häutiger Beutel, der sich an die Innenseite jener dreieckigen Hornplatten vollständig anheftet. Spaltet man den Sack, so schlüpft eine breite, tief sammetschwarze Platte hervor, die Dufour passend mit einer Schuhsohle vergleicht. Aus ihrem schmalen Ende geht ein sehr kurzer, schwarzer Ausführungsgang, welcher in der Nähe jener weißen Buckel und außen neben den beiden Hornkegeln des Rückenschildes angeheftet scheint. Seine äußere Mündung konnte ich nicht sehen; doch habe ich auf das Bestimmteste nachweisen können, daß weder ein Zusammenhang mit den Geschlechtsteilen noch mit dem Dickdarm stattfindet. Mündet der Ausführungsgang in die Leibeshöhle, so habe ich wenigstens sein Ende (eine klare Röhre schien die Fortsetzung der sehr kurzen, schwarzen zu bilden) nicht verfolgen können. Noch merkwürdiger ist der Bau der Schuhsohle selbst. Von außen umgibt die sammetschwarze Fläche eine leichte, sehr feinkörnige, weiße Schicht, die ich für Fett halte. Öffnet man die Schuhsohle, so bilden ihre beiden dicht aufeinander liegenden, ziemlich dicken Wände eine Tasche. Die äußere Bekleidung bildet eine strukturlose Membran. Die ganze innere Wand ist eine Haut mit sehr dicht gestellten Zotten versehen, die relativ lang, innen hohl und jede einzeln in eine scharf begrenzte, sternförmige, schwarze Narbe des Gewebes eingefügt sind. Die Zotten endigen spitz. Wozu diese Organe dienen, ist mir vollständig unklar. Dufour vermutet, daß vielleicht das Männchen die gelegten Eier anhefte und dazu die beschriebenen Organe brauche; ich habe jedoch durch direkte Beobachtung dargetan, daß das Männchen keinen Anteil an dem Akt nimmt. . . .

DUfour's Beschreibung und Abbildung (der weiblichen Organe) sind genau und vollständig. Die Eierstöcke bilden schlanke Spindeln aus etwa 10 Eiröhren, deren convergierende Spitzen im Thorax befestigt scheinen: Der untere Theil ist seitlich durch starke Ligamente an die Bauchwand befestigt. Beide Eierstöcke vereinen sich durch einen kurzen Hals zu einem festen Eileiter, auf dessen etwas erweitertem Anfang je 2 merkwürdige Drüsen aufsitzen. Eine kleine, eiförmige, etwas platte Blase mündet durch einen langen, sehr dünnen und festen, spiralförmigen Faden in den Eileiter. Faden und Blase sind bräunlich und mit einem weißlichen Überzug bedeckt, der dem Fettnetz des Vas deferens sehr ähnlich sieht. Der Faden ist elastisch wie eine Uhrfeder. Seitlich und hinter dem Eileiter liegt die starke Begattungstasche, deren Ausstülpung bei der Begattung oben erwähnt ist. Es mündet der Eileiter nach Aufnahme der Begattungstasche als Scheide zwischen den unter der Spitze des Hinterleibes liegenden länglichen Platten, deren Spitze einen einfachen Scheidentaster trägt. Starke, auf ihrer Rückseite liegende Muskeln richten sie fast senkrecht auf, wenn die ausgestülpte Begattungstasche zwischen ihnen hervorragt. Hinter denselben an der Spitze des Leibes mündet der After. Neben dem After findet sich beim Weibchen wie beim Männchen jener scharf markierte, weiße, halbkuglige Buckel.

Die Eiröhren sind bis gegen die Spitze hin mit einer einfachen Reihe von Eiern in abnehmender Größe erfüllt. Die oberste, feine Spitze der Eiröhren wird durch eine feine, strukturlose Membran gebildet, in der 
ich freie Keimbläschen nicht zu unterscheiden vermochte. Wo sich die ersten Eier zeigen, gewinnt die Wand der Eiröhren ein drüsiges Ansehen."

In einer Arbeit Brauen's (13) aus dem Jahre 1854 finden wir eine kurze, übersichtliche Zusammenstellung der bis zu dieser Zeit an Neuropteren bekannten anatomischen Verhältnisse und also auch der des Genitalapparats derselben. Dazu gibt der Verfasser Beschreibungen dieses Organsystems von Mantispa, Drepanopteryx und Myrmeleon:

"Mantispa pagana F. - Männliche Genitalien. - Die Hoden liegen im 4. Hinterleibsring und sind von ovaler Form, nicht groß und orangegelb. Sie bestehen im Innern aus mehreren Säckchen, die sich beim Zerdrücken des Hodens fächerförmig entfalten. Die Samenleiter sind sehr fein und lang, laufen aber fast gerade bis zur Samenblase. Diese läuft nach vorn in zwei längliche Zipfel aus, die am Ende je ein kleineres Bläschen abschnüren, das nach außen gebogen ist. In der Ebene, in der die Samenleiter einmünden, wird die Samenblase einfach und zeigt nur eine mittlere Furche zwischen zwei kugeligen Erhöhungen. Nach hinten läuft sie wieder in zwei eingebogene Zipfel aus, zwischen welchen wie bei Myrmeleon der Ductus ejaculatorius läuft. Im Ganzen zeigt sich in der Samenblase eine Ähnlichkeit mit Rhaphidia. Ihre Farbe ist weißgelb.

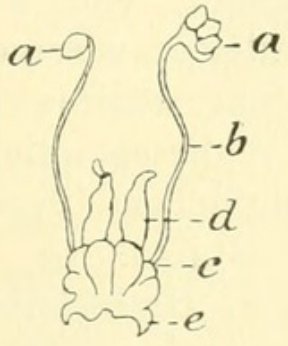

fig. 3 .

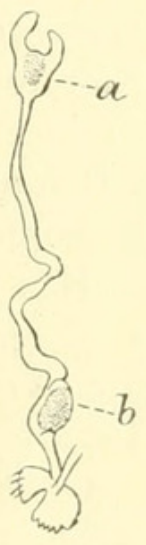

fig. 4".

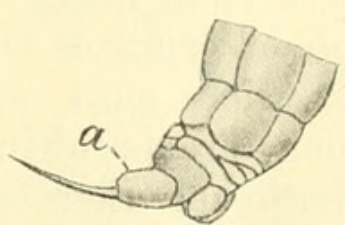

fig. 5 .

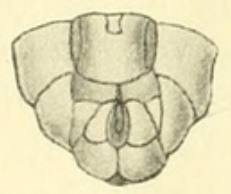

fig. 6 .

fig. 3. $^{1}$ ) Genitalien des Männchens. $a$ Hoden. $b$ Samenleiter. $c$ Samenblase. $d$ Vorderer, paariger Teil. e Hinterer Zipfel.

fig. 4". Receptaculum seminis. a Receptaculum. $b$ Ausführungsgang mit blasiger Anschwellung.

fig. 5. Hinterleibsspitze des Weibchens, von der Seite.

fig, 6. Dieselbe von unten gesehen.

Weibliche Genitalien. - Die Ovarien bestehen aus einer ungeheuren Menge Eiröhren. Die Eileiter spalten sich in mehrere Äste (3 ?), die sich wieder in die Zweige teilen (9 oder 10 ?), auf welchen die Eileiter kammförmig aneinander gereiht sind. Im Vergleich mit Myrmeleon sind also hier eigentlich mehrere kammförmige Ovarien zusammengetreten und bilden so ein büschelförmiges Ovarium, das an der Oberfläche Furchen zeigt, die die Zahl der Kämme von Eierröhren andeuten. Die Eikeime sind

1) Brauer (13).

Zool. Jahrb. XXVII. Abt. f. Anat. 
länglich, fast cylindrisch und am vordern Ende mit einem kleinen Knöpfchen von runder Gestalt versehen. Sie sind sehr klein, ungefähr $1 / 2 \mathrm{~mm}$ lang. Das Ovarium ist von rötlich-gelber Farbe. . . . Die Eileiter sind übrigens kurz und vereinen sich zu einem nicht viel breitern Eiergang, der jedoch länger ist als die Eileiter. Das Receptaculum seminis ist groß, halbkreisförmig, mit zwei cylindrischen Zipfeln endigend. Der Ausführungsgang läuft anfangs fast gerade, dann aber im Zickzack um den Dickdarm, und hat vor seinem Ende, welches sehr fein ist, eine große, bläschenförmige Anschwellung, die jener bei Chrysopa nach LoEw am Ductus ejaculatorius vorkommenden sehr ähnlich geformt ist. Vielleicht ist nur letztere das Receptaculum und die vordere Blase ein Schleimgefäß für die Stiele der Eier, da ich kein anderes accessorisches Organ fand. Der Inhalt ist orangefarben. Der Ausführungsgang mündet am Ende des Eiergangs in denselben.

Drepanopteryx phalaenoides L. - Weibliche Genitalien. - Diese erinnern an den Bau derselben bei Mantispa. Die kurzen Eileiter teilen sich in mehrere (3?), aus kammförmig gestellten Eierröhren bestehende Büschel. Die Eierröhren enthalten drei größere und mehrere kleinere Keime von ovaler, länglicher Form, am obern Ende mit einem Knöpfchen versehen. Die Büschel werden von zahlreichen Tracheen durchsetzt und umzogen und sind nebst diesen von den Endfäden der Eierröhren je zu einem spindelförmigen Ovarium vereinigt. Mit den Fäden der Eierröhren vereinigen sich auch die zum Eierstock gehenden Tracheenzweige, bis zuletzt der Tracheenhauptstamm (einer auf jeder Seite) mit dem Endfaden sämtlicher Eierröhren zum Schlundende gelangt, von wo aus ich den Faden nicht weiter verfolgen konnte. Die Eileiter vereinen sich zu einem kurzen, breiten Eiergang. Das Receptaculum seminis ist meiner Untersuchung an einem Weibchen entgangen. - Wahrscheinlich sind die in allem so verwandten Hemerobius-Arten nach ähnlichem Typus gebaut.

Formicaleo (Myrmeleon aut.) tetragrammicus Pluas. - Männliche Genitalien. - Die Huden liegen am Anfang des 4. Hinterleibssegments, sind oval und von zitronengelber Farbe. Sie enthalten mehrere (6) Säckchen, die von oben nach außen und unten in Spiralform aneinander gereiht sind. Die Samenleiter haben an ihrem Austritt am obern Ende eine kleine, bläschenartige Erweiterung, sind dann fein und lang und laufen bis zum 7. Segment. Die Samenblase ist groß und läuft nach vorn in zwei dicke, abgerundete, am Innenrand eingekerbte Teile aus. Die Vereinigung derselben liegt in der Ebene, in der die Samenleiter seitwärts einmünden. Vor dem Eintritt erweitern sich die Samenleiter. Hinter ihrer Einmündungsstelle biegt sich ein zipfelförmiger Teil der Samenblase in Hufeisenform (einer auf jeder Seite) nach außen und dann neben dem Ductus ejaculatorius nach rückwärts und innen. Der Ductus ejaculatorius ist ziemlich weit, aber kurz. Der Penis besteht aus einem dickern, weichen Grundtheil und zwei gegeneinander gebogenen, langen Hornkräten, die am Innenrand mit einem Zahn bewaffnet sind.

Weibliche Genitalien. - Die Ovarien sind kammförmig und zeigen je 10 Eierröhren mit 3 größern und 2 kleinern Eikeimen von anscheinend gleicher Entwicklung in jeder Eierröhre. Die Eileiter sind kurz, aber 
weit. Der Eiergang ist etwas länger und wenig weiter als ein Eileiter. Das ganze Ovarium ist von weißer Farbe."

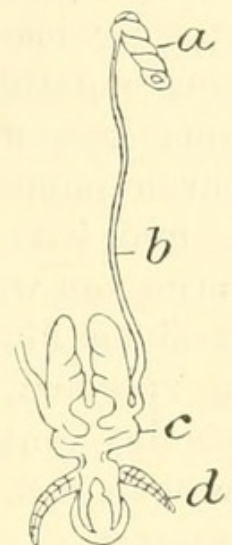

fig. 9.

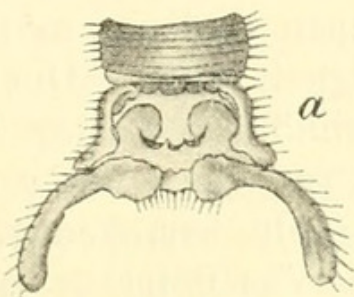

fig. V.

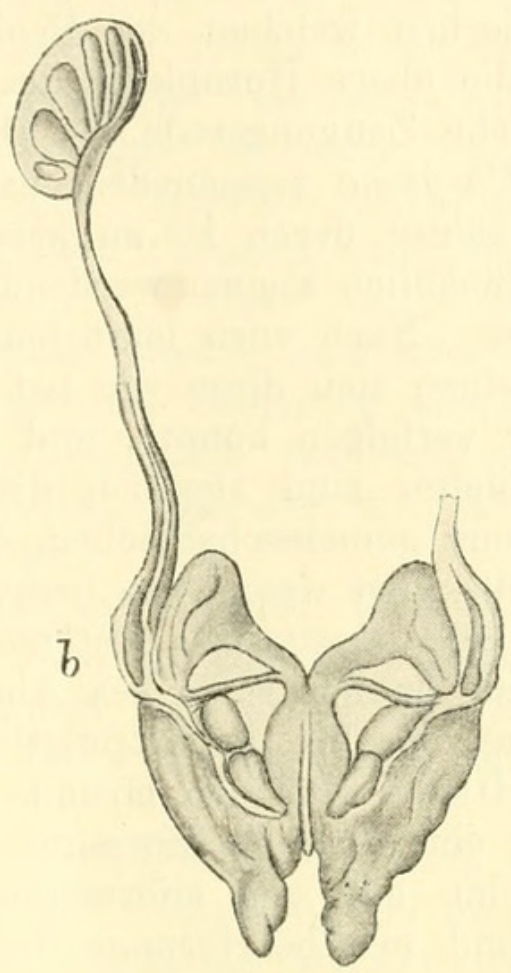

fig. IV.

fig. 9. $\left.{ }^{1}\right) \quad a$ Hoden. $b$ Samenleiter. $c$ Blase von der Rückseite gesehen. d Ductus ejaculatorius und Penis, mit seinen Muskeln hervorgezogen.

fig. IV. Männlicher Geschlechtsapparat von Ascalaphus [BRAUER (12)].

fig. V. Abdominalende von Ascalaphus.

In einer andern Abhandlung aus demselben Jahre bringt BraUer (12) eine Beschreibung der Geschlechtsorgane von Ascalaphus italicus:

Nännliche Zeugungsteile. - Die Hoden liegen im 4. Hinterleibssegment, sind nierenförmig und von rostgelber Farbe. Sie enthalten mehrere (6?) die Spermatozoen einschließende Säckchen, welche sich innerhalb der umhüllenden Membran zu einem Ausführungsgang vereinigen, welcher am hintern Ende in den Samenleiter übergeht. Dieser ist anfangs ziemlich fein und lang, erweitert sich am Ende stark und geht in die sogenannte Samenblase über. Er enthält etwas dunkler gefärbte Spermatozoen. Die Samenblase ist ziemlich groß, mit zwei vordern, mittlern und hintern bläschenförmigen Anhängen. Die Verbindung der einzelnen Bläschen geschieht durch kleine Kanäle; doch ist mir eine Vereinigung zu einem Ausführungsgang nicht genau darzustellen gelungen. Von den Anhängen sind die vordern kuglig mit etwas abgeplatteten Seiten, die mittlern und hintern sackförmig, oval. Die Vorderecken der Samenblasen sind ebenfalls blasenartig erweitert. - Über die vordern Anhänge läuft nach vorn und innen ein feines GefäB, das sich dann nach hinten umbiegt und wahrscheinlich mit demselben der andern Seite zum Ductus ejaculatorius wird, der zwischen den hintern Anhängen sichtbar wird. Der

1) Brauer (13), Formicaleo. 
Penis ist breit, flach und endigt in zwei aus- und vorwärts gebogene, hornige Häkchen. Die ihn bewegenden Muskeln haften in den kleinen Höckern an der Seite des vorletzten Segments, seitwärts von den Haltzangen, zwischen welchen der Penis hervortritt. Er ist leicht zu sehen, wenn man die obere Hornplatte desselben Leibringes entfernt.

Weibliche Zeugungsteile. - Die Ovarien sind kammförmig, doch dadurch von Chrysopa verschieden, daß die Eierröhren immer paarig gestellt sind. Ich zählte deren 10 an jedem Ovarium, und jede Eiröhre enthält wieder 4 allmählich kleiner werdende, ovale Eikerne von weiß- oder rötlichgelber Farbe. Nach vorn läuft jede Eiröhre in einen dünnen Faden aus. Zuletzt scheinen sich diese wie bei Chrysopa zu vereinen, was ich jedoch nicht weiter verfolgen konnte, und legen sich an das hintere Schlundende an. Die Eileiter sind ziemlich dick und vereinigen sich bald über dem Dickdarm zum gemeinschaftlichen, dickern Eiergang. "

Ebenfalls über Ascalaphus (meridionalis) berichtet Dufour (14) 1860 : „Der männliche Ascalaphus unterscheidet sich vom weiblichen äußerlich dadurch, daß er am Ende des Abdomens einen Anhang in Gestalt einer Gabel besitzt, der bei der Copulation in Tätigkeit tritt. Die voneinander getrennten Hoden sind am Grunde der Bauchhöhle befestigt. Jeder von ihnen stellt eine länglich-eiförmige, weiße Drüse dar; unter seiner Hülle bildet er eine aus den eiförmigen Samenkapseln bestehende, zusammengedrängte und maulbeerförmige Spitze. Das Vas deferens ist viermal so lang als der Hoden und haarfein. Die Vesiculae seminales bilden zwei gerundete, ziemlich stark ineinander gewickelte, eiförmige Säcke. - Die Ovarien bestehen aus je einem Bündel von zehn vielkammerigen Eiröhren. Diese vereinigen sich hinten zu einem Kelch. Beide Kelche vereinigen sich zum Oviduct, in dessen Dorsalteil vorn die Bursa copulatrix mündet. Hinten findet sich eine paarige Anhangsdrüse."

McLachlan (15) gibt 1868 in einer systematischen Arbeit über englische Neuropteren unterscheidende Merkmale, die sich bei einer Anzahl von Formen auch auf das Abdominalende und die Genitalanhänge beziehen: "Sialis lutaria L. - "Abdominalende beim Männchen oben einen fleischigen Lappen bildend, in dem sich ein hohler Raum mit einer Verlängerung in der Mitte befindet. Von diesem Lappen entspringen zwei gekrümmte, zylindrische, durchscheinende Anhänge, welche selten zu sehen sind, wenn man nicht auf das Abdomen des lebenden Insects einen Druck ausübt. Ventralklappe groß und abgestumpft."

Sialis fuliginosa P. - "Abdominalende beim Männchen oben mit einem schmalen, fleischigen Lappen, mit einem eiförmigen Hohlraum in der Mitte. Die von diesem Lappen ausgehenden Anhänge sind an der Spitze dicker. Ventralklappe bedeutend kleiner, dreieckig, am Ende etwas zugespitzt."

Rhaphidia (Gattung im allgemeinen). - „Die letzten Ventralsegmente sind am männlichen Abdomen längsgespalten wegen der Insertion des Penis, der gewöhnlich breit und abgeflacht ist. Die Seitenränder dieser Segmente sind meist verdickt und mit Haken versehen. Das Weibchen ist mit einer sehr langen und biegsamen Legröhre bewaffnet, die aus zwei quergestreiften Teilen besteht und mit zwei kleinen Papillen endigt." 
Rhaphidia notata F. - "Vorletztes Segment des Männchens verschmälert, oben in der hinteren Mitte ausgeschnitten, an den Seiten sehr schräg, unten in zwei verdickte Basalstücke endend. In dem durch die abstehenden Ventralränder gebildeten offenen Raum dieses Segments ist jederseits ein dickes, gelbes Gebilde eingefügt. das vor der Spitze, die innerhalb eines eingebogenen Hakens gelegen ist, stark ausgedehnt ist. Penis breit, am Ende zugespitzt, mit einer vertieften Rinne in der Mitte. Über den vorher erwähnten beiden Haken befinden sich zwei bedeutend längere, ebenfalls nach innen gerichtete. ... Oben endigt das Abdomen in Form einer behaarten Klappe, die unten konkav und scharf nach außen gerichtet ist uud von der Seite betrachtet dreieckig aussieht. Beim Weibchen ist das letzte Segment breit abgerundet, die Seiten sehr schräg. "

Auch für andere Arten von Rhaphidia werden mit Rücksicht auf das Abdominalende Unterschiede gegeben.

Sisyra. -- „Abdomen kurz, mäBig gedrungen, beim Männchen am Ende mit zwei einfachen hornigen Anhängen versehen. Beim Weibchen findet sich eine kurze Legeröhre, die (nach dem Tode) nach außen ragt." Für die 3 beschriebenen Arten sind dann die besondern Merkmale angegeben.

Micromus. - „Abdomen kurz, beim Männchen schlank, beim Weibchen mehr gedrungen. Abdominalende des Männchens mit einer konkaven Ventralplatte, in welcher zwei hornige, gebogene, nadelförmige Anhänge gelegen sind." Es folgen die Unterschiede dieser Teile bei 3 Arten.

Hemerobius. — „Abdomen kurz, beim Männchen gewöhnlich mit einem Paar Anhängen versehen, welche meist gegabelt sind. Abdominalende beim Weibchen meist stumpf, zuweilen aber mit sichtbarem Bohrer." Auch hier sind bei einzelnen Arten die besondern Eigentümlichkeiten hervorgehoben.

Megalomus. - „Die Anhänge des Männchens ragen nicht hervor. Es sieht aus, als läge am Ende des Abdomens eine breite, abgerundete Dorsal- und Ventralplatte."

Von den Chrysopa-Arten wird nur Färbung und Behaarung des Abdominalendes berücksichtigt.

Zwischen dieser Zeit, in welcher die Kenntnis der Anatomie des Neuropterenkörpers so bedeutend gefördert wurde, und der Jetztzeit liegt ein langer Zwischenraum, in welchem systematische Arbeiten über Neuropteren vorherrschen. Erst wieder in den Untersuchungen von Gross (16) 1903 über die Ovarien der Insecten finden wir den Bau dieser Organe von Sialis und Chrysopa dargestellt.

Trotz der eingehenden Beschreibungen der innern Genitalorgane vieler Neuropteren und des Zusammenhanges der einzelnen Teile ist eine genauere Einsicht in dieser Beziehung nur durch Untersuchung der histologischen Verhältnisse möglich. Die folgenden Darstellungen sollen hierzu einen Beitrag liefern. 


\section{Männlicher Genitalapparat.}

\section{Sialis Tutaria L. ${ }^{1}$ )}

Das Abdomen von Sialis besteht aus 10 Segmenten, von denen die ersten 8 einen gleichartigen Bau haben, während das 9. in den Dienst des Genitalapparats tritt und mit besondern Anhängen versehen ist. Das 10., kleinste Segment enthält die Mündung des Enddarmes. Den größten Teil des Innenraumes der ersten 5-6 Segmente nimmt eine Höhlung ein, welche von einer dünnen Haut ausgekleidet ist und den Darm ganz auf die Ventralseite des Abdomens drängt, auf dessen Sternalteil die 6 Ganglien liegen. Das 5. und 6 . derselben, von denen das letztere das größte ist, liegen dicht hintereinander im 5. Abdominalsegment.

Im 6. oder zum Teil noch im vorhergehenden Hinterleibsabschnitt liegt der männliche Hoden (Schema Taf. 25, Fig. $1 t$ ), meist hinter dem eben erwähnten Hohlraum oder seitlich davon. Er wird von einer nicht sehr dicken Fettkörperlage (Taf. 25, Fig. 2 ad) eingeschlossen, die von der übrigen Fettkörpermasse deutlich abgegrenzt ist, zwischen die einzelnen Follikel dringt und zahlreiche Tracheen (tr) enthält. Die Lage des Hodens im Segment ist nicht immer eine beständige; bei manchen Individuen liegt das Organ dorsal, bei andern mehr ventral; mitunter hat der eine Hoden diese, der andere jene Lagerung. Auch die Zahl seiner Follikel ist wechselnd; in den meisten Fällen sind es deren 6, mehr oder weniger einzeln hintereinander oder gehäuft liegend. Jeder Follikel (Längsschnitt Fig. 2) ist von einer dünnen Haut $(t)$ mit platten Kernen umgeben, innerhalb welcher ein Belag von größern Zellen $(c)$ liegt. Ihre Gestalt ist am deutlichsten an den Follikelmündungen und deren Übergang in das Vas deferens zu erkennen, wo die Wand aus Zellen ohne scharfe Umgrenzung, mit unregelmäßig länglichen, an den Enden abgerundeten oder zugespitzten Kernen, besteht. Nach dem Grunde der Hodenfollikel hin verschwinden diese Elemente, und an ihrer Stelle sieht man Spermatozoenbündel $(s)$, welche, in eiförmigen Gruppen dicht beisammen liegend, den ganzen Hohlraum erfüllen. Jeder Follikel enthält also 3 Arten von Elementen: Wandständige

1) Vgl. Degeer (1), p. 377 ; Suckow (2), p. 379; Burmeister (4), p. 379; Frey-Leuckart (7), p. 380 ; v. Siebold (8), p. 380; Löw (10), p. 381 ; Mclachlan (15), p. 396. 
Zellen mit großen Kernen, Spermatozoenbündel und, ganz im Grunde, einzelne Spermatozoen, diese aber auch dicht beieinander.

Die Hodenfollikel münden, wie der erwähnte Längsschnitt Fig. 2 zeigt, in einen geräumigen Calyx $(c l)$, dessen Wandung, wie bemerkt, ebenfalls aus einer dünnen Außenhaut besteht, die innen von einer Schicht von Zellen ausgekleidet ist, wie sie im Mündungsteile der Follikel auftreten, während sich außen eine gesonderte Fettkörperschicht befindet, die Fortsetzung derjenigen des Hodens.

Die Vasa deferentia (Schema Fig. $1 V d$ ), welche aus den Calyces hervorgehen, steigen, indem sie allmählich auf $1 / 3$ ihres Durchmessers am Ursprung zurückgehen, jederseits im Abdomen zur Dorsalseite desselben und gehen bis in sein 7. Segment. Ihr Querschnitt Fig. 3 zeigt, daß die Wand außen etwas gekantet, innen in schmale Längsfalten gelegt ist. Die Kerne sind ähnlich denen des Calyx, nur kleiner. Die Basis der Zellen des Vas deferens ist dicht mit einem sehr feinkörnigen, goldbraunen Pigment angefüllt, welches bereits in der Wand des Calyx allmählich auftritt, im weitern Verlaufe der Vasa aber so dicht ist, daß es die Kerne fast verdeckt. - Im Dorsalteile des 7. Segments erweitert sich ihr Lumen schnell, was indessen von ihrer mehr oder weniger starken Anfüllung mit Spermatozoenbündeln abhängig ist. Dabei wenden sie sich ventral zurück, sich gleichzeitig median bis fast zur Berührung nähernd und schwellen plötzlich zu je einer runden, dicht mit Spermatozoen-gefüllten Vesicula seminalis.

Diese hängt wie eine Retorte an jedem Gange (Schema Fig. 1 Vs; Längsschnitt Fig. $4 \mathrm{Vs}$ ). Thre Wandung ist innen glatt, ebenfalls stark pigmentiert, aber dünner als die des Vas deferens, die Zellkerne mehr gerundet.

Der Körper der Vesicula seminalis ist nun in eine vor derselben liegende, eiförmige Drüse (Schema Fig. $1 B$ und Längsschnitt Fig. $4 B$ ), und zwar in deren der Medianebene genäherten Teil, so eingestülpt, daß die Wandungen beider Organe ohne Zwischenraum dicht aneinander liegen. Die dicke Wand der Drüse besteht aus cylindrischen Zellen mit eiförmigen Kernen; dort aber, wo sie der Vesicula seminalis anliegt, ist sie dünn und setzt sich aus kubischen Zellen mit ebensolchen Kernen zusammen, ist also ähnlich der Wandung der Vesicula seminalis an dieser Stelle (Fig. $4 a$ ).

Vor dieser Drüse liegt, wie der Längsschnitt Fig. 4 (Schema Fig. $1 A$ ) ebenfalls zeigt, eine zweite, kleinere Anhangsdrüse $A$ so dicht, daß sie äußerlich nur wie eine Abschnürung der andern aus- 
sieht. Ihre Zellen und Kerne haben auch eine ähnliche Gestalt. Ihr Secret aber färbt sich mit Hämatoxylin gar nicht, mit Pikrofuchsin gelb und nur ganz wenig rot, während das der dahinter liegenden größern Drüse erstern Farbstoff annimmt und durch den letztern dunkelrot wird. Wo beide Räume aneinander stoßen, wird ihre Wand nach deren Mitte hin immer dünner, bis sie dort nur noch eine ganz dünne Membran ohne Kerne darstellt, die häufig eingerissen erscheint (Fig. 4 b).

Alle 3 Organe werden von der auch Hoden und Vas deferens umgebenden dünnen Außenhülle (Fig. $4 t$ ) gemeinschaftlich, nicht gesondert, überzogen.

Das gilt auch von einem sich nun anschließenden Organ (Schema Fig. 1 C), das um den lateralen Teil der Vesicula seminalis herum liegt und mit den dadurch entstehenden Zipfeln bis zu der eiförmigen Drüse reicht (vgl. Fig. 4 C). Sie ist dickwandig und besteht aus cylindrischen Zellen mit eiförmigen Kernen. Dadurch, daß erstere flammenartig geschwungen aussehen und sich mit den Enden durcheinander schieben, liegen auf Schnitten der dickern Stellen stets mehrere Kerne in einer Schicht. Das Drüsensecret färbt sich mit Pikrofuchsin gelb bis gelbrot. Ganz eigenartig ist die Form dieses Organs sowohl innen als außen, wie es die 4 Längsschnitte Fig. 5, $6,7,8$ in der Reihenfolge von der Seite nach der Mittelebene hin verdeutlichen. Der Außenraum $V$ ist die Stelle, wo die Vesicula seminalis eingebettet liegt. Es entstehen dadurch in der Mediana des Organs 2 flügelartige Fortsätze desselben mit schlitzartigem Lumen $(a)$. Ebenso liegen ganz lateral 2 breite Zipfel (Querschnitt Fig. 5 b), mit schmalem, innerm Hohlraume, die zunächst zu einem verschmelzen (Fig. $6 b+b$ ) und sich dann mit dem Hauptraume der Drüse vereinigen. Die Dorsalseite der Drüse zeigt ferner einen charakteristischen Ausschnitt (Schema Fig. $1 c$; Längsschnitt Fig. 6, 7 und $8 e$ ), welcher median an diesem Organ am tiefsten geht. Die nach innen liegende Einstülpung $(d)$, welche dadurch hervorgerufen wird, ist inwendig ebenso wie die ihr benachbarten Teile mit einer ziemlich starken Schicht von gelbem Chitin überzogen ${ }^{1}$ ) und bildet gewissermaßen den Stützpunkt für eine Wand, welche sich, wie Fig. 6 bei $d$ zeigt, durch den lateralen Teil des Organs erstreckt und dadurch 2 dickwandige Kammern (Fig. $5 f$ und $g$ ) bildet. Diese Wand verschwindet etwas weiter nach innen (Fig. 6

1) Löw (10), p. 381. 
zeigt bei $h$ ihren Rest), und das Lumen ist nun ein einziger Hohlraum, welcher aber weiter medianwärts von einer zweiten Falte, (Fig. 7 i), die ebenfalls von jener Einstülpung $(d)$ ausgeht, durchzogen ist, so daß die Kammer $k$ in Fig. 7 und 8 abgetrennt wird. Ganz median endiich befindet sich eine dritte Kammer (Fig. 8 l), welche dorsal über der Mündung (Fig. 8 bei $m$ ) dieses eigenartig. gebauten Organs liegt und ganz von Chitin ausgekleidet ist ${ }^{1}$ ), so daß dieses also 3 solcher Divertikel besitzt.

Der knieförmig gebogene Ausführungsgang dieser Drüse führt nun weiter zu einem in Segment 9 des Abdomens gelegenen Drüsenraum (Schema Fig. $1 D$ ), dessen starke Wandung und Secret derjenigen des zuvor beschriebenen Organs sehr ähnlich ist. Stellenweise ist die Verdickung der Wand, besonders der Außenwand, sehr bedeutend. Die eigentümliche Gestalt dieses Teiles zeigt der Längsschnitt Taf. 26, Fig. 29, welcher mit einem Querschnitt des Drüsenpaares Fig. 30 in Vergleich zu bringen ist. Wie letzterer erkennen läßt, liegen beide mit ihren dünnen Medianwänden fast nebeneinander. Man kann an jeder Drüse 3 Abteilungen unterscheiden, die aber äußerlich nicht zu erkennen sind. Der obere, nach dem Körperende zu hingebogene Abschnitt (Längsschnitt Fig. 29 a) ist von dem Teile $b$ durch eine ringförmige, nach innen vorspringende Leiste abgesetzt und liegt mehr lateral, nach der Medianebene hin sich verkleinernd. Eine zweite Kammer (Fig. 29 und $30 \mathrm{c}$ ) wird vom untern Teil dieser Drüse gebildet und liegt der Medianebene näher, nach dieser hin am größten werdend und taschenartige Divertikel bildend. Beide Teile werden durch das Hauptstück $b$ in Fig. 29 miteinander verbunden, durch welches auch der Querschnitt geht, den Fig.30 darstellt.

Im ventralen Teile des Hauptteiles dieser Drüse, ungefähr in der Gegend, wo ihre untere Kammer liegt, findet sich jederseits die Mündung einer langen, stark entwickelten Anhangsdrüse (Schema Fig. $1 G a)$. deren Querschnitt Fig. $30 a(G a)$ und deren Längsschnitt Fig. 9 zeigt. Thr Anfangsteil befindet sich, in wenige Schleifen gelegt, unterhalb der die Vesicula seminalis umschließenden Drüsenkammern. Sie bildet aber in ihrem weitern Verlaufe keinerlei Windungen, und ihr Mündungsstück trägt einen lateral liegenden und nach hinten vorspringenden Divertikel (Schema Fig. 1 Di). Während die Wand des Hauptteiles aus ziemlich schlank cylindrischen Zellen mit gestreckt eiförmigen Kernen besteht (Längsschnitt Fig.9 b), sind die Zellen des Anfangsteiles breiter, deren Kerne größer und

1) Löw (10), p. 381. 
runder (Querschnitt Fig. 9 a). Im Mündungsgebiete ist die dem Raume $c$ der in Fig. 29 und 30 dargestellten Drüse anliegende Wand dünner und enthält runde Kerne, während die darunter liegende Wand wie vorher beschrieben aussieht. - Das Secret der Anhangsdrüse färbt sich mit Hämatoxylin ganz intensiv dunkel.

Alle Organe mit Ausnahme des Hodens und der Vasa deferentia sind mit einer Muskelhülle umgeben, welche nach dem hintern Körperende hin dicker wird und auf den letzten, dickwandigen Drüsen (Schema Fig. 1 D; Fig. 29 und 30) am stärksten entwickelt ist.

Aus dem Grunde jeder der letztern geht, sehr eng beginnend, ein kurzer Ausfïhrungsgang hervor, welcher sich schnell erweitert. Die Querschnitte beider Gänge zeigt Fig. $10 a$, über einem nach hinten gerichteten Divertikel des unpaaren Ductus ejaculatorius $D e^{\prime}$ (Längsschnitt Taf. 26, Fig. $29 D e^{\prime}$ ), zu welchem sie sich vereinigen. Wo diese Vereinigung stattfindet, zieht sich auf eine kurze Strecke hin eine dadurch entstehende Längsscheidewand durch den Gang, welche allmählich verstreicht (Querschnitte Fig. $11 l$ und Fig. 12 l). Für den ganzen Verlauf des unpaaren Ductus typisch sind 3 Längswülste, von denen der mittlere der größte ist. Fig. 10 zeigt dieselben bei $b$ im Querschnitte. Die gegenüber liegende, ventrale Wand bildet zahlreiche, kleinere Längsleisten. - Die Zellen der Ductuswand sind im Anfange cylindrisch und werden nach dem Ausgange hin mehr kubisch. Sie besitzen einen hellen Randsaum. Umgeben ist der Kanal von einer dicken Ringmuskelschicht.

Das enge Lumen des Ductus ejaculatorius erweitert sich, wie der Längsschnitt Fig. 29 erkennen läßt, ziemlich plötzlich zu einem Raume $(f)$, der von einer Chitinlage mit darunter liegenden kleinen Zellkernen ausgekleidet ist und ein kolbenförmiges Copulationsorgan $\left(g, g^{\prime}\right)$ einschließt. Seinen Bau veranschaulichen außer dem erwähnten Längsschnitte die beiden Querschnitte Fig. 13 und 14. Der erstere läßt bei $f$ den Längsschnitt einer querverlaufenden Tasche erkennen, welche das Organ in ein basales Stück $\left(g^{t}\right)$ und in ein teilweise im Hohlraume frei liegendes $(g)$ teilt. Letzteres besteht, wie Fig. $13 \mathrm{~g}$ zeigt, wiederum aus 2 Hälften. Die Oberfläche trägt einen zarten Belag von farblosem Chitin mit darunter liegenden kleinen, zugespitzten Kernen und ist in zahlreiche, kleine Falten gelegt, eine Wirkung der vielen, kleinen, retrahierend wirkenden Muskelfasern, welche ihn nach allen Richtungen durchziehen (Fig. 13).

Das Lumen der Genitalmündung wird, indem das kolbenförmige Penisgebilde verschwindet, nach außen zu spaltförmig (Querschnitt 
Fig. 14). Während die dorsale Wand (d) desselben dünn bleibt, ist die ventrale $(v)$ stärker, und ihre farblose Chitinlage erscheint in viele Falten gelegt (Querschnitte Fig. 14 u. Fig. 15). Auch hat erstere keinen Muskelbelag, wie es bei letzterer der Fall ist. Die Muskeln der spaltförmigen Genitalöffnung gehen ebenso wie die aus dem Copulationsorgan kommenden zu den lateralen Körperwänden. Während ihre Wirkung offenbar eine Verengung der erstern ist, zeigen die Querschnitte Fig. 14 und Fig. 15 bei $m$ solche Fasern, welche erweiternd wirken.

Fig. 15 läßt schließlich erkennen, wie die Genitalmündung $(f)$ auf der Ventralseite des 9. Segments nach außen endet.

Über den Zusammenhang der vorstehend beschriebenen Organe ist noch einiges zu erwähnen. Deutlich münden ineinander die beiden starkwandigen, gekammerten Drüsen (Schema Fig. $25 C$ und $D$ ). Ebenso deutlich ist die Mündung der Drüse $G a$ in die letztern von beiden. Sehr eng ist, wie erwähnt, der Gang, welcher aus diesen jederseits zu dem Ductus ejaculatorius führt. Dagegen war es mir bei keinem einzigen der untersuchten Exemplare möglich, irgend eine Verbindung zwischen der retortenförmigen Vesicula seminalis (Schema Fig. $25 V_{s}$ ) und der Kammer (Schema bei $B$ ), in die sie hineingestülpt ist, festzustellen und ebensowenig eine solche dieser beiden Teile mit der ersten, dickwandigen Drüse (Schema bei $C$ ). Die Vesiculae seminales waren stets prall mit Spermatozoen angefüllt; in den umgebenden Drüsenräumen waren solche nicht zu finden. Über alle 3 geht aber gemeinsam, sie also nicht einzeln umschließend, die dünne Außenhaut hinweg. Die Verbindung zwischen Kammer $A$ und Kammer $B$ im Schema ist, wie erwähnt, in der Mitte nur eine dünne Membran, die hier häufig zerrissen gefunden wurde, ohne daß indessen eine Secretvermischung zu beobachten gewesen wäre. Die Frage, in welcher Weise diese Organe in Verbindung treten, muß hier offen gelassen werden.

Eigenartig entwickelt sind die am Abdominalende vorhandenen Chitinanhänge, zu deren Erläuterung die Figg. 16, 17, 18, 20 auf Taf. 25 und ein etwas links von der Medianebene geführter Längsschnitt Fig. 31 auf Taf. 26 dienen.

Ventral am Abdominalende bemerkt man zunächst eine zungenförmige, eine flach löffelartig ausgehöhlte Schuppe (Fig. 10a, Fig. 18 abgetrennt dargestellt), deren proximaler Teil $(p)$ aus dünnem, farblosem Chitin, deren distales, abgerundetes Ende $(d)$ aus stärkerm, braunem Chitin besteht und sich in Gestalt zweier Arme nach vorn 
erstreckt, diesem Teile eine hufeisenförmige Gestalt gebend. Die beiden Arme sind durch Chitinleisten $(c)$ verstärkt, welche mit dem Tergit an dessen Endleisten artikulieren. Innere und äußere Oberfläche sind bedornt. Wie der Längsschnitt Fig. 31 bei a zeigt, durchziehen diese Schuppe nicht sehr zahlreiche, horizontal und vertikal verlaufende Muskelfasern. Muskelbündel am Grunde der Schuppe $(b)$ ermöglichen ein Auf- und Niederbewegen derselben.

Über dieser Klappe liegen, am Grunde des Segments und einwärts von dessen Tergit, kulissenartig zwei kleinere Schuppen (Fig. 16 b), welche nach außen etwas gewölbt sind und eine abgerundete Spitze haben. Außen tragen sie kleine Dornen. Sie liegen vor der Genitalöffnung und können durch Muskeln (Längsschnitt Fig. 31c) bewegt werden, welche an ihrem Grunde entspringen und nach hinten und oben gehen.

Das Tergit des Genitalsegments Fig. $16 c$ ist sehr stark chitinisiert und mit starken Dornen bedeckt. Es liegt sternalwärts jederseits mit einer schmalen Chitinleiste $d$ dem löffelförmigen Stück $a$ gelenkig an und verbreitert sich oben plötzlich; zwischen beiden Hälften liegt dorsal in der Medianebene eine Chitinverstärkung (Fig. $17 c^{\prime}$ ), welche in das Tergit eingesenkt ist (vgl. Längsschnitt Fig. $31 d$ ) und aus einem netzartig verzweigten Leistenwerk besteht, das vorn schmal beginnt und hinten am Analsegment breit endigt. In der Mitte ist ein größeres Feldchen frei. Von dieser Platte, deren Leistenwerk in seiner Anordnung ziemlich variabel ist, geht auf jeder Seite, den Darm zwischen sich lassend, ein breiter Muskelzug zu der gegenüberliegenden ventralen Wand (Längsschnitt Fig. $31 \mathrm{~m}$ ).

Hier befinden sich eigenartige Anhänge. Man bemerkt zunächst zwei längliche, an ihren nach außen hin abstehenden Enden gerundete Gebilde aus farblosem Chitin, deren Oberfläche mit feinen Stacheln besetzt ist (Fig. 16e, Fig. 19e). Wie der Längsschnitt Fig. 31 bei $f$ zeigt, hängen beide Gebilde nach der Mitte hin durch einen Höcker zusammen, dessen runder Dorsalteil eine dicke, glatte Lage aus braunem Chitin trägt und in eine ebenso chitinisierte Ausbuchtung des Analsegments paßt. Das braune Chitingerüst dieses Anhangsgebildes zeigt Fig. $19 f$; an seiner Unterseite besitzt es einen eulenschnabelartig gekrümmten Zahn $g$, welcher zwischen allen Teilen in der Mitte liegt. Aus den beiden jederseits liegenden Öffnungen ragt je eins der vorhin beschriebenen Gebilde $e$ hervor. 
Die Muskulatur steht in Zusammenhang mit den oben erwähnten, breiten Lateralzügen des Tergits.

Wie schließlich Fig. 17 bei $h$ zeigt, liegt jederseits am Analsegment ein Feld mit wellenartig gebogenen, stärker chitinisierten, leistenartigen Falten.

Das Abdominalende von Sialis fuliginosa PICt., deren innere Organe ich nicht untersuchen konnte, weicht in den einzelnen entsprechenden Teilen von $S$. lutaria so deutlich ab, daß beide Arten dadurch gut voneinander zu unterscheiden sind. Die von der Bauchseite her dargestellte Abbildung des männlichen Abdominalendes von S. fuliginosa Taf. 25, Fig. 20 zeigt bei a eine Ventralklappe am 9. Segment, die aber bedeutend kürzer ist als bei S. Tutaria, wo sie fast die ganze Genitalregion bis unter das Analsegment bedeckt. Die Lateralklappen $b$ (die Bezeichnungen korrespondieren mit denen von S. lutaria in Fig. 16) von S. fuliginosa sind in typischer Weise so chitinisiert, wie es bei $b^{\prime}$ dargestellt ist. Die Anhänge, welche. darüber liegen, sind zwei an ihrem Grund nebeneinander gelegene, mit den etwas zugespitzten Enden divergierende, kolbige Gebilde $e$, die schwach bedornt sind und aus einem starken Chitinhalbring hervorgehen. Fig. 21 stellt sie umgeklappt, also von ihrer Ventralseite gesehen, und etwas mehr vergrößert dar. Der Unterschied gegen S. lutaria wird sofort deutlich, wenn man die Anhänge dieser Art (Fig. 19) damit vergleicht. Das Tergit des Genitalsegments ist in seiner Form dem von S. lutaria fast gleich, besitzt aber nicht das bei letzterer beschriebene Leistenwerk (Fig. 17 $c^{\prime}$ ).

Das Analsegment ist bei S. futiginosa einfach gerundet. (Vgl. Fig. $17 h$ und Fig. $20 h$ ).

\section{Rhaphidia notata F. ${ }^{1}$}

Den vordern Teil des Abdomens von Rhaphidia nimmt ein Hohlraum ein, der in den Verdauungskanal eingeschaltet ist. Es besteht aus 10 Segmenten, von welchen das 8. durch ein sehr kleines Sternit ausgezeichnet ist. Das Sternit des 9. Hinterleibsegments zeigt eine paarige, konvexe Wölbung (Taf. 25, Fig. $22 n$ ), die innen von Muskeln angefüllt ist. Dahinter liegen um die Mündung des

1) Vgl. Degeer (1), p. 378; Burmeister (4), p. 379; Schnemder (6), p. 380 ; v. Siebold (8), p. 380; Löw (10), p. 382 ; Brauer (13), p. 393 ; McLachlan (15), p. 396. 
Genitalweges herum die Genitalanhänge. - Von den 6 Abdominalganglien ist das letzte für den Genitalapparat in Betracht kommende am größten und liegt im 7. Abdominalsegment.

In demselben Körperabschnitt liegt seitlich auch der paarige Hoden (Schema Taf. 26, Fig. 37t), meist auf der Ventralseite, häufig auch nach der Dorsalseite hin gelagert. Bisweilen ist er gedrungen, meist aber etwas in die Länge gestreckt, so daß er nach vorn bis an das う. Segment reicht. Dieser Gestalt entsprechen auch die Hodenfollikel, welche schlauchförmig sind und, etwas gewunden, der Länge nach nebeneinander liegen. In den meisten Fällen besteht jeder Hoden aus 12 solcher Follikelröhren. Die Fettkörperhülle des Organs ist nicht besonders von der Umgebung abgegrenzt, dringt auch nicht zwischen die Follikel; sie enthält aber zahlreiche, runde, blaßgelbe Pigmentkörnchen. Die äußere Hülle des Hodens ist eine dünne Haut ${ }^{1}$ ) mit platten Kernen; erst gegen den Ausgang jedes Follikels hin treten die innern Zellen in Gestalt einer geschlossenen Wand auf, wie der Querschnitt Fig. 39 zeigt. Ein deutlich ausgesprochener Calyx kommt nicht zustande.

Es schließt sich vielmehr gleich an die gemeinsame Follikelmündung jederseits ein verhältnismäßig enges Vas deferens mit dünner Wandung und linsenförmigen Kernen an (Querschnitt Fig. 38 $V d$, welches, wie das Schema Fig. 37 bei $V d$ zeigt, schräg nach oben geht, in der Mitte des Segments plötzlich knieförmig umbiegt und in der vorigen Richtung nach der Ventralseite zurückgeht. An der Biegung wird das Lumen des Ganges, ein Vesicula seminalis (Schema $V s$ ) bildend, ziemlich weit (Längsschnitt Fig. $38 V s$ ); seine Wand mit ihren platten Kernen verdickt sich dagegen nur wenig. Auf der Ventralseite angelangt, verengt sich die Vesicula wieder (Fig. 38 bei $V s^{\prime}$ ). Das so entstehende, kurze Kanalstück ist etwas gewunden und mündet in die laterale Einbuchtung einer großen Drüse (Schema Fig. $37 V^{\prime}$; vgl. dazu Fig. $38 V^{\prime}{ }^{\prime}$ ).

An dieser Drüse lassen sich leicht drei Abteilungen unterscheiden (Schema Fig. 37 und Längsschnitt Fig. 38 A, B, C). Der erste Teil entsteht durch die eben erwähnte Einschnürung an der Einmündung des Vas deferens und ist gegen den folgenden zweiten durch eine ebensolche Verengung abgegrenzt. Auch das dritte

1) Diese Hülle ist in ihrer Fortsetzung natürlich auch auf den anschlieBenden Teilen des Genitalapparats zu finden; in den Einzelbeschreibungen ist derselben der Kürze halber nicht weiter Erwähnung getan. 
Stück ist durch einen engern Verbindungsgang von dem vorhergehenden unterschieden. Histologisch dagegen hat die Wandung aller drei Abteilungen denselben Bau. Sie ist ziemlich dick und besteht aus cylindrischen Zellen mit eiförmigen Kernen, die im basalen Teil der erstern liegen. Bei jüngern Individuen ist die Wandung stark gefaltet; bei solchen, wo die Organe in voller Tätigkeit und die Drüsenräume prall mit Secret gefüllt sind, verstreichen die Falten, und nur einige niedrige Leisten springen in das Lumen vor. In diesem Fall zeigt das Zellplasma zahlreiche Vacuolen, und die Kerne sind undeutlich. Die drei Abteilungen sind jedoch auch dann noch voneinander zu unterscheiden.

An jede dieser großen Drüsen schließt sich eine kleinere, gerundete Kammer an (Schema Fig. 37 D; Längsschnitt Fig. 38 D), deren Wände dünn sind und platte Kerne enthalten.

Das Schema zeigt bei $G a$ schließlich noch eine Anhangsdrüse, von welcher $G a$ in Fig. 38 einen Längsschnitt darstellt. Thr geräumiger Anfangsteil liegt dorso-ventral. Nach der Mündung zu, welche außen neben der vorher beschriebenen großen Drüse gelegen ist, wird sie enger. Im Bau ihrer Wandung und deren Zellen nebst Kernen hat sie große Ähnlichkeit mit dieser. Die Kerne liegen aber mehr mitten in den cylindrischen Zellen, und das Drüsensecret ist (nach Einwirkung von Alkohol) feinkörnig, während das der Hauptdrüse (unter derselben Bedingung) mehr den Eindruck eines feinen Gerinnsels mit dazwischen liegenden, runden Körperchen macht, die durch Pikrofuchsin gelb gefärbt werden, wodurch das Gerinnsel aber rot wird.

Mit Ausnahme dieser Anhangsdrüse sind die andern Drüsensäcke mit einer Muskellage versehen, die auch auf deren Ausführungsgänge übergeht.

Der Ausführungsgang jeder großen Drüse findet sich auf ihrer Ventralseite da, wo die dritte Kammer derselben in den Drüsenraum $D$ übergeht. Nicht weit dahinter ist auch die Nündung der Anhangsdrüse. Der kurze, etwas gewundene Kanal, in welchen beide führen, ist gebuchtet und von der Fortsetzung der Drüsenmuskeln umgeben. Seine Wandung, welche bedeutend dünner als die der Drüsen ist, besteht aus kleinen, schlank cylindrischen Zellen mit ebensolchen Kernen, die an der Zellbasis liegen. Innen ist der Gang von einer farblosen Chitinlage bedeckt. Der Längsschnitt Fig. 38, welcher bei $E$ diese Verhältnisse zeigt, läßt auch erkennen, 
wie sich dieser ausführende Kanal zum eigentlichen Ductus ejaculatorius $(D e)$ verengt.

Die Wandung des letztern besteht aus kleinen Zellen mit punktartigen Kernen. Sie ist ebenfalls von einem farblosen Chitinbelag. überzogen und in zahlreiche Windungen und Falten gelegt. Die Außenmuskulatur ist hier eine doppelte; unmittelbar auf der Wand befinden sich Längsmuskelfasern, die Fortsetzung des Muskelbelags im Drüsenmündungsgebiete $E$ (das auch wohl zum Ductus gerechnet werden muß), welche als Retractoren bis in das Copulationsorgan gehen. Um sie herum liegt eine Ringmuskelschicht, die aber an der Basis jenes Organs aufhört.

Der kegelförmige Penislängsschnitt Fig. $38 F$, unter welchem der Ductus ejaculatorius in Gestalt einer spaltartigen, mit Chitin ausgekleideten Tasche verläuft und mündet, ist, wie dieser Schnitt zeigt, von einfachem Bau. Desto verwickelter ist der Bau seiner Umgebung, die im Anschluß an die Genitalanhänge in den Fig. 22, 23, 24 und an die halbschematischen Längsschnitte Fig. 32 bis 36 beschrieben werden soll.

In Fig. 22 ist $B$ das 8., $C$ das 9. Abdominalsegment. Es besteht zunächst aus einem stark chitinisierten Tergit, dessen entsprechendes Sternit neben der Medianebene distal je ein halbkugeliges Gebilde $n$ trägt, proximal eine ringförmige Chitinleiste $m$ zeigt. In dieses Sternit ist ferner ein unpaares, zungenförmiges, ganz flach ausgehöhltes Stück $a$ aus braunem Chitin eingelenkt, dessen Gestalt Fig. 23 bei a stärker vergrößert darstellt. Das Ende bildet eine stumpfe Spitze $s$. Seine Mitte ist der Länge nach durch eine stabförmige Verdickung $p$ verstärkt, welche sich an ihrer Basis in zwei kurze Enden teilt und dadurch etwas verbreitert (o). An der Basis der Zunge ist diese jederseits tief ausgeschnitten $(\boldsymbol{r})$. Ihre Ränder sind, mit Ausnahme der gerundeten Spitze, mit feinen, nach vorn gerichteten Zähnen versehen, welche sich am Anfang und am Ende der Zunge auch zum Teil auf ihrer innern Oberfläche finden $(t)$. Letztere ist außerdem mit nicht sehr zahlreichen Dornen besetzt.

Mit der schmalen Basis dieses Stückes in gelenkiger Verbindung steht jederseits ein platter, gekrümmter Chitinstab Fig. $23 u$, der in seinem letzten Drittel rund wird und mit einem Haken endigt, an dem eine noch etwas stärker gekrümmte Spitze zu erkennen ist. Die konkave Fläche des Hakens ist unter seiner Spitze etwas gewunden. Die Haken beider Seiten sind mit ihren Spitzen nach der Dorsalseite und etwas einander zugekehrt, eine Art Zange bildend, 
und zwischen ihnen liegt der Penis. Der Zusammenhang desselben mit diesen Haken und der unpaaren Zunge wird klar, wenn man die Längsschnitte in der Reihenfolge von Fig. 32-36 betrachtet, wobei Fig. 36 einen solchen durch die Mediana darstellt, Fig. 32 einen solchen, der sehr weit lateral gelegen ist. Aus ihnen geht auch die Versorgung der Organe mit Muskelfasern hervor.

Figg. 36 und 35 lassen bei $s$ den Längsschnitt einer Spalte erkennen, deren verbreiterte Basis eine durch Verstärkung kenntlich gemachte Verdickung aufweist. An diese Chitinverstärkung, auf welcher sich jederseits einer der vorher beschriebenen Haken $u$ erhebt, setzt sich ein Muskelbündel o, dessen Fasern nach der Ventralseite gehen und die dort liegende unpaare Zunge quer durchziehen, in deren Mitte aber fehlen. Ein zweites großes Bündel $p$ geht von der erwähnten Verstärkung jederseits dorsal zum Tergit des 9. Segments, hier mit den Segmentmuskeln zusammentreffend. Über den dorsalen Teil der Spalte $s$ ziehen nach rechts und links Querfasern (Querschnitte bei q), die Mittelebene frei lassend, von denen einige an der Basis mit dem Dorsalbündel $p$ zusammenhängen.

Über dem unpaaren, zungenförmigen Stück liegt, an dem Grunde der Längsleiste desselben eingelenkt, jederseits eine dreieckige, abgerundete Klappe (Fig. 22 b), welche nach innen konkav ist und an ihrer Spitze zwei Haken (Fig. 24), einen größern $(d)$ und einen kleinern $(c)$ trägt. Ihre Oberfläche ist mit feinen Dornen bedeckt. In ihrem obern Teile wird sie von einer Leiste $l$ durchzogen, deren Ende am Rande der Klappe mit einem hakigen Anhange gelenkig verbunden ist. Fig. 24 stellt denselben mit seinen einzelnen Teilen dar. Das Stück $a$, welches das Gelenk bildet, ist flach und etwas Sförmig gebogen. Der Haken $b$ ist deutlich von ihm abgegrenzt. Seine Oberfläche trägt ganz feine Dornen, und das dornenlose Ende ist noch besonders umgebogen. Auch diese beiden Haken sind nach oben und etwas nach innen gerichtet. (Einen Rest davon zeigt der Längsschnitt Fig. 35 bei $r$.) Ihre Bewegung vermittelt jederseits ein Muskelzug $v$, der zum Tergit geht, den Enddarm zwischen sich lassend.

Jederseits am Analsegment bemerkt man ein Feld (Fig. $22 e$ ), das 18-20 kleine Höcker enthält. Jeder derselben besteht bei genauerer Betrachtung aus 6 , manchmal 7, birnförmigen Chitingebilden, welche rosettenförmig um einen Ringwall angeordnet sind, der eine Borste trägt. Jede Rosette ist in eine flache, ringförmige Vertiefung der Körperdecke eingesenkt (Fig. 25).

Zool. Jahrb. XXVII. Abt. f. Anat. 


\section{Chrysopa perla L. ${ }^{1}$ )}

Das Abdomen von Chrysopa perla wird aus 10 Segmenten gebildet; das 9. davon enthält die Genitalmündung; das Genitalganglion liegt im 8. Hinterleibsabschnitt.

Am männlichen Abdominalende Taf. 26, Fig. 41 bemerkt man 2 Klappen. Die dorsale $a$ bedeckt in Form einer konkaven Schuppe die Analöffnung, ist an ihrem Hinterrande etwas nach unten gekrümmt und hier schwach ausgebuchtet. Die beiden auf diese Weise hervortretenden, abgerundeten Ecken tragen auf ihrer Außenseite ein von einer kreisförmigen Leiste begrenztes und von ihr fast ganz umschlossenes Feldchen (c), innerhalb dessen eine Anzahl (ca. 20) rosettenförmiger Gebilde mit je einer Borste in der Mitte liegen, deren Aussehen dasselbe ist, wie es die Fig. 25 auf Taf. 25 für Rhaphidia zeigt und vorher beschrieben wurde. Die seitlichen Ränder dieser Dorsalschuppe gehen, tief ausgebuchtet, zur Ventralschuppe und sind durch eine winkelartig gekrümmte Chitinleiste $b$ verstärkt, mit der jederseits eine dünnere Haut' $d$ in Zusammenhang steht, welche die Seitenwand bildet.

Die ventrale Klappe $e$ ist am Ende schwach ausgeschweift. Fig. 43 stellt sie flach ausgebreitet und von innen gesehen dar. Man sieht daran, daß ihr seitlicher Rand von je einer Leiste verstärkt wird, an welcher sich am Ende ein stärkeres Stäbchen $s$ deutlich abhebt, dessen Ende nach außen umgebogen und abgerundet ist. Neben jedem Stäbchen, aber weiter nach innen, erblickt man ein wulstartiges Stachelpolster $p$, das, besonders von oben gesehen, ungefähr den Eindruck einer Schneckenradula macht (Fig. 44) und dessen Beziehung zu dem Ausführungsgang des Genitalapparats auf S. 412 dargestellt ist. Im Grunde des Abdominalelendes, zwischen den Klappen, liegen ferner eine hufeisenförmige Leiste $a$ in Fig. 42 und zwei Chitingebilde, die Fig. $42 b$ wiedergibt. Ganz in der Mitte erhebt sich.auf kegelförmiger Basis ein am Ende umgebogener, kleiner Haken (Fig. 42 c), dessen Ende aber nicht spitz, sondern mehr löffelförmig abgerundet und auf der konvexen Seite mit den Seitenrändern wie zu einer Rinne aufgebogen ist.

Diese charakteristischen Chitinteile des männlichen Hinterleibsendes sind bei den einzelnen Arten von Chrysopa in verschiedenster Weise umgestaltet und für die Systematik wohl von Bedeutung,

1) Vgl. Loew (10), p. 383. 
können aber deutlich nur an Macerationspräparaten zur Anschauung gebracht werden.

Wie schon Löw (10) bemerkt, sind auch die innern Genitalien der Männchen der Chrysopa-Arten nicht gleich gebildet, was besonders vom Hoden zu bemerken ist. Aber auch die ausführenden Geschlechtswege zeigen sich recht verschieden.

Die beiden langgestreckten Hoden von Chrysopa perla liegen im 8. Segment. Ein jeder ist von einer starken Außenhülle umgeben, die ein goldgelbes Pigment enthält, und hat eine schraubenförmig gedrehte Form mit $2^{1} / 2$ Windungen, von denen die zweite die dickste ist (Löw 10). Die Lage der langgestreckten Follikel entspricht diesen Windungen.

Die Vasa deferentia, deren Bau nichts besonderes zeigt, entspringen am proximalen Ende der Hoden und verlaufen dorsal über den Genitaldrüsen nach hinten, wo sie in eine Kammer münden, welche das Schema Taf. 26, Fig. 40 bei a zeigt und von welchen die Fig. 50, 51, 52 auf Taf. 27 bei $a$ und $a^{\prime}$ Längsschnitte enthalten ( $V d$ ist das Vas deferens). Sie liegen in der Medianebene fast nebeneinander, und jede bildet lateral zwei abgerundete Vorsprünge. Die innern Raumverhältnisse sind ziemlich verwickelt und zeigen eine Anzahl in bestimmter Weise angeordnete Wände und Vorsprünge, durch welche mehrere kleine Hohlräume entstehen, die untereinander zusammenhängen. Sie lassen sich mit Rücksicht auf ihren histologischen Bau auf einen Teil $a^{\prime}$ und einen Teil $a$ beziehen. Ersterer ist durch eine einspringende Falte von dem zweiten getrennt; seine Kerne sind schlanker, und die Zellen färben sich schwächer als die des andern. Am deutlichsten sind diese Unterschiede da ausgebildet, wo die Kammern mit breiter, gemeinsamer Mündung in die große Drüse übergehen, die im Folgenden beschrieben ist.

Es sind dies zwei verhältnismäßig große, sackförmige Organe, welche in dem Schema Fig. 40 bei $b$ und $b^{\prime}$ dargestellt sind. Während die nach der Mündung zu gelegenen Hälften derselben in der Mittelebene aneinander liegen, weichen die entgegengesetzten Hälften auseinander. wie auch an dem Längsschnitte Fig. 51 bei $b$ und $b^{c} \mathrm{zu}$ sehen ist, und zwischen diesen Stücken befinden sich, in der Medianebene sich berührend, zwei andere, kleinere Säcke $c$, welche in die großen einmünden und deren proximale Enden gleichsam auf die Seite drängen. Die Wandung der größern Drüsen $b$ ist stark und wird aus cylindrischen Zellen gebildet, deren eiförmige Kerne nach der Mündung 
hin kuglig werden. Die Wand des zweiten, anhängenden Sackes $c$ dagegen ist dünn und enthält platte Kerne.

In den ersten, den Hauptdrüsensack jederseits, öffnen sich ferner noch zwei Räume (Schema Fig. $40 d$ und $e$ ), deren Schnitte Fig. 52 bei $d$ und $e$ wiedergibt. Die Drüse $e$ liegt mit ihrem Fundus weiter lateral als die Drüse $d$ und vor dieser; beide münden aber an derselben Stelle. Die Wand der letztern besteht aus cylindrischen Zellen mit eiförmigen bis kugelförmigen Kernen. Das Plasma ist nach dem Lumen zu nicht scharf abgesetzt, und das Secret springt meist nach dahin strahlenförmig vor (nach Einwirkung der Konservierung). Zellen und Kerne der Drüsen $e$, deren Grund median nebeneinander liegt, sind dagegen cylindrisch.

Die beiden großen Säcke $b$, mit ihnen also alle Genitalräume, öffnen sich in einen gemeinsamen, ziemlich weiten Gang (Schema Fig. $40 f$ ), dessen Längsschnitt Fig. 52, 53, 54 bei $f$ darstellt. Seine Wand ist nicht stark. Die Kerne sind kuglig, werden nach außen hin kleiner und platt, und so geht die Wandung, die ebenfalls dünner wird, allmählich in die der Genitalmündung über.

Letztere ist verhältnismäßig weit und wird ventral an ihrem Ende von der schon bei der Beschreibung des abdominalen Chitinskelets erwähnten Ventralschuppe (Fig. $41 e$ und Fig. 43) begrenzt, deren Längsschnitte die Figg. 52, 53, 54 bei $h$ darstellen, und deren Querschnitt Fig. $45 \mathrm{~m}$ ist. Sie zeichnet sich durch eine sehr stark entwickelte Muskulatur aus, deren Faseranordnung Fig. 52 erkennen läßt. Unterhalb des Stachelwulstes $g$ liegen Fasern $l$, die der Medianebene parallel verlaufen. Die beiden andern Muskelzüge $i$ und $k$ entspringen an derselben Stelle, und zwar da, wo die Ventralschuppe stark nach innen gezogen ist, und verlaufen divergent, die Muskulatur $e$ des Stachelpolsters zwischen sich lassend. Nach der Medianebene der Klappe zu aber wird der Faserverlauf aller drei gleichmäßig in der Art, wie es die Figg. 53 und 54 zeigen. Ein vierter Muskel $m$ (Fig. 52) verläuft jederseits von der Medianebene schräg nach vorn und außen.

Der oberhalb der Ventralklappe liegende Genitalvorraum zeigt, wie in Fig. $54 \mathrm{zu}$ sehen ist, in der Mitte den Chitinhaken $C$ (S. 410) und darunter den Längsschnitt eines schmalen Lappens $B$. Dieser entwickelt sich aber auf jeder Seite zu einem Gebilde, das in außerordentlich zahlreiche, von einem Chitinsaume eingefaßte Falten und Läppchen gelegt ist, und das in Fig. 52 und 53 im Längsschnitt bei $B$ zu sehen ist. Stärkere Vergrößerung bringt noch viel mehr 
kleinere Falten zur Anschauung. Durch diese Gebilde entsteht auf jeder Seite in der Genitalmündung eine Art Tasche $(D)$, deren obere Wand weniger reich gefaltet ist. Die Dorsolateralseite einer jeden Tasche aber trägt eine Anzahl Borsten (Fig. 52 A), von welchen sich jede auf einer kelchförmigen Basis erhebt, wie Taf. 26 Fig. 44 stärker vergrößert zeigt. Die Borsten sind nicht starr, sondern ihre Enden sind so biegsam, daß sie peitschenartig in den Hohlraum hineinragen. Muskulatur ist unter ihnen nur schwach entwickelt. Etwas oberhalb derselben, jedoch nicht damit in Zusammenhang, verlaufen starke Muskelbündel jederseits nach den Seiten des Abdomens.

Jene gelappten, paarigen Gebilde in der Genitalmündung mit dem in der Mitte gelegenen Stachel sind, in Verbindung mit den beschriebenen Stachelwülsten, augenscheinlich das Copulationsorgan. An den Längsschnitten einiger Tiere war zu sehen, wie jene Gebilde ganz aus den Taschen der Genitalmündung herausgestülpt waren, so $\mathrm{da} ß$ die peitschenförmigen Borsten vollständig außerhalb des Körpers lagen. Eine Wirkung der Muskulatur der Ventralklappe wird ferner zur Folge haben, daß das Stachelpolster ebenfalls nach außen gestülpt wird und daß die dann nach der entgegengesetzten Richtung zeigenden Stacheln als Haftapparate dienen können.

\section{Chrysopa vulgaris SCHNEID.}

Ebenso wie die Abdominalenden mit ihren Anhängen scheinen auch die innern männlichen Genitalorgane der Chrysopa-Arten einen verschiedenen Bau zu zeigen. - Die Figg. 56-59 auf Taf. 27 stellen Längsschnitte durch die betreffenden Organe von Chrysopa vulgaris dar. Man kann unter den Genitaldrüsen dieser Art zwei in der Medianebene dicht nebeneinander liegende Kammern mit mehreren Nebenräumen unterscheiden; zu jeder Kammer gehören zwei Anhänge, ein dorsaler und ein ventraler.

Schnitte durch die Hauptkammer der linken Körperseite zeigen die erwähnten Figuren bei $a$ (in der Reihenfolge von der Mediana nach außen). Sie ist dickwandig, mit cylindrischen Kernen, und bildet nach der Seite hin mehrere Divertikel, von denen am charakteristischsten ein nach dem vordern Körperende hin gerichteter, hornartig gebogener (Fig. 56 und $57 a^{\prime}$ ) und ein dorsal und ganz seitlich gelegener sind. Letzterer erweitert sich, wie Fig. 58 $a^{\prime \prime}$ zeigt, zu einem starkwandigen, gerundeten Sacke. Hinten und lateral gelegen, steht mit dieser Hauptkammer ein Drüsenraum in Verbindung, der im wesentlichen dreiteilig ist, und dessen sehr dicke Wand schlanke 
Kerne enthält. Schnitte durch denselben zeigen die Zeichnungen bei $b$.

In den Hauptdrüsenraum mündet dorsal (Fig. 58 da, wohin der Pfeil zeigt) je eine Anhangsdrüse $c$, die dünnwandig ist, mit kubischen Kernen. Ventral liegt jederseits eine zweite $(d)$, die ihr Secret ziemlich nahe der Medianebene in die Hauptdrüse entleert (in Fig. 56 durch den Pfeil angedeutet).

Das Vas deferens geht in die Anhangskammer Fig. $56 b$. Der Ductus ejaculatorius, der in Gestalt eines engen Ganges hier deutlich entwickelt ist, entsteht aus zwei kurzen Ausführungsgängen der Hauptdrüsen, die dicht nebeneinander liegen. Er führt, am Ende etwas gewunden, in eine Spalte des Abdominalendes (Fig. 55, 56, 57) so hinein, daß zwischen seiner Mündung und dem Grunde der Spalte ein taschenartiger Raum $T$ frei bleibt. Am Ausgange der Genitalmündung zeigt Fig. 55 bei $H$ wieder den Längsschnitt des unpaaren, medianen Hakens, Fig. 56 bei $M$ eine der Borsten, wie sie auch bei andern Chrysopen beiderseits auf oder hinter der Basis desselben stehen (vgl. Chr. perla Fig. 52 A). Darunter liegt eine Lage von Muskelfasern.

Aus dem Fange von Chr. vulgaris für den Zweck der vorliegenden Untersuchung wurden ungefähr 3-4 Männchen als zu dieser Art gehörig bestimmt. Bei Betrachtung der Schnittserien stellte es sich dann heraus, daß unter den zahlreichen Exemplaren auch einige wenige waren, die einer andern Art angehörten. Obschon eine Bestimmung derselben nicht mehr möglich war, boten sie doch in betreff des Genitalapparats manches Eigenartige, so daß einige Bemerkungen darüber im Anschluß an einige meist nur im im Umriß gezeichnete Querschnitte hier Platz finden mögen. (Nur die eine Hälfte des Drüsensystems ist dargestellt, in der Reihenfolge von vorn nach hinten; die Bezeichnungen korrespondieren in allen Figuren.)

Die Kammer, welche in Ermangelung einer andern Bezeichnung vorhin als Hauptkammer bezeichnet wurde, ist bei $a$ in den Figg. 59-66 quer durchschnitten. Proximal ist sie nicht sehr entwickelt, distal aber desto stärker und bildet hier. eine Anzahl charakteristischer Nebenräume. Zunächst schnürt sich von ihr ein Zipfel $b$ (Fig. 64) ab, der nach vorn gerichtet ist und hier endigt (Fig. 63 und 62). Darunter liegt ein kleiner, kugliger Anhang $\boldsymbol{a}^{\prime}$ (Fig. 63 und 64), hinter dessen Ende die Hauptkammer a einen Divertikel $a^{\prime \prime}$ (Fig. 65) bildet. Von dem Teile $c^{\prime}$ (Fig. 65, 66, 67), der sich eine kurze Strecke weit nach hinten fortsetzt, geht ein großer, 
lateraler Sack $c$ aus (Fig. 65-68 A), der sich von allen Teilen am weitesten nach hinten erstreckt. Während das Secret des Hauptdrüsensackes mit Hämatoxylin blau wird, verhält sich das der noch weiter zu erwähnenden Räume anders.

Wie sich bei Chr. vulgaris hinten an die Hauptdrüse ein sehr dickwandiges, ganz lateral liegendes Stück anschließt, das 3 Kammern unterscheiden läßt, so entsteht auch hier ein Sack $d$ (Fig. 65), der sich nur wenig nach vorn (Fig. 64), desto weiter aber nach hinten erstreckt (Fig. 66-68 A).

Querschnitt Fig. 59 zeigt den Schnitt zweier Anhangsdrüsen $A$ und $B$. Drüse $A$, ventral gelegen und die größere von beiden, erstreckt sich ziemlich weit nach vorn (Fig. 62) und mündet, wie Fig. 60 zeigt, in die Drüse $B$. Thre Wand enthält kubische Kerne. Drüse $B$, deren Inhalt (nach Einwirkung der Konservierung) das Aussehen von Fadenbündeln (Spermatozoen?) hat, steht, wie Fig. 61 erkennen läßt, mit dem vordern Teile der Hauptdrüse in Verbindung. Die Figg. 62 und 63 enthalten bei $f$ den Querschnitt des Kanals, der in den Ductus ejaculatorius übergeht, während Fig. $67 e$ die Einmündungsstelle des Vas deferens darstellt.

Zur Darstellung des ausführenden Ganges dienen die Querschnitte Fig. 46 und 47. Der Ductus ejaculatorius mündet in eine Genitalspalte Fig. 46, welche seitlich die charakteristischen, weichen Borsten $A$ trägt und ventral bei $B$ den Querschnitt des Zahnes oder Hakens zeigt. Fig. 47 stellt den Querschnitt der Genitalmündung $(G)$ dar.

\section{Hemerobius nervosus $\mathrm{F}^{1}$ )}

Das Abdomen von Hemerobius besteht aus 10 Segmenten. Von den darin liegenden 6 Ganglien ist das letzte als Genitalganglion am größten und liegt im 7. Abdominalsegment.

Die beiden langgestreckten Hoden (Schema Taf. 27, Fig. $72 t$ ) erstrecken sich vom Beginne des 7. Hinterleibsringes bis zum Beginne des 5. Sie bestehen aus je j Follikeln, von denen jeder von einer dünnen Haut umschlossen ist, die in das Innere des Follikels Septen sendet, dieses in Kammern teilend. Alle 5 Follikel umgibt eine gemeinsame, stärkere Hülle, die ein gelbliches, sehr feinkörniges Pigment enthält. Im ausgebildeten Zustande sind die Hoden so groß, daß ihre Querschnitte ${ }^{2} / 3$ von dem des ganzen Abdomens einnehmen.

1) Vgl. McLachlan (15), p. 397. 
Von jedem Hoden entspringt an dessen proximalem Ende ein Vas deferens (Schema Fig. $72 \quad V d$ ), welches ziemlich dicht unter ersterm entlang nach hinten zieht, etwas lateral gelagert ist und dort, wo der Anfang des Hodens liegt, nach oben biegt, um nun seitlich dicht neben dem im 8. und 9. Segment liegenden Drüsenkomplex (vgl. Querschnitt Fig 74 und 75 Vd) nach hinten zu gehen. Hier wenden sich beide Vasa deferentia nach innen und laufen nach der Medianebene, um nach einer ganz kurzen Biegung nach vorn in den Raum $V s$ zu münden. Dieser aber ist, wie sein Längsschnitt $V s$ Fig. 73 erkennen läßt, nur die starke Erweiterung des Vas deferens. Beide Erweiterungen liegen an den Innenseiten des Drüsenkomplexes, verlaufen dort zunächst schräg nach vorn und unten und biegen dann knieartig nach oben um (Fig. $73 V s^{\prime}$ ), dabei enger werdend. Sie legen sich um den vordern, obern Teil der großen Drüse $A$ im Schema Fig. 72 und münden in deren Dorsalteil. Der Längsschnitt Fig. 73 zeigt diese Stelle bei $p$. (In dem Querschnitt Fig. 74 ist bei $V s$ die Erweiterung des Vas deferens an der Stelle getroffen, wo sie nach außen und oben umbiegt, um dorsal verlaufend in die darüber liegende große Drüse zu münden, wie der Pfeil anzeig't.) - Das Vas deferens ist bis zu seiner Erweiterung sehr eng, sein Lumen im Querschnitte rundlich. Die Kerne in der Wandung sind kuglig. Die Wände der Erweiterung sind etwas stärker, ihre Kerne anfangs auch kuglig; weiterhin werden sie schwach cylindrisch.

Den Bau des großen Drüsenraumes, welcher die eben beschriebenen Kanäle aufnimmt, (Schema Fig. $72 A$ ) veranschaulichen der Längsschnitt Fig. 73 bei $A$ und die beiden Querschnitte Fig. 74 und 75 bei $A$. Ersterer zeigt, daß wir an dem Organ einen obern, dorsalen Raum (A) und zwei mit diesem breit zusammenhängende Ventralkammern $B$ und $C$ unterscheiden können, deren Wandungen histologisch differenziert sind. Die Kerne der Wandung des ersten ventralen Raumes sind deutlich cylindrisch, gehen aber allmählich nach dem zweiten hin in solche von mehr kugelförmiger Gestalt über. Während die Wand dieser beiden Teile nicht viel stärker ist als die der Erweiterung des Vas deferens, ist diejenige des Dorsalraumes durch ihre Dicke ausgezeichnet. Charakteristisch sind an diesem Teile zwei von ihrem obern, median gelegenen Wandstücke gebildete, tief in das Innere gehende Falten $a$ in dem Querschnitte Fig. 74, durch welche drei Längsrinnen gebildet werden, die nach dem Ende der Drüse hin verstreichen.

Fig. 73 zeigt weiter bei $E$ den Längsschnitt einer Drüsen- 
abteilung, die durch ihre Kugelform ausgezeichnet ist und zum größten Teil in die eben beschriebene Hauptdrüse gestülpt ist (Schema Fig. $72 E$ ). Mit ihr steht sie durch eine enge Mündung in Zusammenhang. Ihre Wand enthält kuglige Kerne. Das Secret ist (nach Einwirkung der Konservierung) von den Zellen strahlenartig nach innen gerichtet, ähnlich wie auch das des darunter liegenden Teiles der Hauptdrüse.

Ob ein Drüsenraum Schema (Fig. $72 F$, Längsschnitt Fig. $73 F$ ), als ein Divertikel der letztern anzusehen ist oder eine selbständige Anhangsdrüse darstellt, ist schwer zu entscheiden. Für die letzte Auffassung spricht die dünne Wandung dieses Stückes mit kleinen Kernen sowie ihre eingeschnürte Mündung in den letzten großen Drüsenraum (Schema Fig. 72 G), den Figg. 75 und 76 bei $G$ im Querschnitte veranschaulicht.

Dieser, welcher kurz hinter der Mündung der eben erwähnten Anhangsdrüse mit der Hauptdrüse in Zusammenhang steht, ist, wie der (seitlich geführte) Längsschnitt Fig. $73 \mathrm{G}$ zeigt, schwach knieförmig nach hinten gebogen. Das Ende dieser Biegung wendet sich nach der Mittelebene des Abdomens hin, so daß ein Längsschnitt, welcher mehr medianwärts liegen würde, diesen kopfförmigen Teil allein schneidet. (Vgl. den Medianschnitt Fig. 83 bei G.) Auch diese Drüse hat, besonders in ihrem lateralen und ventralen Teile, eine verhältnismäßig starke Wandung. Die Zellkerne sind eiförmig und liegen da, wo die Wand dick ist, mit ihren Enden ineinander geschoben. Wie der Querschnitt Fig. 75 zeigt, bildet dieselbe eine schwach nach innen vorspringende Leiste, die kurz hinter der Einmündung $(a)$ der Hauptdrüse auftritt, so daß an dieser Stelle ein kleines Divertikel $(b)$ gebildet wird. Hinter der Mündung der Anhangsdrüse wird die Wand wieder glatt, und nun springen an derselben Seite zwei andere Falten in das Lumen der Drüse vor, dadurch drei kammerartige Räume bildend (Querschnitt Fig. 76 G).

Einer Darstellung der ausführenden Genitalwege geht zweckmäßig eine solche des Abdominalendes voran (Taf. 27, Fig. 69 und Fig. 70). An diesem fallen sofort zwei dreieckige Klappen $(A)$ auf, die mit ihrem Grunde dem vorangehenden Segment aufsitzen und mit ihren Spitzen nach hinten und etwas nach unten gerichtet sind. Sie schließen die Analöffnung ein. Beide Klappen sind nach außen gewölbt und mit Borsten bedeckt, mit Ausnahme eines medianen Feldes $(a)$, in welchem sich eine Gruppe von rosettenförmigen Gebilden liegt, die ebenso aussehen, wie sie S. 409 von Rhaphidia be- 
schrieben und Taf. 25, Fig. 25 abgebildet sind. Das spitze Ende einer jeden Klappe ist spießförmig ausgezogen (Fig. 69 und 70 bei $s$ ), und darunter liegt ein kleiner Haken $(h)$. Der ventrale Rand bildet einen pyramidenförmigen Fortsatz $(p)$, dessen abgestumpftes Ende ein Büschel langer Borsten trägt, die nach unten und innen gerichtet sind.

Während das letzte Segment in dieser Weise ziemlich kompliziert gebaut ist, findet sich als Anhang des vorangehenden Genitalsegments nur eine unpaare Ventralschuppe (Fig. 69, $70 \mathrm{~B}$ und Fig. 71 isoliert), die nach unten halbkuglig gewölbt ist. Lateralklappen konnte ich nicht feststellen.

Die übrigen für die Genitalwege in Betracht kommenden Chitingebilde zeigt, etwas auseinander gebreitet und stärker vergrößert (Taf. 28, Fig. 85). Sie stehen in engem Zusammenhange mit der Genitalmündung und sind daher in Folgendem mit dieser beschrieben.

Zur Veranschaulichung dieser Verhältnisse dienen außer den Längsschnitten Taf. 28, Fig. 83 und 84 die Querschnitte durch das Abdominalende Fig. 76-82. - In dem ersten Querschnitte (Fig. 76) liegen rechts und links die Schnitte der am weitesten nach hinten gelegenen Drüsen $(G)$. Der Raum zwischen ihnen $(H)$ ist der aus beiden führende Genitalweg. Sein Querschnitt läßt an der septumähnlichen Einstülpung oben und unten dessen ursprüngliche Paarigkeit erkennen. An den Längsschnitten Fig. 83 und Fig. 84 kann man einen obern Teil $A^{\prime}$ unterscheiden, in welchen die davor liegende dickwandige Drüse mündet, und einen untern $A$, aus welchem ein breiter Spalt $B$ mit engem Lumen nach außen führt. Der obere Teil ist dünnwandig mit platten Kernen, der untere dicker mit mehr kubischen Kernen, und die ventrale Wand desselben sowie das Septum zeigen einen farblosen Chitinbelag, welcher in kleine Lappen und Falten gelegt ist. Die seitlichen Wände, welche den Drüsen dicht anliegen, sind sehr dünn.

Der oben erwähnte spaltförmige Ausführungskanal hat eine dünne Wand mit platten Kernen. Seine Mündung liegt hinter der Schuppe Fig. 69 B, Fig. 70 B. (Fig. 83 und $84 C$ im Längsschnitt, in welchem $G$ der Rest der hintersten Drüse, $D$ die basalen Teile der spitzen Enddornen sind.) Der Querschnitt Fig. 79 zeigt unter der ventralen Wand des Spaltes eine Lage zackiger Zellen $(m)$ mit basal gelegenen, eiförmigen Kernen, die weiterhin wieder verschwindet. Die lateralen, nach oben gerichteten Teile des Spaltes $(n)$ sind in viele Falten gelegt. 
In dem Längsschnitte Fig. 83 liegt bei $F$ ferner ein dünnwandiger Raum, welcher mit dem ausführenden Kanal in Verbindung steht, und dessen Inhalt, bei verschiedenen Individuen betrachtet, recht verschieden aussieht. Unser Längsschnitt zeigt eine Grundsubstanz mit gestreckten Kernen; in den Querschnitten Fig. 78 und Fig. 79 macht der Inhalt $(F)$ den Eindruck von Fettkörpergewebe. Vielleicht haben wir es hier mit einem penisartigen Gebilde zu tun, das aber, ebenso wie eine Muskulatur des ausführenden Ganges, wenig entwickelt ist. $\mathrm{Zu}$ beiden Seiten dieses in der Medianebene liegenden Gebildes befinden sich, mit breiter Basis beginnend, 2 Chitingebilde, die nach außen in Form zweier gebogenen Haken endigen (Fig. $75 \mathrm{E}$; Fig. $84 \mathrm{E}$ im Längsschnitte). Zu ihrer Basis gehen verhältnismäßig wenige Muskelfasern, die Fig. 80 bei $m$ zeigt.

Die Gegend um das penisartige Gebilde stellen die Querschnitte Fig. 77, 78, 79 dar, das Chitingerüst derselben isoliert Fig. 85. Dieses besteht der Hauptsache nach aus drei Stacheln: zwei lateralen $(l)$, mit den Spitzen nach innen geneigten und einem medianen $(m)$. Während der letztere unter Bildung eines Kiels in eine breite Basis verläuft, sind die beiden ersten am Grunde mehr hakenartig und stehen hier mit 2 ungefähr bohnenförmig gestalteten Basalstücken (b) in Zusammenhang, wie solche, aber kleiner $\left(b^{\prime}\right)$, auch jederseits neben der Spitze des unpaaren Stachels liegen. Den letztern zeigt uns der Querschnitt Fig. 77 bei $E$ im Längsschnitt. Die beiden Chitinstreifen $D$, welche daneben sichtbar sind, setzen sich in die beiden paarigen Stachel Fig. $78 D$ fort, welche das penisartige Gebilde einschließen. Die Chitinlamelle, welche die Stacheln trägt (in Fig. 85 ist sie ausgebreitet dargestellt), biegt sich, wie an dem Querschnitt Fig. 79 zu erkennen ist, hufeisenförmig um, dorsal den Kiel $K$ bildend, um dann zu verstreichen.

Von der Basis jedes paarigen Stachels, welche von einer stark entwickelten Hypodermis umgeben ist, geht ein Muskelzug seitlich und schräg nach oben zur Segmentwandung (Fig. 77 o). Weiterhin bedeckt dieses Muskelbündel die ganze Außenseite des Stachels, um dann seine Fasern an eine Chitinlamelle $(e)$ zu heften, welche seitlich von jedem Stachel auftritt (Fig. $78 p$ ). Von dieser wendet sich ebenfalls ein Muskelzug $(q)$ schräg nach der obern Körperseite hin, so daß also jene Chitinplatte den zuerst erwähnten Muskel eigentlich nur unterbricht. Von dem dorsalen Kiele gehen einzelne Fasern strahlenförmig zu den obern Kanten der erwähnten Chitinplatte (Fig. 79 r). Wie die Figg. 80, 81, 82 zeigen, verläuft außen von jeder Platte ein 
Muskelzug $s$ schräg nach unten zu den beiden großen Lateralklappen, während die Chitinplatten selbst hinter der Genitalmündung nach innen umbiegen, um mit einem spitzen Haken $t$ in Fig. 82 zu enden. (Vgl. das Chitinskelet Fig. 69 und 70.) Von ihrem obern Teile gehen an dieser Stelle konvergierend zwei Muskelzüge $(u)$ zu einer ventral gelegenen, mittlern Platte $(v)$.

\section{Myrmeleon L. ${ }^{1}$ )}

Das männliche Genitalsegment von Myrmeleon formicarius L. (Taf. 26, Fig. 48) zeichnet sich durch zwei stark chitinisierte, ovale Lateralplatten $A$ aus, welche sich nach der Dorsalseite (Fig. 49) hin verschmälern und in deren Mittellinie spitz zusammentreffen. Ventral schließt sich ein unpaarer zungenförmiger Anhang an, den Fig. 26 auf Taf. 25 von der Innenfläche gesehen und ausgebreitet darstellt. Während er nach seinem Ende hin zugespitzt ist, läuft seine Basis in zwei laterale Leisten aus, die mit einem starken Condylus $(a)$ endigen.

Das Analsegment (Fig. 48 und 49 B) besitzt zwei seitliche, stark chitinisierte Klappen. Beim Auseinanderbiegen derselben bemerkt man zwischen ihnen ein Chitingerüst, welches Fig. 27, Taf. 25 stärker vergrößert darstellt, und von welchem die schwarzgefärbten Höcker $a$ auch dem bloßen Auge auffallen. Sie hängen mit dem Verbindungsstücke $d$ des Gerüstes zusammen, das jederseits in einen flügelartig verbreiterten Seitenteil $b$ übergeht. - $\mathrm{Zu}$ erwähnen ist noch, daß die Chitinbedeckung des Körpers überhaupt von kleinen unregelmäßigen, schwächer chitinisierten Feldern unterbrochen ist, so daß sie unter dem Mikroskop netzartig geadert erscheint. In jedem Felde stehen zwei Borsten, und zwar je eine große, daneben eine kleine (Fig. 28).

Felder mit Rosetten finden sich weder auf den Analklappen noch sonst auf einem Teile des Abdominalendes von Myrmeleon.

Die weitere Beschreibung des innern Baues vom männlichen Genitalapparat bezieht sich auf Myrmeleon formicalynx $\mathrm{F}$.

Die Hoden liegen jederseits vom Darmkanal im 8. Abdominalsegment und bestehen aus je 5 Follikeln, die durch Septen voneinander getrennt sind, welche von der dünnen Hülle des Hodens in dessen Inneres gehen. Über dieser Haut liegt aber noch eine bedeutend dickere Außenhülle mit platten Kernen, welche dicht mit äußerst

1) Vgl. v. Siebold (8), p. 380; Brauer (13), p. 394. 
feinen Pigmentkörnchen angefüllt ist. Innerhalb dieser letztern Haut liegen auch noch die aus den Follikeln hervorgehenden, nur wenig gewundenen Vasa efferentia, und nach deren Vereinigung tritt aus der Hülle das Vas deferens hervor, das in ziemlich gerader Richtung an den Außenseiten der Drüsenorgane nach hinten läuft, hier einige Schlingen bildet und sich dann zur Ventralseite wendet, um in die Vesicula seminalis zu münden. Taf. 28, Fig. 93 zeigt bei $V d$ diese Stelle.

Die Vesicula seminalis mit ihren Kammern hat einen recht verwickelten Bau, der an einer Reihe charakteristischer Querschnitte klargelegt werden soll. Die hier dargestellten gehören der rechten Körperseite an, sind in der Reihenfolge von vorn nach hinten numeriert (Taf. 28, Fig. 86-95), und die dazu gehörigen korrespondierenden Buchstabenbezeichnungen lassen den Zusammenhang der einzelnen Räume erkennen, welche hier der rechts liegenden Vesicula angehören. Fig. 86 zeigt den Querschnitt eines Drüsenrohres $a$, das weit nach vorn liegt und mit einer Anhangsdrüse in Zusammenhang steht, die am Schluß beschrieben ist. In der starken Wand jener Röhre liegen eiförmige Kerne. Ihr Secret wird (nach Alkoholbehandlung) durch Haematoxylin nicht gefärbt und hat einen gelblichen Schimmer. Nach kurzem Verlaufe mündet sie, wie Fig. $87 a$ zeigt, unter Einschnürung ihres Lumens und gleichzeitiger Wandverdickung, in einen Raum $b$, der sich noch etwas weiter nach hinten mit den andern Kammern vereinigt (Fig. $88 b$ und Fig. $89 b$ ). Bevor die Einschnürung in Fig. 87 erfolgt, sind aber bereits Teile von drei andern Kammern (Fig. $87 c, d, e$ ) aufgetreten. Der Raum $c$ ist von den übrigen schon dadurch deutlich unterschieden, daß sich seine Zellen, welche kugelförmige Kerne enthalten, weit weniger intensiv färben als jene, und daß das noch schwächer gefärbte Secret in das Lumen der Kammer strahlenartig vorspringt. Der Raum $d$ dagegen ist, besonders an seiner frei liegenden Außenseite, dickwandig, mit eiförmigen Kernen. Nachdem sich Drüsenraum $c$ noch mit einem Fortsatze um die Außenfläche jenes letzten Teiles $d$ gelegt hat, der bald verschwindet (Fig. $89 c^{\prime \prime}, 90 c^{\prime \prime}$ ), gehen nun beide Räume $c$ und $d$, wie die Schnitte Fig. 88, 89 u. 90 verfolgen lassen (in den folgenden sind sie nicht mehr einzeln bezeichnet), zu einer einzigen Kammer zusammen, nachdem auf der Medianseite noch eine Abteilung $c^{\prime}$ gebildet wurde, die hier von einer fast geraden Innenwand begrenzt wird, welche bei $s$ einen scharf ausgeschnittenen Divertikel bildet. - Die Kammer $e$ in Fig. 87, welche an ihrem Anfang durch ihre 
gewundene Form sowie durch ihre sehr starke Wand auffällt, geht, wie in den Figg. 88, 89 u. $90 \mathrm{zu}$ verfolgen ist, ebenfalls in den entstandenen Hauptraum $c^{\prime}$ über. An der Vereinigungsstelle sind die Kerne schlank cylindrisch und bleiben so an dieser Stelle bis weit nach hinten (Fig. 92).

Ganz hinten endlich bildet die Hauptkammer $c$ noch einen letzten Nebenraum $h$ (in Fig. 93, 94 u. 95) mit dicker Wand, deren Außenseite aus cylindrischen Zellen mit eiförmigen Kernen besteht, die sich von den benachbarten Stellen dadurch abheben, daß ihr Plasma weniger Farbstoff aufnimmt und die Kerne weiter voneinander entfernt sind.

Wenden wir uns zu dem kleinen Divertikel $s$ zurück, der sich (Fig. 88) vom Raum $c^{\prime}$ abzweigt. Wie Fig. 89 und die folgenden verfolgen lassen, ist dieses Stück überall scharf von den andern Teilen abgesetzt. Seine Wand enthält schlank cylindrische Kerne. Er wird im Verlaufe nach hinten zu weiter (Fig. $92 s$ ) und tritt dabei in Verbindung mit 2 Kammern, $F$ (Fig. 90, 91, 92) und G (Fig. 92), die zu einem Raume zusammengehen, der sich noch ein Stück weiter nach hinten erstreckt (Fig. 93-96 F, G) und hier endet.

Der ganze Drüsenkomplex ist von einer schwachen Ringmuskulatur umgeben, welche in Gestalt eines dünnen Septums auch durch die Medianebene geht, die Organe beider Körperseiten trennend. Im Umkreis der Drüse $e$ und in dem Raume zwischen ihr und den benachbarten Wänden ist sie ziemlich kräftig.

Wie am Anfange schon angedeutet worden ist, geht in den Beginn des Schlauches a (Fig. 86 u. 87) eine Anhangsdrüse, die sich vorn in 2 Stücke gabelt. Der Grund eines jeden liegt in der Nähe des Hodens. Die stark gefaltete Wand (Fig. $86 a$ ) enthält große, eiförmige oder fast kuglige Kerne. Das Secret ist (nach Alkoholbehandlung) feinfasrig und färbt sich mit Hämatoxylin schwach bläulich.

Das Divertikel $s$, von dem vorher die Rede war, geht nach außen (hinten) selbständig weiter und führt zur Genitalmündung, wie die Figg. 93-95 zeigen, die mit einem jederseitigen Spalt $s^{\prime}$ beginnt. Letztere entsteht, indem beide Spalte, die anfangs in der Mittelebene liegen, weiterhin verschmelzen (Fig. $96 s^{\prime}$ ). Wie in Fig. 95 bei $e$ zu erkennen ist, liegt dort, wo sie aus dem anschließenden Drüsensystem herausführen, ein aus cylindrischen Zellen mit länglich eiförmigen Kernen bestehender Epithelwulst. Beide Wülste verschmelzen dann zu einem einzigen, median gelegenen (Fig. 96e), 
welcher eine kurze Strecke weit das Dach des unpaaren Raumes bildet, dessen Wand eiförmige Kerne enthält und dorsal und ventral zwei Rinnen (Fig. $96 a$ und $b$ ) bildet. Dieser Raum steht durch eine enge Spalte (Fig. $96 \mathrm{c}$ ) mit dem eigentlichen Ausführungskanal (Fig. $96 d$ und Fig. 97-99d) in Zusammenhang, dessen Wandung. in wellige Längsfalten mit eiförmigen Kernen gelegt ist. Während die Wände anfänglich oben und unten nahe beieinander liegen, so daß das Lumen dazwischen zusammengedrückt erscheint, weichen sie weiterhin (Fig. 98) auseinander, um schließlich ein dreiseitiges Lumen zu umschließen (Fig. 99) und vor der Mündung (Fig. 100 u. $101 d$ ) noch jederseits einen Divertikel zu bilden. Den Ausführungsgang der Genitaldrüsen in Fig. 96 sowie den eigentlichen Ausführungskanal $d$ umgibt eine nicht sehr starke Ringmuskulatur, die auch die Drüse $F, G$ mit einschließt. Sie begleitet den Gang bis zur Mündung, dabei allmählich sehr dünn werdend.

Hinter dem Epithelwulst $e$ in Fig. 96 tritt in dem ausführenden Genitalraume ein Gebilde auf, das einen herzförmigen Querschnitt besitzt (Fig. $97 f$ ). Sein breiterer Teil liegt dorsal; das ventral gerichtete scharfe Ende geht in einen stark chitinisierten Stachel $g$ über, welcher dort liegt, wo die enge Verbindung des eigentlichen Ausführungsganges mit dem unpaaren Ausführungsgang des Genitaldrüsensystems zu finden ist. Mit der Erweiterung des erstern wird dieses Gebilde kleiner, und, wie Fig. 98 darstellt, entstehen daraus schließlich zwei Zellenplatten, die in die Wände des Genitalganges übergehen.

Bei der Beschreibung des Abdominalendes wurde eines Chitingebildes gedacht, das zwischen Anal- und Genitalöffnung gelegen ist (Taf. 25, Fig. 27). Die Figg. 100-103 stellen dar, welche Lage und welchen Zusammenhang dasselbe mit dem Innern des Abdomens hat. Fig. 100 zeigt bei a jederseits den Schnitt einer Chitinleiste desselben, an welche sich ein ziemlich kompliziertes Muskelsystem setzt, dessen weitern Verlauf Fig. 101 darstellt ( $d$ ist, wie vorher erwähnt, der Querschnitt des Genitalausführungsganges). In Fig. 102 sehen wir die beiden seitlichen, median verbundenen Stücke $b$ auftreten (vgl. das Gebilde Taf. 28, Fig. 85 von $M$. formicarius), an deren Ventralteilen sich die starken Muskelmassen $c$ und $e$ heften. In dem Schnitte Fig. 103 endlich ist der Rest der Seitenstücke $b$ getroffen, an deren Enden sich die nach außen divergierend verlaufenden Faserbündel $f$ heften. Zwischen diesem Chitingerüste und dem Enddarme liegt ein hohler Raum (Fig. $103 \mathrm{~g}$ ). 
Weiblicher Genitalapparat.

\section{Sialis Tutaria L. ${ }^{1}$ )}

Die letzten drei Segmente des 10gliedrigen Abdomens der weiblichen Sialis (Taf. 28, Fig. 107 und 108) bilden zusammen einen Kegel. Segment $8(a)$ hat die Gestalt eines schmalen Ringes, der auf der Dorsalseite einen nach hinten geöffneten Ausschnitt zeigt und ventral in der Mittellinie in derselben Richtung einen zungenförmigen Fortsatz (Fig. 107 u. 108 b) trägt, welcher, stärker vergrößert, in Fig. 111 bei $a$ von seiner Außenseite, bei $b$ von der Innenfläche her dargestellt ist. Unterhalb ihres Endes ist diese Zunge außen dicht mit äußerst feinen Borsten bekleidet. Auf jeder Seite dieses Segments ist, was aber erst an stärker vergrößerten Macerationspräparaten deutlich sichtbar wird (Fig. 108), das Stigma eigenartig ausgebildet, wie Fig. 110 (hier das der linken Körperseite) wiedergibt. Es wird von einer flachen, halbringartig gebogenen Leiste $l$ umgrenzt, deren Biegung nach der Medianebene hin liegt. Wie dieselbe Zeichnung bei $m$ darstellt, entspringt an dieser Leiste ein ausgehohlter, an der Spitze nach außen umgebogener und nach vorn gerichteter Haken. Seitlich erhebt sich ein hohler, zugespitzter Kegel (n). Die Umgebung des Stigmas ist mit sehr feinen, dicht gedrängt stehenden Stacheln besetzt, zwischen welchen stärkere und lange Borsten $(p)$ stehen, deren Grund auf einer gewellten, schwach leistenförmigen Erhebung artikuliert.

Das Genitalsegment (Fig. $107 c$ ) zeigt Fig. $108 c$ in maceriertem Zustande, von der Ventralseite gesehen. Man erkennt an dem Chitinskelet, daß es aus zwei stärker chitinisierten Stücken besteht, welche ineinander geschoben werden können. Ventral liegen die in Fig. 108 stark auseinandergezogenen Wände so aneinander, daß sie einen Spalt $(t)$ bilden, der sich bis zum Segmentende erstreckt. (Seine Querschnitte zeigen die Figg. 114, 115 u. 116 bei $t$.) In welcher Beziehung die Genitalmündung zu ihm steht, ist weiter unten dargestellt.

Das Analsegment liegt über dem Genitalsegment, und zwar so, daß es nicht sichtbar ist, wenn man das Abdominalende von $S$. $h$ utaria von der Ventralseite her betrachtet.

1) Vgl. Degeer (1), p. 378; Suckow (2), p. 379; Burmeister (4), p. 379 ; Frey-Leuckart (7), p. 380 ; Löw (10), p. 382 ; McLachlan (15), p. 396; Gross (16). 
Das weibliche Abdominalende von Sialis fuliginosa P. zeigt nicht wie das männliche so charakteristische Unterschiede im Vergleich mit dem der eben beschriebenen Art. Wie ein Vergleich der beiden Figg. 107 (lutaria) und 109 (fuliginosa) erkennen läßt, ist das 8. Sternit von S. fuliginosa ebenfalls schmal. Die beiden jederseits gelegenen Stigmen zeigen aber eine andere, einfachere Ausbildung ihres Chitingerüstes (Fig. 110 von S. lutaria, Fig. 112 von S. fuliginosa), und die kleine, ventrale Zunge desselben Segments von S. Tutaria (Fig. 107 b) fehlt bei der andern Art ganz, während hier unterhalb der betreffenden Stelle ein schwach elliptischer, längs gerichteter Eindruck (b) wahrzunehmen ist. - Auch das 9. Segment ist bei beiden Arten im weiblichen Geschlecht in entsprechender Weise chitinisiert, aber bei S. fuliginosa, abgesehen von der Größe, am Ende mehr abgerundet.

Betrachtet man das Abdomen von S, fuliginosa von der untern Seite aus, so ragt das Analsegment über das kegelförmige Genitalsegment, im Gegensatz zu S. lutaria.

Von den beiden Ovarien von S. fuliginosa gibt Gross (16) Folgendes an: „Die sehr zahlreichen Eiröhren sind von einer gemeinsamen, peritonealen Hülle umschlossen. Die langen Endfäden sind an der gemeinsamen Hülle befestigt." Dann folgt eine ausführliche Beschreibung der Eiröhren und Endkammern.

Die folgende weitere Darstellung bezieht sich wieder auf S. Tutaria. Die paarige Oviducte zeichnen sich durch große, schmale, einspringende Längsleisten mit sekundären Lappen aus. Vor ihrer Vereinigung tritt auf ihrer Außenfläche eine starke Ringmuskulatur auf. Der unpaare Ausführungsgang ist außerordentlich kurz.

Die nun zu beschreibenden Räume des Genitalapparats und ihre Anhänge fallen, besonders wenn man den komplizierten Bau der männlichen Organe in Betracht zieht, durch ihre verhältnismäßig geringe Entwicklung auf und sind ältern Beobachtungen (Löw 10) aus diesem Grunde entgangen.

Betrachten wir zunächst den Längsschnitt Taf. 29, Fig. 105, der ziemlich durch die Mittelebene des Abdominalendes geht. Im untern Teile desselben sieht man zunächst einen Drüsensack $A$, dessen dicke Wände in große Falten gelegt sind. Die innere Hälfte der aus spindelförmigen Zellen bestehenden Wandung enthält länglich eiförmige Kerne und färbt sich leicht, während die periphere Hälfte nur wenig Farbstoff (Hämatoxylin) aufnimmt. Dieser Sack setzt sich, kleiner und enger werdend und zwischen den paarigen Oviducten liegend, 
fort und bildet nun jederseits dort, wo die weiter unten erwähnten kolbigen Gebilde liegen, eine taschenartige Erweiterung, die nicht so weit nach vorn reicht als das verlängerte Mittelstück. Alle Teile stehen weit offen miteinander in Verbindung. Das Drüsensecret wird (nach Alkoholbehandlung) durch Hämatoxylin intensiv blau gefärbt.

Die Wände dieses Drüsensackes gehen, wie derselbe Längsschnitt (und Fig. 106) zeigt, histologisch ziemlich unvermittelt in den dahinter sich anschließenden, ausführenden Raum $B$ über, dessen Wand in zahlreiche kleine Falten und Läppchen mit farblosem Chitinsaum gelegt ist. Die Kerne derselben sind kleiner als die des zuvor beschriebenen Sackes und kurz cylindrisch. Nach dem Ausgang zu, besonders an dessen Dorsalseite, treten an Stelle der kleinen Läppchen größere Leisten mit bedeutend dickerm Belag aus farblosem Chitin, unter dem cylindrische Zellen liegen $(m)$. Die ventrale Mündungslippe trägt außerdem einen Belag von sehr feinen Zähnchen (Fig. 105 n). Die Umgebung der Zellkerne ist in der Wandung dieses Ausführungsraumes, besonders unter den feinen Lappen, so dicht von gelbbraunen Pigmentkörnchen angefüllt, daß es oft schwer ist, die Kerne selbst zu erkennen.

Kurz hinter der Mündung der Oviducte springt nun in den eben beschriebenen Raum jederseits von dessen Dorsalseite her und ziemlich weit seitlich gelegen ein kolbenförmiges Gebilde vor, das den zuerst beschriebenen Drüsensack $A$ von dem Vestibularteile abscheidet. Fig. 113 zeigt bei $C$ im Querschnitt die Lage dieses Kolbens, Fig. $106 C$ einen solchen im Längsschnitt, Fig. $105 C$ dessen Rest in einem der Medianebene nahe gelegenen Schnitt. Jeder Kolben ist wie die angrenzende Wand in zahlreiche Falten gelegt, deren Kerne sich von denen des erstern auch nicht unterscheiden. Auf der Oberfläche ist er dicht mit feinen Stacheln besetzt, und man hat den Eindruck, als könne er durch eine Art Erection stark ausgedehnt werden.

In seinem Innern liegt ein ganz kleiner, hufeisenförmig gekrümmter Kanal mit kubischen Kernen in seiner Wandung (Fig. 106 $D$ und Fig. $113 D$ ), der in die Ausbuchtung bei $E$ einmündet.

In dem nahe der Mittelebene geführten Längsschnitt Fig. 106 findet sich ferner dorsal über dem Ausführungsgang ein Divertikel $F$, von welchem nach hinten zu jederseits eine taschenartige Fortsetzung ausgeht, wie die Querschnitte Taf. 28, Fig. 114 und Taf. 29, Fig. 115 bei $F$ darstellen. Die Dorsalwand derselben zeichnet sich 
durch ein dickes Drüsenpolster aus, dessen schlank cylindrische bis spindelförmige Zellen schlank eiförmige Kerne enthalten, die im basalen Teile derselben liegen. Die periphere Schicht der Zellen des Polsters färbt sich kaum, läßt aber einen schmalen Saum (Chitin?) erkennen.

Alle diese Teile übertrifft an Ausdehnung ein mit seinem Grunde bis ins 7. Abdominalsegment reichender Sack, der unpaar ist, dicht unter dem Rücken liegt und die halbe Breite des ganzen Abdomens einnimmt. Seine Wandung ist aber nur dünn, mit platten Kernen darin (Querschnitte Taf. 28, Fig. 117 G u. Fig. 122 G). Charakteristisch für erstere sind außen liegende Zellengruppen (Fig. $122 H$ ), die äußerlich Ähnlichkeit mit den Fettkörperzellen der Umgebung haben, aber etwas größer sind und ein dunkles Plasma zeigen. Das Innere des großen Sackes enthält unregelmäßig gestaltete Körner (nach Einwirkung von Alkohol auf das Secret), wie in Fig. 122 dargestellt ist. Beim Eröffnen der Drüse erscheinen sie rötlich; unter dem Mikroskop sind sie undurchsichtig und erscheinen schwarz. Dieser „mit einer schwärzlichen Flüssigkeit gefüllte Anhang“ wird auch bereits durch v. Siebold (8) erwähnt.

Bisher ist noch nicht von dem diese einzelnen Teile umgebenden Muskelbelag die Rede gewesen, weil sich dessen Verteilung besser unter Bezugnáhme auf die beschriebenen Genitalräume und deren Querschnitte im Zusammenhange darstellen läßt. Nur die starke Ringmuskulatur der paarigen Oviducte wurde erwähnt. Sie steht auf den einander zugewendeten Wandungen dieser Kanäle mit den Längsfasern in Zusammenhang, welche den zwischen den Oviducten liegenden unpaaren Fundus der dickwandigen Drüse $A$ in Fig. 105 und 106 umgeben, und ist hier am stärksten entwickelt, wird aber im weitern Verlauf der Oviducte auch an deren Lateralund Dorsalwand stärker, während weiterhin von ihrer der Drüse zugekehrten Seite Fasern nach oben und etwas nach außen zum Tergit verlaufen. Im weitern Verlaufe beginnt auch die Ringmuskulatur des großen, dünnwandigen Dorsalsackes $G$ in Fig. 122, die aber auf der Oberseite nicht geschlossen ist, sondern, wie dieselbe Figur zeigt, jederseits zum Tergit geht und noch mehr nach hinten auf der Ventralseite eine Kreuzung der Fasern aufweist, zwischen welchen ein dünnes Längsfaserbündel $L$ verläuft. In dieser Region des Genitalapparats ist nun der Raum zwischen den Oviducten, den kolbenförmigen Körpern und der dickwandigen Drüse dicht von Muskelmassen angefüllt, während der Muskelbelag ventral nur unter 
der letztern etwas entwickelt ist. - Dann treten Querfasern in die beiden stark gefalteten Kolben und deren Lappen hinein, zwischen welchen der sehr kurze, unpaare Ausführungsgang der beiden Oviducte liegt, der mit dem Genitalvorraume weit offen in Verbindung steht.

Während nun bei Betrachtung von weitern Querschnitten jene Kolben allmählich verschwinden, bekommt der Ausführungsgang die Form eines liegenden Kreuzes; die so entstehende Genitalmündung ist von einer dünnen Längsfaserschicht und von einer dicken Ringmuskellage umschlossen. Die darüber liegende Dorsaldrüse dagegen hat ihren Muskelbelag verloren.

Dann verschwindet allmählich die Ventralwand dieses Ganges; ihren Rest zeigt der Querschnitt Fig. 114 V, und darunter liegt nun ein weiter Raum, der sich unten bei $t$, dem Querschnitt der langen Genitalspalte (vgl. Fig. $107 t$ ), öffnet. Inzwischen sind dorsal die beiden Wülste ( $M$ in Fig. 114 u. 115) aufgetreten, über denen je eine weite Trachee verläuft. Sie schließen sich allmählich nach unten ab, und es entstehen auf diese Weise die beiden Taschen $F$ in Fig. 115 (vgl. Längsschnitt Fig. 106 F). Das Dach des Vorraumes über der Genitalspalte $t$ ist nun platt geworden (Fig. 115), und darüber hin spannen sich Muskelfasern $(N)$, die bis zu den lateralen Seiten des Sternits gehen. Die darüber gelegene große Dorsaldrüse hat sich inzwischen zu einem Ausführungsgang (Fig. 115 $G$ ) verengt, der sich abermals mit einer Ringmuskelschicht umgibt. Während nun die Genitalspalte immer schmaler wird, mündet dieser Gang in letztere, indem sich seine Muskulatur noch eine Strecke weit bogenartig darüber fortsetzt, wie der Querschnitt Fig. 116 darstellt.

Es fragt sich, welche von den beschriebenen Organen des Genitalapparats als Bursa copulatrix und als Receptaculum seminis anzusehen sind. In Siebold-Stannius' Lehrbuch (8) finden wir die Bemerkung, daß die Scheide zwei seitliche, als Samentaschen fungierende, blindsackförmige Ausstülpungen besitzt. Diese Anschauung scheint insofern richtig zu sein, als ich die beiden Divertikel hinter den mehrfach erwähnten Kolben (Längsschnitt Fig. 106 E) dicht mit Spermatozoen angefüllt fand und daß in diese Räume auch die kleinen, in den Kolben gelegenen Anhangsdrüsen $C$ münden. Der Stachelbesatz der Kolben und ihrer Umgebung spricht in Hinsicht auf die bei vielen andern Insecten vorkommenden Gebilde dieser 
Art am Beginn der Bursa, daß diesem Teile bei Sialis die Funktion einer Bursa copulatrix zukommt.

\section{Rhaphidia notata F. ${ }^{1}$ )}

An dem 10gliedrigen Abdomen von Rhaphidia ist der ventrale Teil des 9. Segments in die bekannte Legeröhre umgewandelt. Das kleine 10. Segment (Taf. 29, Fig. 117 u. 119 a), welches die Analöffnung enthält, liegt über dem vorhergehenden und dem Ursprunge der Röhre. Seine Seiten tragen (bei $a^{\prime}$ ) wie bei den bisher behandelten Formen (ausgenommen Sialis) eine Anzahl jener mit je einer Borste versehenen Rosetten, wie sie Taf. 25, Fig. 25 vom Männchen abgebildet sind.

Das Chitingerüst der Legeröhre des Genitalsegments (Fig. 117 u. 119 b) besteht aus zwei dorsalen, symmetrischen Teilen $(f)$ (Fig. 117 stellt nur den linken dar) und einem von ihnen eingeschlossenen, ventralen Stück (Fig. 119 e). Erstere bilden zusammen eine ventral der Länge nach offene Scheide, welche dorsal in der Mittellinie, wo beide Stücke miteinander verwachsen sind, eine tiefe Längsfurche zeigt, wie an den Querschnitten (Fig. 129 u. 130) bei $m$ zu erkennen ist. Die Chitindecke bildet Verstärkungen in Form nebeneinander liegender, querer Plättchen, die durch schmale, geringer chitinisierte Felder getrennt sind, und trägt spärliche, kleine Borsten. Das Ende jeder Scheidenhälfte ist löffelförmig und mit einem länglich eiförmigen, sehr zarten Anhange versehen, der mit wenigen, ganz feinen Borsten besetzt ist (Fig. 118).

Das unpaare ventrale Stück (Fig. 119 e) beginnt kahnförmig, durch eine Leiste jederseits mit dem Segment verbunden. Der feine Faden, in welchen es ausläuft, liegt in der von den beiden Dorsalstücken gebildeten Scheide und wird hier durch je eine Längsleiste derselben, die in eine entsprechende Furche des Ventralstückes passen, in seiner Lage gehalten. Diese Leisten rufen an dem Legerohr die Fig. 117 bei $c$ bemerkbare Chitinverstärkung hervor.

Das Sternit des 8. Segments (Fig. 117 d) liegt in Form einer quergestellten Schuppe über dem Ursprunge der Legeröhre, die Copulationsöffnung bedeckend.

Die Ovarien von Rhaphidia habe ich nicht untersucht, und auch

1) Vgl. Degeer (1), p. 378; Burmeister (4), p. 379; Schneider (6), p. 380 ; v. Siebold (8), p. 380 ; Löw (10), p. 382; Brauer (13); McLachlan (15), p. 396. 
Gross berichtet nichts darüber. Nach Löw (10) sind sie büschelförmig, im Gegensatz zu andern Neuropteren, deren Ovarium kammförmig ist. BRAUER (13) dagegen gibt für Rhaphidia ein büschelförmiges Ovarium wie auch bei Sialis, Mantispa und Drepanopteryx an.

Die paarigen Oviducte haben in ihrem Anfange eine dünne Wand mit platten Kernen. Nach der Stelle hin, wo sie sich zum Oviductus communis (Schema Fig. 120 und Längsschnitt Fig. 121 Od) vereinigen, treten allmählich wenige niedrige Längsleisten auf, die aber nach und nach zahlreicher werden, während die Wand selbst dicker und ihr Chitinbelag stärker wird. Vor letzterm, dessen Rand etwas gezackt erscheint, hebt sich die Zellenschicht mit ihren nunmehr gerundeten Kernen deutlich begrenzt ab (Querschnitt Fig. 123). Außen ist auf dem unpaaren Oviduct inzwischen ein dünner Muskelbelag. aufgetreten. Noch weiterhin nehmen die Zellen der Wand Cylinderform an mit ebenso gestalteten Kernen; die äußere Muskulatur wird stärker, und so geht der Gang in einen Vorraum über, den der Längsschnitt Fig. $121 V$ zeigt, und in den auch die andern Genitaldrüsen münden.

Die Querschnitte Taf. 29, Fig. 125-127 lassen bei $V$ erkennen, wie dieser Vorraum, breiter werdend, nach außen mündet, während die um den unpaaren Oviduct befindliche Ringmuskulatur verschwindet, und wie an seine Dorsalseite schräg von oben her kommende Faserbündel $m$ treten, die zum Teil in die Lappen, welche die Mündung seitlich begrenzen, verlaufen.

Der Längsschnitt Fig. 121 zeigt eine für Rhaphidia charakteristische Eigentümlichkeit: eine doppelte Genitalöffnung. Der soeben beschriebene, breite Ausführungsgang, den im Mündungsgebiete eine starke Chintinlage auskleidet und dessen Hypodermis mit cylindrischen Kernen hier ebenfalls stark entwickelt ist, führt nämlich im 8. Segment des Abdomens nach außen und bildet hier die Copulationsöffnung $G$. Nach hinten zu aber setzt sich ein zweiter, sehr enger Gang (Fig. $121 G^{\prime}$ ) aus dem Vorraume in die Legeröhre hinein fort (Querschnitte Fig. 125-129 $G^{\prime}$ ), in dessen Lumen Längsleisten mit feinen Läppchen ragen. Sie enthalten eiförmige, zugespitzte Kerne (stärker vergr. Fig. 125 a). Der Gang endigt an der Spitze der Legeröhre als sehr enger Kanal, bei dessen Erwähnung auch Löw (10) seiner Verwunderung Ausdruck gibt, wie die großen, langgestreckten Eier hindurchtreten können.

Zur Veranschaulichung der Lage und Gestalt der in den Genitalvorraum mündenden Anhangsdrüsen dient, im Vergleich mit dem 
Längsschnitt Fig. 121, das Schema Fig. 120. Es zeigt zunächst bei $A$ dorsalwärts einen geräumigen, verhältnismäßig dünnwandigen Sack. Seine mit platten Kernen versehene Wand springt nur wenig in das Lumen vor in Gestalt von niedrigen Leisten und Falten, die da am zahlreichsten entwickelt sind, wo dieser Sack, die Bursa copulatrix, in den benachbarten, nach außen führenden Raum $B$ führt. Der Fundus der Bursa trägt, wie das Schema bei $A^{\prime}$ andeutet, ventral einen kleinen, blind endigenden Schlauch. Der aus der Bursa führende Raum $B$ im Schema, den der Längsschnitt gleichfalls bei $B$ zeigt und dessen Ausführungsgang im Querschnitt Fig. 124 bei $B$ getroffen ist, ist, namentlich in seinem Hauptteil, durch den starken Chitinbelag seiner Wandung ausgezeichnet, in der länglich eiförmige Kerne enthalten sind. Auch hier ist die hypodermale Zellenschicht von der Chitinlage ziemlich scharf abgegrenzt. Die Innenwand ist in große, abgerundete Falten und Lappen gelegt, die das Lumen ziemlich stark verengen. Außen findet sich eine dicke Lage von Ringmuskeln.

Das Receptaculum seminis (Schema Fig. $120 R$, Längsschnitt Fig. $121 R$ ), unter dem eben beschriebenen Ausführungsgang der Bursa gelegen, ist eiförmig. In den Schnitten fällt es durch seine kräftig entwickelte Wandung auf, die aus sehr schlanken, cylindrischen Zellen gebildet wird, in denen spindelförmige Kerne liegen. Wie das Schema zeigt, hat es am proximalen Ende einen blindsackartigen Fortsatz $r$. Jederseits trägt es ferner einen kurzen, akzessorischen Drüsenschlauch $r^{\prime}$, schon von v. Siebold (8) hervorgehoben. Alle Teile sowie auch der breit entspringende, knieförmig umgebogene Ausführungsgang (Längsschnitt Fig. 121 D) zeigen den Bau des Hauptteils.

Der Ausführungsgang des Receptaculums geht schräg nach unten, legt sich über den unpaaren Oviduct und wird immer enger, seine Wand dementsprechend dünner, wie der Querschnitt Fig. 125 bei $D$ veranschaulicht. Eine Ringmuskellage umschließt ihn, deren Fasern mit denen des vestibularen Ausführungsganges im Zusammenhang stehen, und er ist in derselben gleichsam eingebettet. Wie derselbe Schnitt zeigt, ist auch die Muskulatur des unpaaren Oviducts durch ein jederseitiges Querfaserbündel $n$ mit der Muscularis des Vestibulums verbunden.

Querschnitt Fig. 126 stellt weiter das Lageverhältnis der Copulationsöffnung zu dem Kanal innerhalb der Legeröhre dar. Wir sehen außen die Schnitte derjenigen Teile des Genitalsegments, aus welchen die von den paarigen Längsstücken gebildete Scheide der 
Röhre hervorgeht, während das dazwischen liegende Stück den Beginn des eingeschlossenen unpaaren Ventralteiles darstellt, welches darin so eingefügt ist, wie Fig. 128 bei $e$ zeigt (vgl. S. 429). Bei $D$ in Fig. 126 hat sich der in Fig. 125 noch sehr enge Ausführungsgang $D$ des Receptaculums erweitert und mündet in den darunter liegenden, nun ebenfalls sehr eng gewordenen Oviduct $G$. Das darüber gelegene, halbkreisförmige, jederseits offene Mündungsgebiet, zu dessen Dach die beiden schräg verlaufenden Muskelbündel $m$ verlaufen, gehört der Copulationsöffnung an. In den Figg. 127-130 ist zu erkennen, daß die Oviductöffnung $G^{\prime}$, je weiter nach dem Ende zu desto mehr, auf eine gekrümmte, von oben nach unten gerichtete Spalte reduziert wird, die unten durch das unpaare Mittelstück der Legeröhre geschlossen ist. Fig. 129 gibt einen Querschnitt wieder, wie er sich gleich bleibt im ganzen Verlaufe der Röhre, die von Längsfasern durchzogen wird, und in welcher jederseits eine Trachee verläuft (Querschnitt Fig. 128).

\section{Chrysopa perla L. ${ }^{1}$ )}

Während bei den Männchen von Chr.perla und Chr.vulgaris im Bau des innern Genitalapparats auffallende Verschiedenheiten festzustellen waren, sind dessen Organe beim weiblichen Geschlecht in ihren wesentlichen Teilen sehr gleichmäßig gebaut.

Das Chitingerüst des Endes des aus 10 Ringen bestehenden Abdomens von Chr. perla (Taf. 29, Fig. 131) ist verhältnismäßig einfach gestaltet. Das Genitalsegment trägt unten zwei gerundete, am Hinterrande ganz wenig ausgezogene Klappen $V$, die mit der Ventralwand in Zusammenhang stehen. Es liegt auf der Ventralseite dem vorangehenden 8. Segment dicht an. Zieht man es aber von diesem weg und etwas nach oben, so erscheint hier in der zwischen beiden Ringen entstehenden Lücke ein kleiner, unpaarer Anhang, den Fig. 132 ausgebreitet, von der Fläche gesehen und etwas stärker vergrößert wiedergibt. Bemerkenswert sind die an seinem Ende liegenden Höcker mit dem dazwischen befindlichen Ausschnitt.

Die beiden Seitenflächen des Analsegments $A$ tragen bei $a$ je eine Gruppe der schon in den andern Beschreibungen erwähnten Rosetten, die hier von einem Chitinring vollständig umgeben sind.

Beim lebenden Tiere liegen diese Teile des Abdominalendes so dicht mit ihren Rändern aneinander, daß sie auf der schräg nach

1) Vgl. Löw (10), p. 384; Gross (16). 
vorn und unten gerichteten Ventralfläche (und Hinterfläche) des Abdomens eine geschlossene Längsspalte bilden. Die charakteristischen Teile sind nur an Macerationspräparaten deutlich zu erkennen.

An solchen fällt ganz besonders ein auf der innern Ventralseite des 9. Segments liegendes, kugelförmig gekrümmtes Chitingebilde von schwarzbrauner Farbe (bei Chr. vulgaris ist es schwach gelblich) auf mit einem schwanzartigen, nach seinem Ende zu heller werdenden Anhange, dessen äußere Fläche dicht mit kleinen Höckerchen besetzt ist (Fig. 133). Es ist das Chistinskelet des unten beschriebenen Receptaculums mit seinem Ausführungsgang.

Das Genitalganglion findet sich im 8. Segment.

Die aus 8 Eiröhren zusammengesetzten Ovarien beider ChrysopaArten sind in neuerer Zeit von Gross (16) genauer beschrieben worden.

Der unpaare Ausführungsgang, zu dem sich die beiden Oviducte vereinigen, zeigt anfangs eine fast glatte Innenwand mit schwach zylindrischen Kernen, die sich aber bald in eine Anzahl wellenförmiger Falten legt (Längsschnitt Fig. 134 Od), in denen die Kerne schlanker sind, am meisten an der Stelle, wo der Gang in die Mündung übergeht und diese Falten wieder aufhören. Das letzte Ende derselben (Längsschnitt Fig. 134 bei $M$ ) ist in Längsfalten gelegt. Zwischen diesem Teile und dem vorher erwähnten Abschnitt des Oviducts aber ist dieser in eigenartiger Weise ineinander geknäult, wie einige Schnitte davon in derselben Figur bei $N$ erkennen lassen. Das Lumen der Windungen ist eng; die Kerne in der Wand sind rund, fast eiförmig.

Die Figur zeigt weiter bei $B$ den Längsschnitt eines Sackes, der Bursa copulatrix, dessen von einer starken Lage farblosen Chitins mit darunter liegender großkerniger Hypodermis ausgekleidete Wand in große Falten gelegt ist. Sein Grund biegt nach hinten um und geht in Gestalt eines engen Kanals mit ähnlich beschaffener Wandung in das Receptaculum seminis über, dessen auffallendes Chitinskelet bereits erwähnt wurde, und das auch an Schnitten durch seine starke Entwicklung auffällt.

Dieser Teil besteht aus einem Rohr, das schneckenartig eingerollt ist und dessen beide Windungen zusammen wie eine abgeflachte Kugel aussehen. Fig. 142 zeigt einen Teil desselben $(R)$ im Längsschnitte an der Stelle, wo die Bursa copulatrix $B$ mit ihm in Zusammenhang (b) steht. Der innere, gelbbraune Chitinbelag ist, wie erwähnt, sehr dick, ebenso die darunter gelegene Hypodermis, welche diese Eigenschaft besonders da zeigt, wo die Kammer in ihren 
Ausführungsgang übergeht, von dem die Figg. $142 D$ und 140 einen Schnitt zeigen. Die hypodermalen Zellen sind hier sehr schlank cylindrisch. Die Kerne sind kuglig und liegen im Zellgrunde. Das Plasma ist strahlenartig nach innen gerichtet. Der Kanal biegt vom Hauptraume aus ventral und nach hinten um, hier einige Windungen bildend.

Indem er allmählich enger wird, verschwindet die eine Hälfte seiner Wandung, so daß von ihr nur noch ein rinnenförmiges Halbrohr bleibt, das aber noch immer denselben Bau wie vorher zeigt. Dieses legt sich nun an die dorsale Wand des Ausführungsganges des Oviducts so an, wie der Längsschnitt Fig. 134 bei $R$ zeigt, dessen Wand begleitend und mit ihm nach außen mündend.

Der Vorraum, in welchen die beschriebenen Genitalkanäle gehen, bildet kurz vor seinem Ausgang, wo er innen durch starke Lappen und Falten mit dicker Lage farblosen Chitins ausgezeichnet ist, eine ziemlich tiefe Tasche mit ebensolchen Bildungen (Längsschnitt Fig. $134 \mathrm{C}$ ). Der distale 'Teil der die Genitalmündung begrenzenden ventralen Körperwand zeigt unter einer leistenartigen, zugeschärften Zunge $l$ einen Hohlraum, in welchen der wulstige und abgerundete Rand des proximalen Teiles $p$ hineinragt.

Dorsal über allen diesen Teilen, der Wand der Bursa copulatrix ziemlich dicht anliegend, findet sich eine weit nach vorn reichende große Anhangsdrüse (Fig. 134 A). Bei jüngern Individuen sind ihre Wände stark zusammengefaltet und liegen innen ziemlich dicht nebeneinander. Im Zustande der Secretion dehnt sich aber das Organ so aus, daß es nur noch wenige Falten zeigt, wie die erwähnte Figur darstellt. Die Zellen, welche die Wand dieser Drüse zusammensetzen, sind cylindrisch und flammenartig gebogen. Die schlank eiförmigen Kerne liegen im basalen Teile derselben (Fig. 135 stärker vergrößert). ${ }^{1}$ ) Die Mündung des Sackes, dessen Secret durch Hämatoxilin nur schwach gefärbt wird, liegt ziemlich weit hinten im Ende des 9. Segments, und zwar steht er hier mit einem zweiten Drüsenraum in Verbindung (Längsschnitt Fig. 134 E), von ihm histologisch scharf getrennt. Seine dünnen Wände, die in den Innenraum zahlreiche dünne Septen mit feinen sekundären Bildungen dieser Art sendet, enthält platte Kerne. Sie mündet nicht unmittelbar in

1) Im Übersichtsbild Fig. 140 sind die Kerne zu stark cylindrisch gezeichnet. 
den Genitalvorraum, sondern in eine hintere Abteilung desselben (Fig. $134 F$ ).

In diesen Nebenraum sendet noch ein enger Drüsenschlauch $G$ sein Secret, dessen Anfangsteil zusammengeknäuelt ist, so daß die Wände außen dicht gedrängt nebeneinander liegen. Ihre kubischen Zellen enthalten am Grunde ebensolche, verhältnismäßig große Kerne (Fig. 136 stärker vergrößert).

Wo dieser dünne Schlauch in den Nebenraum $F$ mündet, liegt vor ihm eine Leiste $H$, von welcher strahlenartig gestellte Chitinborsten in ihn hineinragen (vgl. den Querschnitt von Chr. vulgaris Fig. 137 bei $H$ ).

Zum Schluß sei noch einiges über die Muskulatur der beschriebenen Organe bemerkt. Wie der Längsschnitt Fig. 142 bei $m$ zeigt, zieht vom Grunde des Receptaculums zum Grunde des Verbindungskanals zur Bursa copulatrix ein starkes, sehr charakteristisches Muskelbündel, dessen Fasern sich hier umwenden, sich um jene Organe legen und in die Muskulatur des aufgeknäulten Mündungsstückes des Oviducts übergehen, diesen dicht umgehend (in Fig. 134 der Deutlichkeit halber weggelassen).

Ferner liegen im Ende des Genitalsegments Faserzüge (Fig. 134n), von dessen Dorsalseite divergent nach der Ventralseite gehend und den Genitalvorraum zwischen sich lassend. Sie setzen sich fort bis in die Leiste, welche hinten die Genitalmündung begrenzt (vgl. den Querschnitt von Chr. vulgaris Fig. 137).

\section{Hemerobius nervosus F. ${ }^{1}$ )}

Das weibliche Abdominalende von Hemerobius (Taf. 29, Fig. 138) hat sehr große Ähnlichkeit mit dem von Chrysopa. Das 9. Segment $(G)$ trägt unten zwei blattartige, elliptische, nach außen gewölbte Anhänge $(V)$, welche an ihrem Grunde auf der Bauchseite in der Mittellinie zusammenhängen. Mit ihnen in Verbindung steht, ähnlich wie bei Chrysopa (vgl. Fig. 132), ein unpaarer ventraler Anhang, den Fig. 139 von der Fläche gesehen darstellt. Die beiden durch den distalen Einschnitt entstehenden Äste hängen durch ihre Enden mit je einer der Genitalklappen zusammen.

Am 10., dem Analsegment $(A)$, fehlen auch beim weiblichen

1) Frey-Leuckart (7), p. 380 ; v. Siebold (8), p. 381 ; Mclachlan (15), p. 397. 
Hemerobius die Felder mit den Rosetten $(a)$ nicht, sind aber hier nicht von einer Chitinleiste umgrenzt.

An den Macerationspräparaten fällt ferner ein mehrfach gewundenes, dunkles Chitingebilde auf, das Gerüst des Ganges des Receptaculıms. - Das Genitalganglion, aus der Verschmelzung des 6. und 7. Bauchganglions bestehend, findet sich im 8. Abdominalsegment.

Auch der Bau des innern weiblichen Genitalapparats ist dem Chrysopa so verwandt, daß in Hinblick auf den Längsschnitt Fig. 143 einige kurze Bemerkungen über denselben genügen.

Dieser zeigt bei $O d$ den Oviduct, bei $R$ das Receptaculum und einen Teil seines Ausführungsganges $D$, bei $B$ die Bursa copulatrix. Letztere besitzt am Grunde eine Verlängerung, die als Ductus seminalis $b$ mit dem Hauptraum des Receptaculums in Verbindung steht. Die Stelle, wo dies der Fall ist, zeigt Fig. 141 in einem etwas stärker vergrößerten Längsschnitte, an dem zu erkennen ist, daß das Receptaculum hier einen kleinen, kugligen Anhang $a$ trägt. Die in seinen Hauptraum $(R)$ ragenden Zacken sind Reste von Septen, welche den seitlichen Teil des Organs in einige untereinander zusammenhängende Kammern teilen. - Die Oviductmündung ist nicht so stark gefaltet wie bei Chrysopa.

Im Gegensatz zu letzterer, bei welcher Anhangsdrüsen stark ausgebildet sind, findet sich bei Hemerobius nur eine solche, die aber auch nur wenig entwickelt ist und in Gestalt eines Schlauches, der innen in Längsfalten gelegt ist (Querschnitt Fig. 143 A), unmittelbar in den Genitalvorraum mündet.

Die ventrale Wand, welche diesen umgibt, ist sehr stark und nach oben und innen geschlagen, wie der Längsschnitt bei $B$ zeigt, wozu die zahlreichen Muskelfasern dienen, die ihn, von der Mediana nach den Seiten verlaufend, durchziehen. Dadurch wird die Genitalmündung $M$ weit von der Bauchseite nach oben gerückt. Der Vorraum selbst besitzt keine starke Faltung; die Kerne in seiner Wand sind linsenförmig.

\section{Myrmeleon formicarius $\mathrm{L}^{1}$ )}

Das Abdominalende vom weiblichen Myrmeleon dieser Art stellt Taf. 28, Fig. 104 von der lateralen Seite gesehen dar. Das Genitalsegment besitzt eine Anzahl charakteristischer Chitinverstärkungen

1) Vgl. v. Siebold (8), p. 381; Brauer (13), p. 394. 
und Anhänge. Zunächst sieht man jederseits zwei braune Platten $a$ und $a^{\prime}$, die proximal scharf abgegrenzt sind, distal aber allmählich heller werden und in das farblose Chitin der Umgebung verlaufen. Die Ventralseite des Segments zeigt eine konvexe Erhöhung $b$, und vor dieser liegen zwei kegelförmige Fortsätze $c$, von welchen je eine braune Leiste $d$ ausgeht, die aber nicht frei ist, sondern nur eine Verstärkung in der Ventralwand darstellt und in den Seiten der Vorwölbung verstreicht. Die Fortsätze selbst sind stark beborstet, und die Borsten, welche denen sehr ähnlich sehen, mit denen die Körperoberfläche der Larven besetzt ist, unterscheiden sich von den übrigen des Abdomens durch ihre bedeutende Stärke und ihre im Verhältnis dazu geringe Länge. Sie sind am Ende pfriemenartig gebogen und sitzen mit ihrem Grunde in einem Ring, der sich in Gestalt eines Höckers auf der Oberfläche erhebt, und dadurch bekommen jene Fortsätze ihr eigenartiges Aussehen. $W_{0}$ sie in die Körperwand übergehen, werden auch die Borsten kleiner.

Zwei ganz in derselben Weise beborstete Hervorragungen $(d)$ liegen ferner hinten am Genitalsegment unterhalb der Genitalmündung. Sie sind abgerundet und entspringen an einer ventralen Wölbung des Segments.

Das kurze Analsegment $e$ besteht aus zwei dorsal verbundenen Klappen. Die Chitinverstärkungen derselben sind ein kurzes, dorsales Feld jederseits, das nach unten zu spitz ausläuft, und ein größeres Feld, das den untern Rand der Klappen bildet. Auch diese Verstärkungen sind in derselben Weise mit solchen Borsten besetzt, wie sie vorher beschrieben wurden, und die starken, ringwallartigen Polster geben den Klappen das Ansehen, als wären sie mit Warzen bedeckt. — Felder mit Rosetten oder ähnliche Gebilde finden sich nicht.

Einen Längsschnitt durch die innern weiblichen Genitalorgane stellt Taf. 29 Fig. 144 dar. Der Oviductus communis $O d$ ist hinter der Vereinigungsstelle der beiden paarigen Oviducte stark gefaltet. Seine Wand enthält cylindrische Kerne, die weiterhin, wo sie glatter wird, platter werden. Vor der Mündung findet noch einmal starke Faltenbildung statt. Den Oviductus communis umgibt eine dünne Ringmuskulatur, an seinem Beginn liegen darüber noch Längsfasern.

Sehr stark ausgebildet ist die Bursa copulatrix, von welcher der Längsschnitt bei $B$ einen Teil wiedergibt. Ihre mit einer 
Schicht farblosen Chitins ausgekleidete Wand ist in zahlreiche größere und kleinere Längs- und Querfalten gelegt, in denen platte Kerne liegen. Nach ihrem Grunde hin erweitert sich die Bursa beträchtlich und sendet große Divertikel zwischen die Windungen des Receptaculums. Der Grund des Sackes scheint mit ganz feinen, gelben Chitinzähnchen besetzt zu sein.

Zwischen Oviduct und Bursa copulatrix liegen die Windungen des Receptaculums. Dasselbe beginnt nicht wie bei Hemerobius und Chrysopa mit einem geräumigen Sacke, der allmählich in einen Kanal übergeht, sondern ist von Anfang an eine dickwandige Röhre mit engem Lumen (Fig. $144 R$ ) und basal liegenden, cylindrischen Kernen, die sich nach der Mündung zu mehr und mehr verengt. Letztere befindet sich am Hals der Bursa, kurz vor dessen Ausgang in den Genitalvorraum. Innen ist die Bursawand mit gelbem Chitin ausgekleidet. Eine Verbindung des Bursagrundes mit dem Receptaculum, wie sie bei vorher beschriebenen Formen angetroffen wurde, ist hier nicht vorhanden.

Der Raum zwischen Bursa und Receptaculum ist dicht mit Muskulatur angefüllt, deren Fasern in den verschiedensten Richtungen durcheinander liegen, eine Folge der zahlreichen Falten des erstern Organs und der Windungen des letztern. Nach der Mündung beider hin richten sie sich mehr gleichlaufend zur Körperachse und treten in Zusammenhang mit den Muskelfasern, welche die Oviductmündung umgeben. Eigenartig ist ein Muskelzug $(m)$, der vom Grunde der Bursa nach unten zu unter den Oviductus communis geht, und ein anderer $(n)$, der ventral von diesem schräg nach unten und vorn verläuft, die Segmentmuskulatur o durchkreuzend und sich an der Wand des Sternits befestigend.

Oberhalb des bei Myrmeleon nur gering entwickelten Genitalvorraumes mündet endlich noch eine lange schlauchförmige Kittdrüse $G$, die mit vielen Windungen über den Grund des Receptaculums beginnt und dann dorsal in fast gerader Richtung über diesem verläuft. Ihre Wand ist dick; die cylindrischen Kerne derselben liegen basal. Die Mündung, welche etwas erweitert ist, zeigt dorsal ein queres Muskelbündel $p$ und ventral einen kurzen Längsfaserzug $q$, welche beide mit der Muskulatur des Genitalvorraumes oberhalb des Bursaausganges in Zusammenhang stehen.

Eine Darstellung der offenbar recht verwickelt gebauten Genitalmündung vermag ich aus Mangel an Material nicht zu geben. 
Aus demselben Grunde ist zum Schluß in Folgendem nur das abdominale Körperende von Osmylus maculatus F. 'und von Ascalaphus macaronius Scop. dargestellt.

Das Abdominalende des männlichen Osmylus maculatus F. ${ }^{1}$ ) gibt Fig. A in der Seitenansicht wieder.

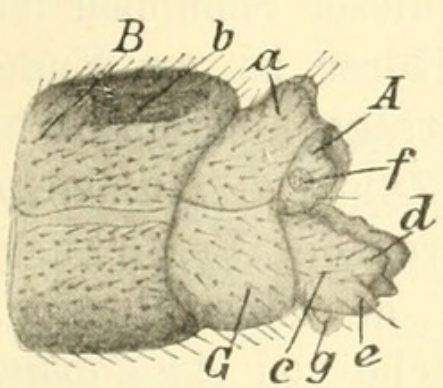

Fig. A.

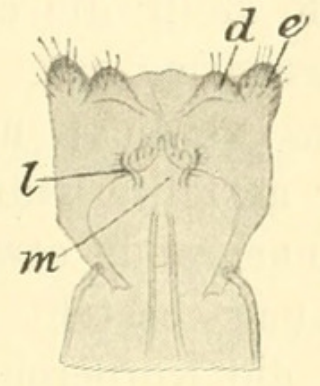

Fig. B.

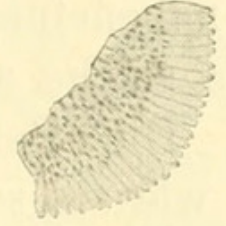

Fig. C.

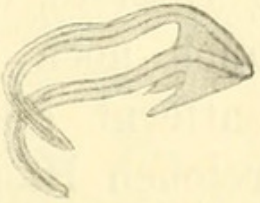

Fig. D.

Segment 8 (Fig. A $B$ ) zeigt unter dem Tergit ein eigenartiges Gebilde $b$ von schuhsohlenförmiger Gestalt, das schon von Dufour beschrieben ist. Durch Maceration desselben erhält man eine taschenartige Chitinhaut, die innen mit feinen Dornen besetzt ist und an den Rändern einen Saum besitzt, wie Fig. C stärker vergrößert, darstellt.

Das 9. Segment (Fig. A $G$ ) ist dorsal jederseits neben der Mediana höckerartig aufgetrieben (Fig. A $a$ ) und trägt auf der Bauchseite eine aus zwei symmetrischen Hälften bestehende Klappe $c$, von denen an ihrem distalen Rande zwei mit stärkern Borsten besetzte Höcker $(d$ u. $e)$ bildet. Fig. B stellt diese Ventralklappe von ihrer Innenseite gesehen und ausgebreitet dar. $d$ und $e$ sind die erwähnten Höcker. Die dunkel gehaltenen Stellen sind die stärker chitinisierten. Bei $m$ befindet sich ein medianer Einschnitt, zu dessen beiden Seiten sich je eine kleine Leiste $l$ höckerartig erhebt. Die hintern Enden der Ventralklappe laufen in einen Condylus aus, der mit einer Leiste des 8. Segments artikuliert. Auf dem Boden der Klappe endlich liegt ein Chitingebilde (Fig. A g), dessen eigentliche Gestalt Fig. D wiedergibt.

Das Analsegment (Fig. A A), welches kapuzenartig geformt ist, ist jederseits blasig aufgetrieben und trägt hier eine kleine, halbkugelförmige Erhöhung $f$, auf der die bekannten Rosetten liegen.

1) Vgl. Dufour (9), p. 384 ; HaGen (11), p. 388. 
Fig. E stellt das männliche Abdominalende von Ascalaphus (macaronius Scop.?) ${ }^{1}$ ) von oben gesehen dar. Das Tergit des 9. Segments bildet auf jeder Seite einen lateralen, gerundeten Ausschnitt $A$ und einen medianen, etwas nach unten gebogenen Fortsatz $B$. Die bekannten, zangenförmigen Fortsätze $C$ gehören den beiden Schuppen an, welche, ventral miteinander verbunden, das Abdomen hinten und unten abschließen. Fig. F stellt die eine dieser Schuppen im Zusammenhang mit ihrem Zangenarme dar. Letzerer ist am Ende nach innen gebogen und etwas verdickt und trägt hier einwärts gerichtete, dicht nebeneinander gestellte, starke Zähne $d$, von denen auch noch einige solche am Innenrande etwas von der Verdickung entfernt stehen. Die Beborstung besteht aus denselben langen, reichen Haaren, wie sie sonst die Körperoberfläche von Ascalaphus bedecken; nur die Ränder des unpaaren, medianen Fortsatzes sind von sehr feinen, kurzen Borsten umsäumt.

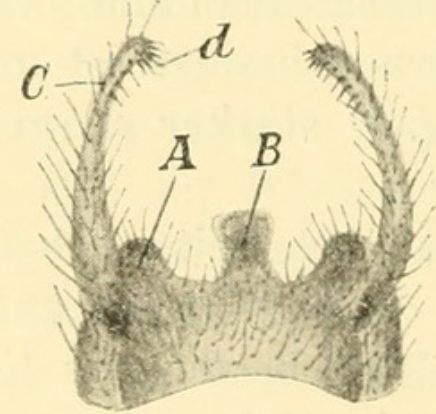

Fig. E.

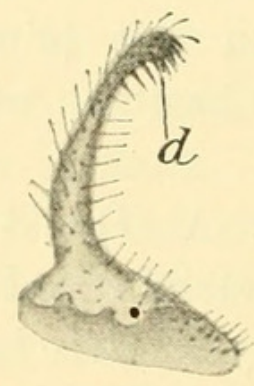

Fig. F.

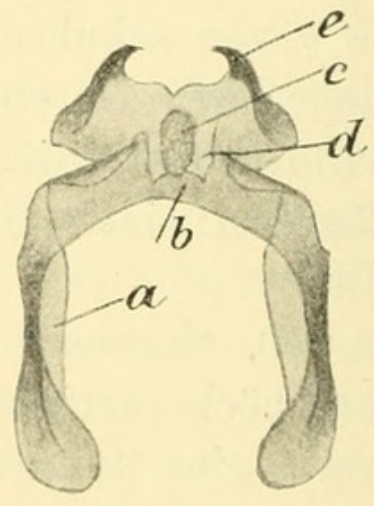

Fig. G.

Ein eigenartiges Chitingebilde, das in Gestalt und Lage an das von Myrmeleon (Taf. 25, Fig. 27) erinnert, liegt zwischen Genitalund Analöffnung und ist in Fig. $G$ in seinen Einzelheiten abgebildet. Es besteht aus zwei flügelartig verbreiterten, abgeplatteten Armen $a$, welche eine Torsion zeigen und durch die Leiste $b$ hufeisenartig verbunden sind. In der Mitte befindet sich eine Platte $e$, die unregelmäßig siebartig durchlöchert ist und von einem Saum $d$ umgeben wird, der nach hinten in zwei dünne zugespitzte Enden ausläuft. Nach der andern Seite sind die Ecken der Platte in je einen starken, gekrümmten Haken $e$ verlängert.

Einen sehr einfachen Bau besitzt das weibliche Abdominalende. Das Genitalsegment trägt jederseits eine ventrale, ausgehohlte

1) Vgl. Brauer (12), p. 395; Dufour (14), p. 396. 
Schuppe, deren Ränder mit langen, weichen Borsten wie beim Männchen besetzt sind. Unten sind beide Schuppen miteinander verbunden.

Weder beim Männchen noch beim Weibchen finden sich am Analsegment Bildungen, wie sie in Gestalt von Rosetten bei vielen andern Neuropteren angetroffen werden.

Eine zusammenfassende Übersicht über den Bau der Genitalorgane der Neuropteren nach den aus den vorangehenden Untersuchungen gewonnenen Resultaten zu geben ist nicht möglich, da die Zahl der untersuchten Gattungen eine zu geringe ist, was damit zusammenhängt, daß von den weniger häufig vorkommenden Formen eine genügende Menge Material zum Zweck der Konservierung schwierig zu erlangen ist. Es seien deshalb nur einige allgemeine Bemerkungen hier angefügt.

Die innern männlichen Genitalorgane der Neuropteren sind am schwierigsten miteinander in Vergleich zu bringen, besonders in Beziehung auf die ausführenden Drüsenräume. Bei allen findet sich ein paariger Hoden, ein meist gering entwickelter Ductus ejaculatorius, und ebensowenig ist ein Copulationsorgan in dem Grade ausgebildet wie bei andern Insectengruppen, z. B. Lepidopteren. Für die Copulation erforderliche Haftapparate der verschiedensten Art liegen in der Umgebung der Genitalmündung.

Einen sehr verwickelten Bau aber hat die Vesicula seminalis mit ihren Anhangskammern (weniger zahlreich bei Rhaphidia), die meist im Bau ihrer Wandung sowie in der Art ihres Secrets deutlich voneinander zu unterscheiden sind. Meist kommen dazu noch Anhangsdrüsen. Die Kammern bei den verschiedenen Gattungen aufeinander zu beziehen, ist wohl nur auf dem Wege der Entwicklungsgeschichte möglich.

Leichter durchzuführen ist eine Vergleichung der weiblichen Genitalorgane der verschiedenen Gruppen. Hierbei steht Sialis durch die paarige Ausbildung derselben bis fast zur Genitalmündung, besonders aber durch die geteilte Bursa copulatrix, allen andern gegenüber. Bei den übrigen untersuchten Formen finden sich Bursa copulatrix, Receptaculum seminis und eine dorsal gelegene Anhangsdrüse, die mit dem ventral gelegenen Oviduct in einen gemeinsamen Genitalvorraum (Vestibulum) münden. Bei Chrysopa und Hemerobius steht die Bursa am Grunde durch einen engen Gang mit dem Re- 
ceptaculum in Verbindung, bei Rhaphidia und Myrmeleon dagegen nicht. Das Receptaculum seminis ist bei allen (Sialis ausgenommen) ein dickwandiger, starker, nach seiner Mündung hiin aber dünn werdender Schlauch, dessen enges Lumen von einer starken Lage gelben Chitins ausgekleidet ist. Bei den Chrysopen und auch bei Hemerobius ist dieses Organ am stärksten ausgebildet. Für Rhaphidia ist die infolge des Vorhandenseins der Legeröhre auftretende doppelte Genitalöffnung eigentümlich.

Charakteristisch sind schließlich die Rosettenfelder, wie sie in derselben Art der Ausbildung an den Analklappen beider Geschlechter vorkommen, bei Myrmeleon, Ascalaphus und auch Sialis aber fehlen. Sialis scheint also in jeder Beziehung den andern NeuropterenGruppen auch in Beziehung auf den Genitalapparat gegenüberzustehen. Unter den andern Gattungen stellen sich Chrysopa und Hemerobius als nahe verwandt zusammen.

Berlin, im November 1908. 


\section{Literaturverzeichnis.}

1. Degeer, Abhandlungen zur Geschichte der Insekten. Übers. von Götze, Vol. 2, Teil 2, Nürnberg 1779.

2. Hegetschweiler, Dissertatio de Insectorum genitalibus, Zürich 1820.

3. Suckow, Über die Geschlechtsorgane der Insekten, in: Zeitschr. organ. Physik, Vol. 2, 1828.

4. Burmeister, Handbuch der Entomologie, Vol. 2, Teil 2, Berlin 1838.

5. Rambur, Histoire naturelle des Insectes Nevroptères, Paris 1842.

6. SchneIder, Monographia Generis Rhaphidiae, Breslau 1843.

7. Frey und Leuckart, Lehrbuch d. Anatomie d. wirbellosen Thiere, Leipzig 1847.

8. Siebold, Lehrburh d. vergl. Anatomie d. wirbellosen Thiere, Berlin 1848.

9. Dufour, Recherches sur l'anatomie et l'histoire naturelle de l'Osmylus maculatus, in: Ann. Sc. nat. (3), Zool., Vol. 9, 1848.

10. Löw, Abbildungen und Bemerkungen zur Anatomie einiger Neuropterengattungen, in: Linnaea entomol., Vol. 3, 1848.

11. HAGEN, Die Entwicklung und der innere Bau von Osmylus, ibid., Vol. 7, 1852.

12. Brauer, Beiträge zur Kenntnis des inneren Baues und der Verwandlung der Neuropteren, in: Verh. zool.-bot. Ver. Wien, Vol. 4, 1854, p. 466.

13. - ibid., p. 704 .

14. Dufour, Recherches anatomiques sur l'Ascalaphus meridionalis, in: Rev. Mag. Zool. (2), Vol. 12, 1860.

15. McLachlan, Monograph of the British Neuroptera, in: Transact. entomol. Soc. London, 1868.

16. Gross, Untersuchungen über die Histologie des Insectenovariums, in : Zool. Jahrb., Vol. 18, Anat., 1903. 


\section{Erklärung der Abbildungen. ${ }^{1}$ )}

Tafel 25 .

Fig. 1. Schema des männlichen Genitalapparats (rechte Hälfte) von Sialis lutaria L.

$t$ Hoden, $V d$ Vas deferens, $V s$ Vesicula seminalis, $A, B, C, D$ Drüsenkammern, Ga Anhangsdrüse, De Ductus ejaculatorius.

Fig. 2. Längsschnitt durch Hoden und Vas deferens von Sialis lutaria (S. 399).

Fig. 3. Querschnitt durch das Vas deferens von Sialis lutaria.

Fig. 4. Längsschnitt durch die Vesicula seminalis $(V s)$ und die beiden davor gelegenen Drüsenkammern $(A$ und $B)$ von Sialis lutaria (S. 399).

Fig. 5-8. Längsschnitte durch die hinter der Vesicula seminalis gelegene Drüsenkammer von Sialis lutaria (im Schema Fig. $1 \mathrm{C}$ ), von der Körperseite nach der Mittelebene $\mathrm{zu}$ in der Reihenfolge der Figurennummern (S. 401).

Fig. 9. Längsschnitt $(b)$ durch den Hauptteil der Anhangsdrüse von Sialis lutaria ơ (im Schema Fig. $1 \mathrm{Ga}$ ); Querschnitt (a) durch den Anfangsteil derselben (S. 401).

Fig. 10-15. Querschnitte durch den ausführenden Genitalgang von Sialis lutaria ơ (S. 402).

Fig. 16. Abdominalende von Sialis lutaria ơ (S. 403), von der Seite gesehen.

Fig. 17. Dasselbe, von oben gesehen.

Fig. 18. Ventralklappe am Genitalsegment von Sialis lutaria $\delta$ (Fig. 19a), von innen gesehen.

1) Der Kürze halber ist bei den einzelnen Figurenerklärungen auf die betreffende Seite im Text hingewiesen. 
Fig. 19. Ventrale Anhänge am Abdominalende von Sialis lutaria $\delta$ (Fig. 19e).

Fig. 20. Abdominalende von Sialis fuliginosa P. ठ․ (S. 405), von der Ventralseite gesehen.

Fig. 21. Ventrale Anhänge am Abdominalende von Sialis fuliginosa (Fig. 20e).

Fig. 22. Abdominalende von Rhaphidia notata F. (S. 409), von der Seite gesehen.

Fig. 23. Ventralklappe am Genitalsegment von Rhaphidia notata F. (Fig. 22a) mit Anhängen.

Fig. 24. Lateralklappe am Genitalsegment von Rhaphidia notata $\delta$ (Fig. 22b) mit Anhang.

Fig. 25. Rosetten von den Analklappen von Rhaphidia notata (Fig. 22e) (S. 409).

Fig. 26. Ventralklappe am Genitalsegment von Myrmeleon formicarius L. तै.

Fig. 27. Chitingerüst zwischen Genital- und Analöffnung von Myrmeleon formicarius L. o (S. 420).

Fig. 28. Borstenfelder der Chitindecke des Abdomens von Myrmeleon formicarius L. ठ (S. 420).

\section{Tafel 26.}

Fig. 29. Längsschnitt durch die hinterste Drüsenkammer von Sialis lutaria of (im Schema Fig. $1 D$ ) und den ausführenden Genitalgang.

Fig. 30. Querschnitt durch die beiden Drüsen, deren Längsschnitt Fig. 29 zeigt.

Fig. 31. Längsschnitt durch das Abdominalende von Sialis lutaria ( $a$ Ventralklappe in Fig. 16a).

Fig. 32-36. Längsschnitte durch das Genitalende von Rhaphidia notata $\delta$, von der Körperseite nach der Mittelebene zu, in der Reihenfolge der Figurennummern.

Fig. 37. Schema des männlichen Genitalapparats (rechte Hälfte) von Rhaphidia notata.

$t$ Hoden (S. 406), $V d$ Vas deferens (S. 406), Vs Vesicula seminalis (S. 406), A, B, C, D Drüsenkammern (S. 406), Ga Anhangsdrüse (S. 407), $E$ ausführender Kanal (S. 407), De Ductus ejaculatorius (S. 408).

Fig. 38. Längsschnitt durch das Abdomen von Rhaphidia notata ơ (Bezeichnungen wie in Fig. 37).

Fig. 39. Querschnitt durch den Anfangsteil des Vas deferens von Rhaphidia notata.

Fig. 40. Schema des männlichen Genitalapparats von Chrysopa perla L., von der Dorsalseite. 
Fig. 41. Abdominalende von Chrysopa perla o, von der Seite gesehen (S. 410).

Fig. 42. Im Abdominalende von Chrysopa perla đ̊ gelegene Chitinteile.

Fig. 43. Ventralschuppe des männlichen Abdominalendes von Chrysopa perla (Fig. 41e) ausgebreitet und von innen gesehen.

Fig. 44. Borsten aus dem Genitalvorraum $D$ (bei $A$ in Fig. 52 auf Taf. 27), stärker vergrößert.

Fig. 45-47. Querschnitte durch die Genitalmündung von Chrysopa sp. ठิ (S. 414).

Fig. 48. Abdominalende von Myrmeleon formicaris L. ठิ (S. 420), seitliche Ansicht.

Fig. 49. Dasselbe von der Dorsalseite.

\section{Tafel 27.}

Fig. 55-58. Längsschnitte durch das Ende des Abdomens von Chrysopa perla. (Bezeichnungen mit denen des Schemas Fig. 40 übereinstimmend.)

Fig. 59-68. Querschnitte durch die Genitaldrüsen von Chrysopa sp. ठठ (S. 414).

Fig. 69. Abdominalende von Hemerobius nervosus F. ठ, seitliche Ansicht (S. 417).

Fig. 70. Dasselbe von der Ventralseite.

Fig. 71. Ventralklappe $B$ aus den Figg. 69 und 70 .

Fig. 72. Schema des männlichen Genitalapparats (rechte Hälfte) von Hemerobius nervosus.

$t$ Hoden (S. 415), Vd Vas deferens (S. 416), Vs Vesicula seminalis (S. 416), $A, B, C, D, E, F, G$ Drüsenkammern (S. 416).

Fig. 73. Längsschnitt durch die Drüsenkammern des männlichen Genitalapparats von Hemerobius nervosus. (Bezeichnungen denen im Schema Fig. 72 entsprechend.)

Fig. 74-76. Querschnitte durch die Drüsenkammern des männlichen Genitalapparats von Hemerobius nervosus (rechte Hälfte; Fig. 76 beide Hälften). (Bezeichnungen wie in Fig. 72 und 73.)

Fig. 77-82. Querschnitte durch das Abdominalende (die Genitalmündung) von Hemerobius nervosus.

\section{Tafel 28.}

Fig. 83-84. Längsschnitte durch die Genitalmündung von Hemerobius nervosus.

Fig. 85. Chitinteile in der Genitalmündung von Hemerobius nervosus $\delta$.

Fig. 86-95. Querschnitte durch die männlichen Genitalräume (rechte Hälfte) von Myrmeleon formicalynx F. in der Reihenfolge der Figuren- 
nummern von vorn nach hinten. (Bezeichnungen in den einzelnen Figuren korrespondierend.)

Fig. 86a. Querschnitt durch die Wandung einer Anhangsdrüse (in den Raum $a$ in den Figg. 86 und 87 mündend), stärker vergrößert.

Fig. 96-99. Querschnitte durch den Genitalausführungsgang von Myrmeleon formicalynx.

Fig. 100-103. Querschnitte durch den hintersten Teil des Abdominalendes von Myrmeleon formicalynx (S. 436).

Fig. 104. Weibliches Abdominalende von Myrmeleon formicarius L., seitliche Ansicht.

Fig. 105-106. Längsschnitte durch das Abdominalende von Sialis lutaria $q$ (S. 425).

Fig. 107. Weibliches Abdominalende von Sialis lutaria, von der Ventralseite (S. 425).

Fig. 108. Dasselbe nach einem Mazerationspräparat, die Teile des Genitalsegments auseinandergezogen.

Fig. 109. Weibliches Abdominalende von Sialis fuliginosa P., von der Ventralseite (S. 425).

Fig. 110. Chitinleisten eines Stigmas im 8. Segment von Sialis lutaria .

Fig. 111. Teil $\mathrm{b}$ aus den Figg. 107 und 108 stärker vergrößert.

Fig. 112. Chitinleisten eines Stigmas im 8. Segment von Sialis fuliginosa q.

Fig. 113-114 (anschließend Fig. 115 u. 116 auf Taf. 29). Querschnitte durch das Abdominalende von Sialis lutaria o, in der Reihenfolge von vorn nach hinten.

\section{Tafel 29.}

Fig. 115-116 (vgl. Fig. 113-114).

Fig. 117. Weibliches Abdominalende von Raphidia notata F., Seitenansicht (S. 429). hängen.

Fig. 118. Ende der Legeröhre von Raphidia notata mit seinen An-

Fig. 120. Schema des weiblichen Genitalapparats von Raphidia notata.

$A, A^{\prime}, B$ Teile der Bursa copulatrix (S. 431), $R, r, r^{\prime}$ Receptaculum seminis mit seinen Anhängen (S. 431). D Ausführungsgang des Receptaculums (S. 431), Od Oviduct (S. 430), V Genitalvorraum (S. 430), $G$ Copulationsöffnung (S. 430), $G^{\prime}$ Verlängerung des Oviducts innerhalb der Legröhre.

Fig. 121. Längsschnitt durch das weibliche Abdominalende von Raphidi anotata. (Bezeichnungen denen im Schema Fig. 120 entsprechend.)

Fig. 122. Querschnitt durch die dorsale Anhangsdrüse im Genitalapparat von Sialis lutaria + (S. 427). 
Fig. 123. Querschnitt durch die Wand des Oviductus communis von Rhaphidia notata.

Fig. 124-130. Querschnitte durch das weibliche Abdominalende (und die Legeröhre) von Rhaphidia notata.

Fig. 131. Weibliches Abdominalende von Chrysopa perla L., Seitenansicht (S. 432).

Fig. 132. Ventraler Anhang am Grunde des Genitalsegments von Chrysopa perla.

Fig. 133. Chitinskelet des Receptaculum seminis von Chrysopa perla.

Fig. 134. Längsschnitt durch das weibliche Abdominalende von Chrysopa perla.

$B$ Bursa copulatrix (S. 433), Od Oviductus communis (S. 433), $N$ Schnitte durch die vor der Mündung gebildeten Schleifen des Oviductus, $M$ Falten der Oviductmündung im Längsschnitt, $R$ Halbröhre des Receptaculum seminis in der Oviductmündung, $A, E, G$ System der Anhangsdrüsen (S. 434).

Fig. 135. Querschnitt durch die Wand des Drüsenschlauches $A$ in Fig. 134, stärker vergrößert.

Fig. 136. Querschnitt durch die Wand des Drüsenschlauches $G$ in Fig. 134, stärker vergrößert.

Fig. 137. Querschnitt durch das weibliche Abdominalende (Genitalmündung) von Chrysopa vulgaris SCHNEFD.

Fig. 138. Weibliches Abdominalende von Hemerobius nervosus F. (S. 435).

Fig. 139. Ventraler Anhang am weiblichen Genitalsegment von Hemerobius nervosus.

Fig. 140. Längsschnitt durch den Anfangsteil des Ausführungsganges aus dem Receptaculum von Chrysopa perla, stärker vergrößert.

Fig. 141. Längsschnitt durch den Zusammenhang des Receptaculums mit dem Ductus seminalis von Hemerobius, stärker vergrößert.

Fig. 142. Längsschnitt durch Bursa copulatrix $(R)$, Receptaculum seminis $(R)$, dessen Ausführungsgang $(D)$ und Ductus seminalis $(b)$ von Chrysopa perla.

Fig. 143. Längsschnitt durch das weibliche Abdominalende von Hemerobius nervosus (S. 436).

$B$ Bursa copulatrix, $b$ Ductus seminalis, $R$ Receptaculum seminis, $D$ Ausführungsgang des Receptaculums, Od Oviduct, A Anhangsdrüse, $M$ Genitalmündung.

Fig. 144. Längsschnitt durch das weibliche Abdominalende von Myrmeleon formicarius L.

$B$ Bursa copulatrix (S. 437), $R$ Receptaculum seminis (S. 438), Od Ovidnct (S. 437), G Anhangsdrüse (S. 438). 


\section{$2 \mathrm{BHL}$ Biodiversity Heritage Library}

Stitz, Hermann. 1909. "Zur Kenntnis des Genitalapparats der Neuropteren." Zoologische Jahrbücher. Abteilung für Anatomie und Ontogenie der Tiere 27, 377-448. https://doi.org/10.5962/bhl.part.21341.

View This Item Online: https://www.biodiversitylibrary.org/item/43567

DOI: https://doi.org/10.5962/bhl.part.21341

Permalink: https://www.biodiversitylibrary.org/partpdf/21341

\section{Holding Institution}

MBLWHOI Library

\section{Sponsored by}

MBLWHOI Library

\section{Copyright \& Reuse}

Copyright Status: NOT_IN_COPYRIGHT

This document was created from content at the Biodiversity Heritage Library, the world's largest open access digital library for biodiversity literature and archives. Visit BHL at https://www.biodiversitylibrary.org. 